NBER WORKING PAPER SERIES

\title{
HOSPITALS AS INSURERS OF LAST RESORT
}

\author{
Craig Garthwaite \\ Tal Gross \\ Matthew J. Notowidigdo \\ Working Paper 21290 \\ http://www.nber.org/papers/w21290
NATIONAL BUREAU OF ECONOMIC RESEARCH
1050 Massachusetts Avenue
Cambridge, MA 02138
June 2015

This research was made possible by a data-use agreement between the authors and the American Hospital Association that allows the confidential hospital financial data to be used for academic research. The agreement placed no constraints on the conclusions of the analysis except that they be factually accurate and the results do not represent the conclusions or opinions of the data provider. We thank Leemore Dafny, David Dranove, Joe Doyle, Amy Finkelstein, Emily Oster, Jesse Shapiro, and Heidi Williams for helpful discussions, and seminar participants at BU/Harvard/MIT Health Policy, the University of California-Irvine, Carnegie Mellon University, the University of Chicago, Cornell University, the University of Illinois, the Robert Wood Johnson Foundation at the University of Michigan, the New York Federal Reserve, Northwestern-IPR, The RAND Corporation, Rice University, Stanford University, Syracuse University, the University of Texas-Austin, Vanderbilt University and Yale University for useful comments. We thank Scott Bates for assistance with the American Hospital Association data, and we thank Mark He, Angela Li, Alen Makmudov, and Mariel Schwartz for excellent research assistance. Notowidigdo thanks the Initiative on Global Markets at the Booth School of Business for financial support. All authors are deeply grateful to the Robert Wood Johnson Foundation (Grant \#72183) for financial support. The views expressed herein are those of the authors and do not necessarily reflect the views of the National Bureau of Economic Research.

NBER working papers are circulated for discussion and comment purposes. They have not been peerreviewed or been subject to the review by the NBER Board of Directors that accompanies official NBER publications.

(C) 2015 by Craig Garthwaite, Tal Gross, and Matthew J. Notowidigdo. All rights reserved. Short sections of text, not to exceed two paragraphs, may be quoted without explicit permission provided that full credit, including $(\mathrm{C}$ notice, is given to the source. 
Hospitals as Insurers of Last Resort

Craig Garthwaite, Tal Gross, and Matthew J. Notowidigdo

NBER Working Paper No. 21290

June 2015

JEL No. H51,I11

\begin{abstract}
$\underline{\text { ABSTRACT }}$
American hospitals are required to provide emergency medical care to the uninsured. We use previously confidential hospital financial data to study the resulting uncompensated care, medical care for which no payment is received. We use both panel-data methods and case studies from state-wide Medicaid disenrollments and find that the uncompensated care costs of hospitals increase in response to the size of the uninsured population. The results suggest that each additional uninsured person costs local hospitals $\$ 900$ each year in uncompensated care. Similarly, the closure of a nearby hospital increases the uncompensated care costs of remaining hospitals. Increases in the uninsured population also lower hospital profit margins, which suggests that hospitals cannot simply pass along all increased costs onto privately insured patients. For-profit hospitals are less affected by these factors, suggesting that non-profit hospitals serve a unique role as part of the social insurance system.
\end{abstract}

Craig Garthwaite

Department of Strategy

Kellogg School of Management

Northwestern University

2001 Sheridan Road

Evanston, IL 60208

and NBER

c-garthwaite@kellogg.northwestern.edu

Tal Gross

Department of Health Policy and Management

School of Public Health

Columbia University

600 West 168th Street, Sixth Floor

New York, NY 10032

and NBER

tg2370@columbia.edu
Matthew J. Notowidigdo

Northwestern University

Department of Economics

2001 Sheridan Road

Evanston, IL 60208-2600

and NBER

noto@northwestern.edu 


\section{INTRODUCTION}

Over the last decade, roughly 15 percent of Americans had no health insurance at any one time (US Census, 2013). Even after the full implementation of the Affordable Care Act (ACA), approximately 10 percent of the population will remain uninsured (CBO, 2013). Furthermore, many of those who gain coverage may be underinsured, facing large deductibles that exceed their available liquidity (Hamel et al., 2015). That lack of universal and complete coverage is partly the result of deliberate policy decisions. For example, the ACA excludes undocumented immigrants from many of its benefits and many state governments have, to date, not implemented the ACA's Medicaid expansion. In addition, the benchmark insurance plans used to determine the magnitude of the ACA subsidies are only expected to cover seventy percent of average medical expenditures, leaving even the newly insured exposed to costly medical bills.

Those policy decisions are often justified based on the estimated cost to the government of covering the uninsured. ${ }^{1}$ It is misleading, however, to estimate only the cost to the government - doing so fails to capture the full cost of the uninsured. At a minimum, these costs include the fact that the uninsured still demand health care and, due to a variety of factors, hospitals are mandated to treat them regardless of their ability to pay. For example, the Emergency Medical Treatment and Active Labor Act (EMTALA) requires that hospitals provide emergency medical treatment to all patients. In addition, non-profit hospitals must provide a community benefit in order to maintain their tax exemptions. And even beyond those legal constraints, medical ethics require that physicians treat certain patients regardless of ability to pay (Annas, 1985).

\footnotetext{
${ }^{1}$ For example, Virginia Governor Bob McDonnell commented, "Virginia simply cannot afford to become the bank for a federally designed expansion of Medicaid." Similarly, Georgia Governor Nathan Deal stated, "I did not judge it prudent to expand the eligible population of an entitlement program... since our state is already spending approximately $\$ 2.5$ billion in state taxpayer funds annually." Regarding immigration, former Speaker of the House, Nancy Pelosi, argued: "[i]t is stated very clearly in the Affordable Care Act, [and] it is our position in the immigration bill: no access to subsidies in the Affordable Care Act. Secondly, no access to Medicaid; no cost to the taxpayer. That has always been the Democratic position" [emphasis added].
} 
In this paper, we argue that, as a result of these factors, hospitals serve as the "insurers of last resort" in the American health care sector. ${ }^{2}$ When policymakers decide not to provide health insurance for a portion of the population that otherwise could not afford insurance, hospitals ultimately bear the cost of that decision. To describe this role of hospitals, we study the determinants of hospital uncompensated care costs. We then examine whether this burden is equally shared across hospitals of different ownership types and finally estimate whether the degree to which hospitals ultimately bear the financial burden of this role as informal insurers through decreased profits.

First, we examine how shifts in the local demand for uncompensated care - arising from changes in the uninsured population - affect hospital uncompensated care. We use 28 years of previously confidential, hospital-level financial data. Those data were compiled by the American Hospital Association and made available to us through a data-use agreement. We estimate that each newly uninsured person leads to nearly $\$ 900$ in uncompensated care costs. That association is remarkably robust to state and year fixed effects, the inclusion of time-varying state economic controls, and region-by-year fixed effects.

One concern with those state-level panel estimates is that they may be subject to omittedvariables bias or reverse causality. To address that concern, we complement our results with two case studies of large-scale public health insurance disenrollments. The two disenrollments both occurred in 2005, in Missouri and Tennessee. Estimates from these reforms isolate the effect of sudden, plausibly exogenous increases in the uninsured population. Exploiting both within- and across-state sources of

\footnotetext{
2 Policymakers have long recognized the unique nature of the health care sector in that hospitals often provide services without compensation. As a result, policymakers have created funding streams to compensate hospitals for uncompensated care costs. Perhaps the most important of these funding streams are Disproportionate Share (DSH) payments. DSH payments are intended to compensate hospitals for providing care to low-income populations, and states are given broad latitude in how to spend the funds. In practice, though, DSH payments are much lower than the cost of uncompensated care provided by hospitals. Hospitals also receive other forms of government assistance, but most of these are not directly tied to the amount of uncompensated care that the hospitals provide and instead provide general support for the variety of other services hospitals provide to the community. As a result, they do not directly compensate hospitals when the hospital faces more uninsured patients. For example, when states reduce the generosity of Medicaid benefits there is no corresponding increase in the value of these local tax benefits.
} 
variation, we find that these disenrollments increased hospital uncompensated care costs. The magnitude of the change in costs following those disenrollments is similar to our state-year estimates.

We then study the local supply of uncompensated care. In particular, we test whether uncompensated care is tied to each specific hospital, or whether the costs can spillover across hospitals following changes in market structure. As an example of such a spillover, consider the case of Saint Elizabeth's Hospital in Belleville, Illinois. Hospital executives planned to move the main location out of the downtown area. This led executives at the remaining downtown hospital to fear that their hospital would "be overwhelmed and will get most of the area’s uninsured and Medicaid patients” (Galewitz, 2015).

To study such dynamics, we measure the effects of a hospital closure on neighboring hospitals. Defining the local market as either the county or the hospital service area (HSA), we estimate a statistically significant decline in total uncompensated care provided in the market after a closure. However, this decline likely results from an overly strict geographic market definition. Supporting this argument, when we define the local market more broadly, using local commuting zones (Tolbert and Sizer, 1996; Autor and Dorn, 2013), we estimate a statistically significant increase in uncompensated care costs for the remaining hospitals in the market but no statistically significant change in the total uncompensated care provided. This nearly complete spillover of uncompensated care to the remaining hospitals suggests that the demand for uncompensated care is relatively inelastic and represents a market-level and relatively non-discretionary fixed cost for hospitals. The results also suggest that commuting zones may be a useful market definition when studying the health care consumption of non-elderly uninsured adults. $^{3}$

Taken together, our results demonstrate the importance of hospital-provided uncompensated care in filling in the gaps of the social health insurance system in the United States. In 2012, hospital

\footnotetext{
3 These results also contribute to a broader understanding of the industrial organization of health care markets. Gaynor, Ho and Town (2014) summarize the research on the structure of these markets. They focus on the welfare effects of changes in firm concentration. However, they do not discuss the role of uncompensated care. Our results demonstrate that changes in the structure of the local market can have meaningful, negative effects on firms' patient margins. This can have several implications for research in this area. For example, a complete analysis of the benefits of increased concentration must account for the accompanying increased uncompensated care costs per hospital.
} 
uncompensated care exceeded $\$ 46$ billion. By comparison, this amounts to nearly 30 percent of 2012 Medicaid payments for inpatient and outpatient hospital spending. ${ }^{4}$ Uncompensated care costs are also large relative to the industry's profits. Holding all else constant, if hospitals only served paying customers, their 2012 profits would have been approximately 70 percent larger (Herman, 2014).

Importantly, the role of hospitals as informal insurers is not simply the unintended result of social insurance or the fact that the service provided is necessary for the survival of its customers. Both of these are characteristics of grocery stores, for example, which sell a vital product that is partially financed by social insurance in the form of food stamps. And yet, grocery stores that accept food stamps are not required to provide "uncompensated food" for individuals who are either ineligible for food stamps or have exhausted their monthly benefits. Similarly, this informal insurance does not mechanically occur because the government has chosen to use third parties in the provision of social insurance programs. Recently, the government has expanded the use of third parties as part of the Earned Income Tax Credit and the food stamps program without raising the costs of private firms (Kopczuk and Pop-Eleches, 2007; Saslow, 2013).

Instead, hospitals have become informal insurers as a result of deliberate policy decisions that (1) leave a portion of the low-income population without health insurance and (2) require hospitals to treat patients regardless of their ability to pay. As a result, Medicaid provides financial protection not only to its direct beneficiaries, but also to the hospitals that would have still been required to treat Medicaid recipients were they to be uninsured. That finding is consistent with the contemporaneous work of Finkelstein, Hendren, and Luttmer (2015), who estimate that Medicaid enrollees only value their insurance coverage at approximately $\$ 0.50$ of the cost. Our results show that one reason for this undervaluation is that uninsured individuals often receive care at hospitals without providing direct payment. As a result, both our results and those of Finkelstein, Hendren and Luttmer show that a large fraction

\footnotetext{
${ }^{4}$ This calculation assumes that the percentage of spending on inpatient and outpatient services is similar across the Medicaid Fee for Service and Managed Care programs.
} 
of Medicaid spending is a transfer from the government to private parties. The majority of these transfers result from unpaid medical bills and are therefore a transfer to hospitals and physicians.

The existence of those transfers, however, does not speak to economic incidence. Many policymakers assume that hospitals simply pass on the cost of uncompensated care to privately insured patients by raising prices. For example, the text of the ACA states, "[t]o pay for [uncompensated care], health care providers pass on the cost to private insurers, which pass on the cost to families. This costshifting increases family premiums by on average over $\$ 1,000$ a year. By significantly reducing the number of the uninsured, the requirement, together with the other provisions of this Act, will lower health insurance premiums." Cost shifting was also cited by Chief Justice Roberts in the Supreme Court decision upholding the constitutionality of the ACA. Roberts wrote: "hospitals pass on the cost [of uncompensated care] to insurers through higher rates, and insurers, in turn, pass on the cost to policy holders in the form of higher premiums" (National Federation of Independent Business v. Sebelius).

Despite the frequent pronouncements of policymakers, the ability of hospitals to actually pass on uncompensated costs is not well established either theoretically or empirically (Dranove, 1988; Morrisey, 1994; Timmins, 2014; Dranove, Garthwaite, and Ody, 2014). ${ }^{5}$ We examine the potential for uncompensated-care cost shifting by studying how shocks to uncompensated care affect hospitals' patient-care profit margins. If hospitals pass along all uncompensated care onto private insurers, then an increase in the uninsured population should not affect these profit margins. We find, however, that increases in the uninsured population lead to a decline in hospital patient-care profit margins. Those results demonstrate that, if cost-shifting occurs at all, hospitals cannot pass through all uncompensated care costs onto their privately insured patients. A back-of-the-envelope calculation suggests that hospitals absorb approximately two-thirds of the costs from uncompensated care. ${ }^{6}$

\footnotetext{
${ }^{5}$ In theory, pass-through will only occur at hospitals that had not set profit-maximizing prices. If non-profit firms do not solely maximize profits, then they may pass on uncompensated care costs to private insurers. But existing research indicates that many non-profit hospitals behave in a manner consistent with profit maximization (Dranove, Garthwaite, and Ody, 2014).

${ }^{6}$ The decline in profits also speaks to a concern with this paper's focus on uncompensated care as measured by adjusted charges. There exists concern regarding whether adjusted charges accurately measure true economic costs. The drop in
} 
Hospitals, however, do not bear these increased costs equally. We find that non-profit hospitals predominantly bear the burden of serving as insurers of last resort. For example, we find that increases in the uninsured population primarily affect the costs of non-profit hospitals. By contrast, for-profit hospitals are largely unaffected. Similarly, when a hospital closes, nearby non-profit hospitals bear a greater share of the burden of the spillover of uncompensated care costs.

Those findings shed light on whether nonprofit hospitals are simply "for-profits in disguise" (Weisbrod, 1988). That view, for instance, was held by former chair of the Senate Finance committee, Charles Grassley, who said "[n]onprofit hospitals and for-profit hospitals have often been indistinguishable" (Pear, 2015). In contrast to this prevailing belief, our findings show that non-profit hospitals fill the gaps in the existing social health insurance system to a degree that is not true of for-profit hospitals. This finding contributes to work that examines differences between non-profit and for-profit firms (Weisbrod 1988; Sloan and Vraciu 1983; Norton and Staiger, 1994; Duggan, 2002; Dranove, Garthwaite, and Ody 2014). Given the limitations of our data, we cannot conclusively say that this is the result of different intrinsic motivations of the firm, as opposed to differences in the selection of services that attract uninsured patients. However, we find that even when we limit the sample to similar geographies and hospital types, we continue to find evidence that non-profit firms bear a greater share of the costs from changes in the demand for uncompensated care.

Finally, we conclude the paper by using our estimates to analyze the consequences of the ACA. We estimate that insuring 25 million more Americans under the ACA would reduce the uncompensated care costs of hospitals by $\$ 20$ billion, approximately 43 percent of the 2012 level. Additionally, hospitals in states that do not implement the ACA's Medicaid expansion will face higher uncompensated care costs than those in states which implement the expansion. We calculate that the money states will "save" from not expanding Medicaid is less than the hospital uncompensated care costs generated by

profits we estimate suggest that changes in the share uninsured cause meaningful changes in hospital finances. Put another way, in the case where hospitals are not able to pass any of their uncompensated care costs onto privately insured customers, our estimates suggest each newly uninsured person costs hospitals $\$ 600$. This provides a robust lower bound that does not require any assumptions about how we convert uncompensated care charges to costs. 
not expanding Medicaid. Our estimates thus suggest that the decision not to implement the ACA's Medicaid expansion achieves savings for the government at the expense of local hospitals.

The remainder of the paper proceeds as follows. Section 2 discusses the relevant institutional details on the provision of hospital uncompensated care. Section 3 discusses the hospital-level data used in the analysis. Section 4 focuses on the demand for uncompensated care, presenting state-panel estimates and supporting evidence from two case studies in Missouri and Tennessee. Section 5 examines the supply of uncompensated care, presenting evidence of spillovers of uncompensated care across hospitals after a hospital closure. Section 6 examines the role of hospital ownership type in this setting. Section 7 estimates how much of the financial incidence of uncompensated care falls on hospitals and Section 8 concludes.

\section{Why Do Hospitals PROVIDE UnCOMPENSATEd CARE?}

Typically, firms only serve paying customers. ${ }^{7}$ But in health care, hospitals routinely provide care to patients who are unable or unwilling to pay. In 2010, US hospitals provided approximately $\$ 40$ billion of care, 5.8 percent of total expenses, without payment. From 1984 through 2010, the absolute amount of uncompensated care steadily increased and the relative amount varied between 5.4 and 6.4 percent of expenses. To place this number in some context, consider that from 1992 through 2010, average hospital operating margins ranged from a low of 2.0 percent to a high of 5.5 percent.

Few previous studies have focused on hospital uncompensated care. A small literature has described trends in uncompensated care over time (Mann et al., 1997; Cunningham and Tu, 1997). To our knowledge, only two other studies have focused on the relationship between uncompensated care and the size of the uninsured population (LoSasso and Seamster, 2007; Davidoff et al., 2000). Both of these studies find a small association between public health insurance generosity and uncompensated care during the early 1990s. However, they focus on time periods with Medicaid expansions that were pri-

${ }^{7}$ Firms often provide services prior to actual payment, and some consumers do default on their debts. But in most industries beyond health care, the firms are not forced to continue to do business with customers who do not pay. 
marily aimed at children, which likely lowers their power to detect a relationship between public health insurance and uncompensated care. Two other studies conduct time series analyses of changes to state Medicaid programs (Blewett et al., 2003; APS Healthcare, 2006). More recently, DeLeire et al. (2014) examined publicly released financial data from for-profit hospital chains since the implementation of the ACA and found large decreases in the share of admissions from uninsured patients. The paucity of other studies is likely driven by the lack of publicly available data on hospital finances.

Given that private hospitals are large and sophisticated firms, the inability to secure payment for services rendered cannot be rationalized as a simple operational inefficiency. Given that fact, the open question is why do hospitals continue to provide billions of dollars in care without compensation? Some of these costs are the result of true bad debt that firms in all sectors face, i.e. services for which the hospital expected compensation but for which they were unable to collect payment. A large portion, however, stems from charity care, services that the hospital provided without expecting compensation. ${ }^{8}$

There are a variety of reasons that hospitals provide uncompensated care. In this paper, we consider two of the most-discussed reasons: (1) federal regulations and (2) preferential tax treatment. There are many regulations that govern how hospitals treat patients who do not pay. Perhaps the most important of these regulations is the Emergency Medical Treatment and Labor Act (EMTALA), which requires that hospitals treat all individuals requiring emergency care regardless of their insurance status. Passed in 1985, EMTALA was a federal statute that expanded on a number of state laws requiring hospitals to treat all patients regardless of their ability or willingness to pay. ${ }^{9}$ However, it should be noted

\footnotetext{
${ }^{8}$ The line between bad debt and charity care is often unclear. For instance, some hospitals may classify care as bad debt when they expected the patient not to pay but still sent them a bill. The determination of uncompensated care as either bad debt or charity care is imprecise and varies across hospitals and over time. As a result, we focus on aggregate uncompensated care - i.e., the sum of bad debt and charity care - in all of our analysis.

${ }^{9}$ The statute established three main responsibilities for hospitals that participate in the Medicare program. Such hospitals must provide a medical screening exam to any patient who presents themselves at the hospital requesting treatment. If that patient is determined to have an emergency medical condition, they are required to provide the necessary treatment to stabilize the patient. Finally, if they are unable to stabilize the patient, they must transfer the patient to an appropriate facility for treatment. Hospitals must also accept transfers if they are the appropriate facility for treatment and report any inappropriate transfers. Of particular importance in our setting, these actions must not be delayed to inquire about the insurance status of the patient, and hospitals cannot deny services to people based on their ability to pay (GAO, 2001). If hospitals violate EMTALA, they are subject to a variety of financial penalties. The ultimate sanction they face is the disbarment from participating in the Medicare program, a sanction imposed thirteen times from 1986 through 2001 (Zibulewsky, 2001). The imple-
} 
that even after full implementation of this regulation analyses have shown that the uninsured still receive less intensive care for emergency treatments in hospitals (Doyle, 2005).

Beyond EMTALA, the health care sector is also unique in the large share of non-profit, privatesector firms. Over seventy percent of private hospitals are non-profit organizations. In exchange for being exempt from federal, state, and local taxes, these firms are expected to provide a community benefit. While there are many factors that contribute to a community benefit, such as medical research and teaching, perhaps the most discussed and easily quantified is uncompensated care (Nicholson et al., 2000). ${ }^{10}$ As a result, these hospitals may provide medical services to patients without compensation even if they do not enter the hospital through the ED.

Whether non-profit hospitals behave differently from for-profit hospitals remains an open question in the literature. Several studies compare the amount of uncompensated care provided by hospitals of different ownership types. In general these studies find that ownership status is a factor in the provision of uncompensated care by hospitals (Sloan, Morrissey, and Valvona, 1988).

However, subsequent work highlighted that these simple comparisons ignore the fact that firm ownership status and location are not exogenous, particularly for new entrants. To this end, Norton and Staiger (1994) find that non-profit and for-profit hospitals located in the same area provide similar levels of uncompensated care. Similarly, Duggan (2002) finds that non-profit hospitals respond similarly to for-profit firms when they compete in the same market as for-profit hospitals. Dranove, Garthwaite and Ody (2014) find that, across most dimensions, non-profit hospitals react to financial shocks in the same way economic theory predicts a for-profit firm would react. The one exception being that non-

mentation of EMTALA evolved over time. It was not until 1994 that the Center for Medicare and Medicaid Services (CMS) published final regulations for the statute. Additional guidance was provided in subsequent regulations. For instance, CMS advised hospitals not to inform patients that they may be charged prior to the patient being stabilized. For the purpose of defining a patient's arrival at a hospital, CMS defined a hospital campus to be anything within 250 yards of its main buildings (GAO, 2001). Given the slow evolution of the regulatory structure around EMTALA, it is difficult to pinpoint the exact date when the law was binding. Perhaps for this reason, there has been no comprehensive study to document the effects of EMTALA.

${ }_{10}$ Prior to 1969, IRS regulations required that hospitals provide charity care in order to qualify for their federal tax exemption. However, new regulations in that year broadened the criteria to include other activities that benefited the community (GAO, 2005). 
profit firms suffering financial shocks are more likely to stop offering relatively unprofitable services. As a result, many economists believe that non-profit and for-profit hospitals are similar, a belief epitomized by Weisbrod's (1988) characterization of non-profit hospitals as "for-profits in disguise."

This paper's results contradict that view. We find a consistent pattern of evidence that non-profit hospitals are more exposed to changes in demand for uncompensated care. That pattern persists even when we limit the sample to for-profit and non-profit hospitals in the same market. That said, we cannot rule out that non-profit hospitals may choose to serve areas within these markets where they are more exposed to demand for uncompensated care resulting from changes in the share of the market's population that is insured. However, we note that over the long term these location decisions themselves are not fixed and therefore represent a choice made by non-profits.

Policymakers have created several programs intended to provide partial compensation for hospitals that provide care to low-income populations. The largest of these payments come from the Disproportionate Share Hospital (DSH) payments which are components of both the Medicaid and Medicare programs. ${ }^{11}$ The purpose of the Medicare DSH program is to compensate hospitals for the burden of treating a low-income population, which is believed to have higher costs than the average payment received under Medicare. Broadly speaking, hospitals that exceed a predefined threshold receive an adjustment in their Medicare reimbursements.

Similarly, Medicaid DSH payments are targeted at hospitals treating low-income populations and are "intended to recognize the disadvantaged financial situation of those hospitals because low-income patients are more likely to be uninsured or Medicaid enrollees" (Mitchell, 2013). The total amount of federal spending on DSH is fixed each year and does not increase with the size of the uninsured population. In 2012, $\$ 17.1$ billion was spent on Medicaid DSH payments. Hospitals are eligible to receive DSH payments if their Medicaid inpatient utilization rate exceeds 1 percent. In addition, hospitals are

\footnotetext{
11 First established in 1986, Medicare DSH payments are a function of the number of patients that a hospital has who qualify for both Medicare and the Supplemental Security Income (SSI) programs as well as those that qualify for Medicaid but not Medicare.
} 
guaranteed to receive some DSH payments if either their Medicaid inpatient utilization rate is at least one standard deviation higher than the mean for their state or their percentage of low-income patients exceeds 25 percent.

Outside of these restrictions, states are given broad latitude in the distribution of DSH payments. For example, Mitchell (2013) notes that in 2007 Oregon only distributed DSH funds to 9 of its 58 hospitals; that same year, every hospital in New Jersey received funds. As a result of the autonomy provided to states, it is not clear whether DSH payments effectively target hospitals providing large amounts of uncompensated care or instead assists hospitals that have large amount of underpayments from Medicaid. ${ }^{12}$ If hospitals are made financially whole by the DSH program for uncompensated care costs, then their role as informal insurers is limited. However, if DSH payments are primarily targeted towards hospitals with large numbers of publicly insured patients, then the decision of hospitals to provide uncompensated care represents a true financial cost of their role in the social safety net.

\section{DATA}

Our primary data on hospital uncompensated care costs consist of proprietary financial data obtained through a research partnership with the American Hospital Association (AHA). The data are collected as part of the annual AHA survey, which is the most complete measure of the structure and finances of American hospitals. ${ }^{13}$ We obtained AHA survey data from 1984 through 2011. The survey asks hospitals the amount of medical care that they provide without any compensation. As described above, hospitals provide uncompensated care through two primary channels: charity care and bad debt. ${ }^{14}$ Charity care are services for which a hospital never intended to collect payment, whereas bad debts are costs

\footnotetext{
12 The uncompensated care costs we discuss in this paper do not include these underpayments and instead focus only on services for which the hospitals receives no compensation.

13 One concern is that - because the survey is handled by a trade association - hospitals may provide inaccurate information. Appendix Figure A1 compares uncompensated care data from the AHA to reports for the Tennessee Joint Annual Report, a mandated reporting system in that state. These data are remarkably consistent, showing that reports to the AHA, at least in Tennessee, are quite similar to those to the state regulatory body.

14 Importantly, our definition of uncompensated care does not include any portion of hospital costs that exceed reimbursements from government programs such as Medicare and Medicaid.
} 
related to services for which a hospital attempted to collect payment but was not paid (American Hospital Association, 2010). The methods of classifying uncompensated medical costs across these two categories vary greatly by provider and over time. For example, Rundall et al. (1988) state that for-profit hospitals are more likely to report uncompensated care as bad debt rather than charity care. By contrast, non-profit hospitals might be more inclined to define these costs as charity care. Over time, these patterns can change. For instance, a non-profit hospital may become concerned about an impression that they are not aggressive enough (or they are being too aggressive) in tracking down non-payments. Given this unclear distinction, we consider solely the sum of bad debt and charity care, total uncompensated care costs. ${ }^{15}$

A second complication is that hospitals report the outcome as charges rather than costs. A wellknown problem in the study of hospital finance is the growing spread between the list price that hospitals charge for a service and the actual payments these facilities receive from private payers. As a result, charge-based measures of uncompensated care provide an inaccurate description of actual costs. We therefore use a cost-to-charge ratio to approximate the actual costs of providing services. ${ }^{16}$ Since our data cover a long time period, we adjust the resulting uncompensated care costs to 2011 dollars using the CPI-U series, and we make similar adjustments for all other dollar values in the survey, such as patient revenue and hospital expenditures.

A final concern with the AHA data is that it focuses on dollars, not visits. For that reason, we also digitized the Joint Annual Reports (JAR) of health care facilities in Tennessee each year. These data are collected by the Tennessee Department of Health from licensed health care facilities in Tennessee.

\footnotetext{
${ }^{15}$ Given these concerns, our data-use agreement with the AHA only allows us to study total uncompensated care in those data.

${ }^{16}$ Specifically, we calculate each hospital's cost-to-charge ratio as total expenses divided by the sum of gross patient revenue and other operating revenue, and we average this measure across years for each hospital. Appendix Table A1 reports results using the following alternative cost-to-charge ratios: state-by-year average cost-to-charge ratios, annual average cost-tocharge ratios, hospital-by-year cost-to-charge ratios, and a "jackknife" measure which computes each hospital's average costto-charge ratio excluding the current year. One advantage of the jackknife measure is that if uncompensated care costs affect a hospital's profit margin (which would occur if hospitals cannot pass through the cost shock), then this will mechanically affect the hospital's cost-to-charge ratio. The results are qualitatively similar regardless of which cost-to-charge ratio we use, so we use the hospital average for simplicity.
} 
While many of the data in these reports are duplicative of the data in the AHA survey, the JAR data also include other outcomes, such as the number of admissions or visits by payer type.

We identify spillovers of uncompensated care across hospitals with systematic data on hospital closures. We obtained such data for 1987 through 2000 from reports generated by the Office of the Inspector General (OIG) at the Department of Health and Human Services. The OIG data were originally compiled by the Center for Medicare and Medicaid Services and various state agencies and associations (OIG, 2000). We merge the OIG records to the AHA hospital data and consider a hospital closed when it is both listed as a closure in the OIG data and no longer appears in the AHA hospital data. In total we identify 359 closures from 1987 through $2000 .^{17}$

Finally, for the state-panel analysis, we use the March Supplement to the Current Population Survey (CPS). The CPS is an annual survey of employment, income, and health insurance outcomes. The March CPS asks about insurance coverage in the previous year and we use these data to determine the share of the state population between the ages of 21 and 64 that lacks insurance each year.

\section{THE DEMAND FOR UNCOMPENSATED CARE}

This paper's first goal is to study the demand for uncompensated care. In particular, we study how changes in the uninsured population affect hospital uncompensated care. Section 4.A. examines the relationship between the share of a state that is insured and the amount of uncompensated care provided by its hospitals. The section focuses on state-by-year variation in the size of the uninsured population. Section 4.B. complements those results with a case study, the 2005 Missouri Medicaid disenrollment. Section 4.C. focuses on a second case study, the 2005 Tennessee Medicaid disenrollment, which affected non-traditional Medicaid beneficiaries.

\footnotetext{
${ }_{17}$ An alternative way to identify hospital closures would be to identify hospitals that simply cease to exist in the AHA data. However, hospitals that merge but maintain separate physical locations are often combined into one entry in the AHA data. Since we cannot separate mergers from closures, this strategy would inaccurately classify facilities as closed when they remain open.
} 


\section{A. Health Insurance Penetration and Uncompensated Care}

The size of the uninsured population should be a major factor in the provision of uncompensated care. After all, if individuals are insured, then they need little uncompensated care. ${ }^{18}$ To explore this relationship, Figure 1 presents the share uninsured versus total uncompensated care costs per capita. Panel A suggests a strong cross-state relationship between these two variables, while Panel B shows a similar relationship using changes within states over time. To further explore this relationship and quantify its magnitude, we estimate the cross-sectional relationship between state-level data on the share uninsured and uncompensated care costs. Table 1 presents estimates of a cross-sectional regression for 1990, 1995, and 2000. In all years, we observe a positive, statistically significant relationship between the share of the population without insurance and the amount of hospital uncompensated care. For example, in 1995, a ten-percentage-point change in the share uninsured was associated with a $\$ 910$ increase in uncompensated care costs per capita. This relationship is concentrated among hospitals with an ED.

Of course, these cross-sectional relationships may simply reflect longstanding differences across states and over time. For that reason, we estimate the following panel-data regression:

$$
y_{s t}=\alpha_{s}+\delta_{t}+\beta \cdot \text { PercentUninsured }_{s t}+X_{s t}^{T} \Gamma+\varepsilon_{s t} .
$$

Here, $\alpha_{s}$ are state fixed effects, $\delta_{t}$ are year fixed effects, $X_{s t}$ is a vector of controls added to some specifications, and $\varepsilon_{s t}$ is an idiosyncratic error term that allows for arbitrary correlation between observations based on the same state. The coefficient of interest, $\beta$, represents the change in uncompensated care costs based on the percentage of the population uninsured and is identified off of changes within states over time. We consider two measures of uncompensated care costs: (1) uncompensated care costs per capita, and (2) uncompensated care cost as a percentage of hospital expenditures. ${ }^{19}$ Note that when we

\footnotetext{
18 The insured may also consume uncompensated care if they do not pay their cost-sharing expenses, and this may have become more common in recent years. For example, in 2006, only 3 percent of workers with employer-provided insurance had deductibles greater than $\$ 2,000$ and only 10 percent had deductibles greater than $\$ 1,000$. By 2012 , these numbers grew to 14 and 34 percent respectively (Rae, Panchal, and Claxton, 2012).

${ }^{19}$ All of the per capita calculations use CPS estimates of the adult population between the ages of 21 and 64 in each stateyear, which matches same population used to calculate the percent uninsured.
} 
consider uncompensated care costs per capita, $\beta$ can also be interpreted as the change in uncompensated care costs for each newly uninsured person. ${ }^{20}$

Table 2 presents estimates of equation (1) for a variety of hospital samples. Panel A presents estimates for the full sample of hospitals in the AHA. The estimates in column (1) suggest that each newly uninsured person is associated with $\$ 856$ in hospital uncompensated care costs. That estimate remains similar when we include a set of time-varying state-level controls (column 2); region-by-year fixed effects (column 3); or both the region-by-year fixed effects and state-level economic controls (column 4).

To place this estimate in context, consider that 8 percent of the uninsured report an inpatient visit each year. ${ }^{21}$ Thus an uncompensated-care cost per uninsured person of $\$ 900$ translates into a cost of nearly $\$ 11,000$ per uninsured inpatient visit. By contrast, Pfuntner et al. (2013) estimate that each uninsured inpatient stay costs $\$ 8,300$. We note, however, that the AHA uncompensated care costs are based on both inpatient and outpatient visits. Carper and Machlin (2013) estimate that inpatient services account for 71 percent of medical spending relative to total inpatient, outpatient, and ED visits. This suggests a cost per uninsured person that utilizes medical services of approximately $\$ 11,690$, which is very close to the scaled estimate above.

Columns (5) through (8) present a similar pattern for uncompensated care as a percentage of hospital expenditures. With the full set of controls, the point estimates suggest that a one percentage-point change in the share uninsured is associated with a 0.16 percentage-point change in uncompensated care as a percentage of costs. On average, uncompensated care accounts for 5.7 percent of expenditures, which means this is a 2.8 percent change in this outcome.

As described above, under EMTALA hospitals with an emergency department are required to treat emergent patients regardless of their ability to pay. Therefore, Panels B and C of Table 2 present regression estimates based on whether a hospital currently operates an ED. These estimates demonstrate

\footnotetext{
20 That is, when per-capita uncompensated care is the outcome of interest, the state population is in the denominator in both the outcome and the independent variable of interest. Thus, $\beta$ represents both the effect of a change in a percentagepoint increase in the uninsured share and the effect of one additional uninsured state resident.

${ }^{21}$ Authors' calculations based on the National Health Interview Survey.
} 
that the increase in uncompensated care following an increase in share uninsured is entirely driven by hospitals with an ED. Facilities without an ED exhibit a small and statistically insignificant increase in uncompensated care when the share insured decreases. This is true regardless of the covariates included in the specification, the sample, or the definition of uncompensated care costs. ${ }^{22}$

Finally, we note that not all hospitals should be expected to experience increased uncompensated care. The AHA data contains information on a wide variety of hospitals, from large, general acute-care facilities to ambulatory surgical centers and rehabilitation facilities. Panel D presents regression estimates for a sample limited to adult and child acute-care facilities with an ED. These estimates are similar to the estimates for all hospitals with an ED, suggesting that nearly all of the change in uncompensated care costs following an increase in the share uninsured is borne by acute-care hospitals. This suggests that the observed relationship is not driven by a third unobserved variable affecting the finances of the entire hospital sector.

As discussed in Section 2, in recognition of the role that hospitals play in the social safety net, they are provided with DSH payments that are meant to partially reimburse them for treating Medicaid recipients and the uninsured. States retain great freedom as to how they distribute Medicaid DSH funds. Therefore, we test whether hospitals that receive DSH payments are also those that drive the above results. Appendix Table A3 presents estimates of the relationship between the share uninsured and hospital uncompensated care costs stratified by whether the hospital receives any DSH payments. ${ }^{23}$ The table suggests roughly similar effects on both types of hospitals and is consistent with DSH payments not fully compensating hospitals for the uncompensated care they provide.

Overall, these estimates suggest a robust association between the demand for uncompensated care and actual uncompensated care costs. To further examine the magnitude of our estimates, we compare

\footnotetext{
22 There could be a concern that hospitals with an ED happen to be located in areas where there are more marginally insured individuals that demand uncompensated care when their insurance status changes. We address this concern by studying uncompensated care in hospitals that close their ED but otherwise remain open, and we compare uncompensated care in these hospitals before and after the ED closure. These results are reported in Appendix Table A2, and we find that uncompensated care drops by approximately 40 percent in the years following the closure of an ED.

${ }^{23}$ Hospitals are categorized based on the hospital-level DSH payments they received in 2005. This is the first year we were able to obtain audited reports for the distribution of these funds at the hospital level.
} 
them to the results of the Oregon Health Insurance Experiment. Finkelstein et al. (2012) find that those who received new insurance as a result of the Oregon Health Insurance Experiment consumed an additional $\$ 1,000$ in hospital charges and saw a decrease in medical collections of $\$ 390$. Assuming that only bad-debt charges are sent to collection agencies, and applying both Oregon's 2009 cost-to-charge ratio and the distribution of charity care and bad debt in our AHA data, we estimate that each newly insured person reduced the uncompensated care costs for Oregon hospitals by approximately $\$ 550$ in 2011 dollars with an upper bound of the confidence interval of nearly $\$ 1,021$. This implied estimate is broadly similar to the main state-year estimate, above, of $\$ 887$.

Although the state-panel estimates are robust to various control variables, we cannot rule out bias from unobserved, confounding trends. For example, a recession could increase the share uninsured in a state and also decrease the ability of previously uninsured individuals to pay for their hospitalization out of their own pockets. In addition, the results could be subject to bias due to reverse causality. Some researchers have hypothesized that it is the availability of charity care that induces consumers to become uninsured (Coate, 1995). Such a phenomenon would bias our results, although it should be noted that existing empirical evidence of this potential mechanism suggests that to the extent uncompensated care crowds out private insurance coverage this effect is small (Rask and Rask, 2000; Herring, 2005; LoSasso and Meyer, 2006). Nevertheless, to address this concern, we complement the state-level panel analysis by studying large, sudden increases in the uninsured population. We focus on two such increases, which both arose from large-scale public health insurance disenrollments in Missouri and Tennessee. These are the two largest disenrollments during the sample period covered by our data. Overall, the results from these two case studies lead to similar conclusions as the state-level panel regressions above.

\section{B. The Missouri Medicaid Disenrollment}

Following the 2001 recession, Missouri faced many years of revenue shortfalls. From 2001 through 2005, state revenues declined by 0.6 percent each year (Blouin et al., 2005). This resulted in budget cuts of over $\$ 2$ billion over that time period, with nearly half of those reductions coming from social servic- 
es, health, and mental-health services. Chief among these cuts was a sharp reduction in the generosity of the state's Medicaid program in 2005. In 2004, Missouri Medicaid provided insurance for over 900,000 low-income state residents. As a result of the 2005 policy changes, approximately 150,000 residents lost access to Medicaid and SCHIP (Zuckerman, Miller, and Pape, 2009). ${ }^{24}$

The reduction in generosity came primarily from five policy changes. First, a reduction in the income limits for parents from 75 percent of the federal poverty line (FPL) to the income limits for the Temporary Assistance for Needy Families limits of approximately 17 to 22 percent of FPL. Second, the state increased premiums for children in families earning more than 150 percent of FPL (premiums were previously required for those earning more than 225 percent of FPL). Third, the state made families ineligible for SCHIP if they earned more than 150 percent of FPL and had access to employer provided insurance costing less than $\$ 335$ per month. Fourth, the state eliminated the Medicaid Assistance for Workers with Disabilities (MAWD) program, which allowed disabled workers earning less than 250 percent of FPL to buy into the state Medicaid program. Finally, fifth, the state created an annual reinvestigation program to ensure eligibility (Zuckerman, Miller, and Pape, 2009).

The severity of the cuts in Missouri means that those who lost coverage were similar to the traditional beneficiaries of public health insurance gaining and losing insurance in the panel-data estimates above. For example, approximately half of those losing insurance were low-income parents with incomes between 17 and 75 percent of the FPL (Ku and Solomon, 2005). As a result, the magnitude of the effect of the Missouri disenrollment serves as a useful benchmark for our panel-data estimates.

The reductions in the generosity of Missouri's Medicaid program provide a sudden shock to the state's uninsured population that should be unrelated to previous trends or other contemporaneous events in these markets. We begin by examining uncompensated care costs in Missouri versus neighboring states. Figure 2 presents uncompensated care costs in Missouri versus the other 6 states in the

24 The effect of the Missouri disenrollment exhibited little regional variation. Examining county-level Medicaid enrollment data, the county-level Medicaid caseload reduction ranged from 0.3 to 4.8 percentage of the population. The median reduction was approximately 2 percentage points and the interquartile range was 1.55 percent to 2.46 percent. As a result, in our empirical analysis, below, we are only able to compare changes in uncompensated care in Missouri to those in similar states - we cannot exploit within-Missouri variation in the effect of the disenrollment. 
North-West Midwest over the same time period. ${ }^{25}$ Following the disenrollment, there was a sudden increase in aggregate uncompensated care for Missouri's hospitals as compared to those in the comparison states. Importantly, prior to the disenrollment, hospital costs in Missouri and neighboring states followed roughly similar trends.

To identify the magnitude of the increase in uncompensated care, we turn to a difference-indifferences regression analysis:

$$
y_{s t}=\alpha_{s}+\delta_{t}+\beta \cdot I\{s=\text { Missouri }\} \cdot I\{t \geq 2006\}+\varepsilon_{s t} .
$$

The variable $y_{\text {st }}$ represents the uncompensated care per capita for state $s$ and year $t$. The model includes state fixed effects $\left(\alpha_{\mathrm{s}}\right)$, year fixed effects $\left(\delta_{\mathrm{t}}\right)$, and an error term $\left(\varepsilon_{\mathrm{st}}\right)$.

The key coefficient of interest is $\beta$, the difference-in-differences estimate of the effect of the change in Medicaid. This coefficient is identified by comparing outcomes in Missouri before and after the policy change to outcomes in neighboring states. The key identifying assumption is that outcomes in Missouri would not have evolved differently relative to other neighboring states in the absence of the disenrollment. The similar pre-trends in Figure 2 provide supporting evidence for that identifying assumption.

The first column of Table 3 presents the estimates of equation (2) and suggests an approximately $\$ 23$ increase in annual uncompensated care costs per capita in Missouri compared to hospitals in surrounding states. While it is estimated that 150,000 lost public insurance coverage as a result of the Missouri disenrollment, Zuckerman et al. (2009) estimate that the number of uninsured in Missouri increased by only 103,000 from 2004-2006. Considering both ends of this range, our estimated change in per-capita uncompensated care costs suggests a cost per uninsured person of $\$ 556-\$ 786$. That range is slightly below the estimates from the state-year estimates above.

\footnotetext{
25 In particular, we include North Dakota, South Dakota, Nebraska, Kansas, Minnesota, Iowa, and Missouri in the sample.
} 


\section{C. The TennCare Disenrollment}

The Tennessee disenrollment involved the termination of a large Medicaid expansion program targeting a population not traditionally eligible for public health insurance. Specifically, the Tennessee expansion program targeted "uninsured" and "uninsurable" state residents regardless of income. As a result of the lack of an income requirement, the expansion enrollees had higher incomes than traditional Medicaid enrollees. In 1995, over 40 percent had incomes above 100 percent of the federal poverty line. In addition, relative to traditional TennCare enrollees, they were more likely to be white, between the ages of 21 and 64, and to not have children at home.

The expansion program made TennCare more expensive than anticipated, and, by 2001, the system faced a budget shortfall of over $\$ 300$ million (Chang and Steinberg, 2009). As a result, beginning in late July of 2005, Tennessee disenrolled beneficiaries older than age 19 from the program. ${ }^{26}$ Approximately 4 percent of the non-elderly adult population of Tennessee lost public insurance coverage. ${ }^{27}$ Many disenrollees were able to secure private coverage, but in a previous paper we found that approximately 70,000 remained without insurance for many years after August 2005 (Garthwaite, Gross, and Notowidigdo, 2014). For them, the loss of insurance may have led to uncompensated care. It is that possibility that we assess here.

\section{C.1 CROSS-STATE COMPARISON}

Figure 3 presents uncompensated care costs for hospitals in Tennessee and those in other Southern states. Following the disenrollment, uncompensated care costs suddenly increased in Tennessee. Similar to Missouri, prior to the disenrollment, the costs for each set of states were similarly trending. Howev-

\footnotetext{
${ }^{26}$ Tennessee also cut certain services for the remaining enrollees. Perhaps the most significant reduction in benefits for those retaining coverage affected prescription drug coverage. In 2004, drugs accounted for 33 percent of overall TennCare spending. Effective August 1, 2005, TennCare beneficiaries retaining coverage were limited to 5 prescription drug refills per month of which no more than 2 could be brand name medications (Blue Cross Blue Shield, 2005). From 2005 to 2006, total TennCare spending fell by approximately $\$ 1.7$ billion, with nearly $\$ 1.23$ billion of this reduction coming from reduced pharmacy payments. After the reform, prescription drugs accounted for only 21 percent of overall TennCare expenditures (TennCare, 2005).

${ }^{27}$ For more institutional details on the TennCare disenrollment, see Garthwaite, Gross, and Notowidigdo (2014).
} 
er, in the years after the disenrollment there was a sharp change in uncompensated care costs for hospitals in Tennessee compared to hospitals in other Southern states.

Column 2 of Table 3 presents difference-in-differences estimates with uncompensated care costs per capita in each state as the outcome of interest. It suggests that, following the TennCare disenrollment, Tennessee hospitals provided approximately $\$ 42$ more in annual uncompensated care costs per capita after the disenrollment compared to similar hospitals in other Southern states. ${ }^{28}$ Given the size of the TennCare disenrollment, this coefficient suggests that each newly uninsured person generated approximately $\$ 1,048-\$ 1,678$ in uncompensated care costs, with the range depending on the amount of crowdout exhibited by the expansion population.

These estimates are larger than the corresponding Missouri-based and state-year panel estimates, but that comparison is unsurprising. Roughly a third of the Tennessee expansion population were excluded from the private insurance market because of pre-existing conditions, and so were in poor health. A McKinsey and Company analysis found that the expansion population in its entirety had 40 higher Medicaid expenditures than a traditional TennCare enrollee (McKinsey, 2003). A forty percent increase over our main state-year panel estimate would be $\$ 1,242$, which is very close to the midpoint of the TennCare estimates. Importantly, many of those expected to gain coverage through the Affordable Care Act come from a similar sub-population. Therefore the use of uncompensated care by this population is an important component of the potential change in costs from the ACA expansion.

\section{C.2 WITHIN-TENNESSEE ANALYSIS}

The cross-state evidence of an increase in uncompensated care in both Tennessee and Missouri suggests a causal relationship between the size of the uninsured population and hospital uncompensated care. A remaining concern is that another, contemporaneous event within each state is driving the esti-

\footnotetext{
${ }^{28}$ In 2004, Tennessee hospitals provided approximately $\$ 670$ million in uncompensated care.
} 
mates. For this reason, we next exploit the substantial, within-state variation in exposure to the TennCare disenrollment to estimate the effect of the disenrollment on uncompensated care. ${ }^{29}$

While the disenrollment was enacted simultaneously across Tennessee, the number of citizens who lost coverage varied a great deal across the state. We obtained county-level enrollment data from the Bureau of TennCare annual reports for 2004 and $2005 .^{30}$ The percentage of a county's population losing health insurance in the year after the disenrollment ranges from a low of 0.8 to a high of 9.1. The median county experienced a drop in enrollment of 3.3 percentage points, and the interquartile range was 2.7 to 5.0 percentage points. We aggregate these disenrollment data into the 14 health-department regions in the state identified by the Tennessee Department of Health. We construct regression models which interact the region-specific change in share of population enrolled in TennCare with an indicator variable for the years following the disenrollment. Specifically, we estimate the following regression:

$$
y_{r t}=\lambda_{r}+\delta_{t}+\beta\left(\Delta \text { TennCare }_{r, 2004-2005}\right) \cdot I\{t \geq 2006\}+\varepsilon_{s t}
$$

where $y_{r t}$ is the outcome of interest for region $r$ and year $t$. This model includes region-specific fixed effects $(\lambda)$ and year fixed effects $(\delta)$. Given the lack of reliable annual estimates of the population in each health department region, we consider a dependent variable that is the log of the uncompensated care in the health department region. We will then compare this magnitude to the estimate from a loglinear specification of equation (2).

The key coefficient of interest in equation (3) is $\beta$, which estimates the effect of the TennCare disenrollment by exploiting differences across regions in the magnitude of decline in TennCare enrollments

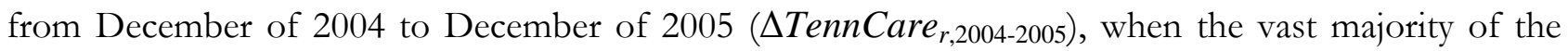
TennCare disenrollment occurred. The key identifying assumption is that the uncompensated care in these hospital regions would have evolved similarly in the absence of the disenrollment. While we can-

\footnotetext{
${ }^{29}$ The lack of regional variation in exposure to the Missouri Medicaid disenrollment makes this type of analysis infeasible for that disenrollment.

30 These are the earliest available annual reports for TennCare. While quarterly reports for earlier years exist, those documents do not contain enrollment by county and eligibility category. Our attempts to receive earlier enrollment data from TennCare administrators were unsuccessful.
} 
not test this assumption directly, we show below that trends in uncompensated care in these regions were not evolving differently in the years before the disenrollment in a way that was correlated with our measure of exposure to the disenrollment.

We begin by comparing changes in unadjusted sample means across health department regions. Figure 4 depicts the relationship between $\Delta$ TennCare $_{r, 2004-2005}$ and the change in total uncompensated care from 2004 and 2005 to 2006 and 2007. We observe a strong negative relationship: regions with larger decreases in TennCare enrollments experienced larger increases in uncompensated care costs. Figure 5 presents the results of a simple falsification test: it depicts the relationship between the same changes in TennCare enrollments in 2005 and differences in uncompensated care before and after 2002 rather than 2005. Importantly, the negative relationship that we observe in Figure 4 is not present in Figure 5.

We next quantify the magnitude of the changes in uncompensated care costs with a withinTennessee regression analysis. Column (4) of Table 3 reports results from estimating equation (3) with the logarithm of the total amount of uncompensated care in each Tennessee health department region as the outcome of interest. ${ }^{31}$ The first column demonstrates that hospital regions with a larger decrease in TennCare enrollment experienced a statistically significant increase in uncompensated care costs. Scaling this estimate by the average disenrollment in Tennessee suggests an approximately 18-percent increase in uncompensated costs. For the purposes of comparison, column (3) of Table 3 presents es-

\footnotetext{
31 Our preferred within-state analysis exploits variation across Tennessee health department regions. We prefer this level of aggregation because it provides a large number of geographic areas $(N=14)$. At the same time, health department regions are large enough to allow for a relatively accurate estimate of the change in TennCare eligibility in the area as well as to minimize the possibility of spillovers across areas, both of which would attenuate the results. In order to demonstrate that our results are not sensitive to this unit of analysis, Appendix Figures A2, A3, and A4 as well as Appendix Table A4 consider a number of alternate geographies. These include the 8 hospital referral regions (HRRs) and 81 hospital service areas (HSAs) in Tennessee, as well as the 9 Economic Development Districts established by the Tennessee Development District Act of 1965. The estimated impacts at the development district and the HRR level are similar in magnitude to the main estimates in Table 3, although the within-state estimates using HRRs are not precisely estimated $(p=0.327)$. The estimated impact for the 81 HSAs is statistically significant at conventional levels but the magnitude is roughly half of the preferred estimates which use the larger health department regions in Table 3. This likely arises from a greater degree of measurement error; as discussed in more details below, HSAs are much smaller than the other areas. In addition, dividing Tennessee into HSAs may allow more spillovers in uncompensated care across smaller HSAs as compared to the other three geographic categories. Such spillovers indicate that the incidence of the TennCare disenrollment likely extends beyond the hospitals directly affected by the disenrollment and represents an important area of future work.
} 
timates of the cross-state specification using the logarithm of uncompensated care rather than uncompensated care costs per capita as the dependent variable. The estimates from the log-linear cross-state specification are remarkably similar to the scaled version of the within-state estimate.

A remaining concern with these within-state estimates involves pre-existing time trends specific to each region. We address this concern with a placebo exercise. Column (5) of Table 3 presents the estimates from a sample containing region-level uncompensated care costs from 1997-2004. We present the coefficient on an interaction between the (future) 2004-2005 change in TennCare enrollment with an indicator for the years after 2001. The panel, reassuringly, presents no evidence of a statistically or economically significant relationship.

\section{C.3 ANALYSIS OF THE UTILIZATION OF HOSPITAL SERVICES}

A final concern with the results above, and all of the estimates that rely on AHA data, is that uncompensated costs may be driven by accounting rules, and thus may provide an incomplete picture of the actual care provided without payment. For that reason, we next explore the effect of the disenrollment on tangible medical services, such as inpatient admissions and outpatient visits. We obtain data on such outcomes for Tennessee hospitals from the digitized JAR data described in Section 3.

Figures 6(a) through 6(d) plot the change in inpatient admissions and outpatient visits in Tennessee hospitals by insurance status. Figure 6(a) suggests a sudden decline in such visits after 2005. That decline is consistent with the disenrollment; there were fewer TennCare beneficiaries after 2005. Figure 6(b) suggests that some of those who became uninsured, became self-pay patients at Tennessee hospitals. By contrast, Figure 6(c) suggests a slight increase in privately insured patients. ${ }^{32}$

\footnotetext{
32 In our previous work (Garthwaite, Gross and Notowidigdo, 2014), we found that roughly half of those who lost TennCare coverage became uninsured, while the other half entered the labor market to procure private coverage. Figures $7(\mathrm{~b})$ and 7 (c) are consistent with that finding, in that we see an increase in both uninsured and private visits at Tennessee hospitals. The increase in private encounters in Figure 7(c) is small, but obscures a starker pattern for inpatient visits. Appendix Figure A5 presents the change in inpatient hospital visits for privately insured patients, and suggests a large, sudden increase after the disenrollment. The slight overall increase in privately insured hospital encounters is a combination of the large increase in inpatient admissions and a much smaller increase in ED visits. Such a pattern may result from the differential cost sharing for ED visits between Medicaid and most private insurance plans. There is debate in the literature about the effect of the private insurance on the use of the ED (Kolstad and Kowalski, 2012; Miller, 2012; Anderson et al., 2012; Taubman et al. 2014). Appendix Figure A6 presents the number of ED visits by year in Tennessee. Prior to the disenrollment, the number
} 
We compare the magnitude of this change in self-pay visits to the estimates based on the AHA data above. In 2007, there were approximately 980,000 self-pay visits. However, if the trend in self-pay visits had continued on its pre-disenrollment trend, we estimate there would have been only 740,000 self-pay visits. From 2002-2005 the average revenue from a TennCare patient was approximately $\$ 500$ per visit. Accounting for the fact that Medicaid is known to pay below the cost of care, we estimate that the increase in self-pay visits cost hospitals approximately $\$ 138$ million. Reassuringly, that number is broadly similar to the estimated changed in uncompensated care per capita for Tennessee in Table 3, which suggests that the disenrollment increased uncompensated care costs by $\$ 158$ million.

\section{ThE SUPPLY OF UnCOMPENSATED CARE}

The estimates above suggest that the demand for uncompensated care, which is a function of the size of the uninsured population, affects hospital uncompensated care costs. Hospitals in a local market serve as the "residual payer" for medical services following changes in the generosity of public health insurance. In this way, private hospitals provide an additional form of social insurance in that they are health insurers of last resort.

If the uninsured require a certain amount of medical care regardless of their ability to pay, and hospitals in a market serve as insurers of last resort, then the amount of uncompensated care hospitals provide should also be a function of the supply of medical services by other nearby hospitals. We examine this hypothesis next. To do so, we estimate the spillovers of both uncompensated and compensated care across hospitals following the closure of a local hospital. If the provision of uncompensated care occurs because the uninsured demand a minimum and unavoidable quantity of medical services for which they cannot pay, then closing competing facilities should not reduce the total provision of un-

of visits is smoothly increasing. However, beginning in 2005 there is a break from this trend and the number of visits remains roughly level in the subsequent years. This decline provides suggestive evidence that insurance coverage increases rather than decrease the use of the ED. 
compensated care in a geographic area. Instead, each remaining hospital should see its uncompensated care costs increase, as uninsured patients are reallocated from the closing facility to the remaining hospitals in the market. However, if hospitals provide care solely at their discretion or if the very existence of a facility induces care that otherwise would not be demanded, then a hospital closure would reduce the total amount of uncompensated care in a local market.

\section{A. UnCOMPENSATED CARE SPILlovers From Hospital Closures}

We examine spillovers of uncompensated care across hospitals with a combination of the OIG and AHA data on hospital closures. In total, we identify 359 hospital closures from 1987 through 2000 that exist in our sample. The vast majority of the closures in our data are for acute-care hospitals. We therefore limit our sample to acute-care hospitals with an emergency department, the hospitals that are most likely to receive new patients following the closure of an acute-care hospital in their market.

A key question is how to define the local market. A market definition that is too narrow will miss out on patients who move to hospitals outside of the defined market. On the other hand, a market definition that is too broad will lack the power to detect economically meaningful spillovers. We begin our analysis at the county level, the market definition considered by Duggan (2002). Examining the patterns in our data, we find that when considering spillovers across hospitals, both counties and hospital service areas (HSAs) are too narrow of a market definition and we move to results using a definition based on the commuting patterns of local residents.

Using the OIG closure data, we identify a sample of 117 counties that suffered a large hospital closure as the first closure in this time period, where we define large closures as those where the closing hospital accounted for an above-average percentage of uncompensated care among closing hospitals, or more than nine percent of the total uncompensated care in the local market. ${ }^{33}$ In our sample of large

\footnotetext{
33 Some markets suffered more than one closure throughout our sample period. For consistency across markets, we only include the first closure from these markets and only include markets where the first closure is a large closure. We find simi-
} 
closures, the mean closing hospital accounted for approximately 35 percent of the county's uncompensated care costs in the year prior to its closure. Using this sample, we estimate the following event-study specification:

$$
y_{c t}=\lambda_{c}+\delta_{t}+\sum_{i=-4}^{5} \beta_{i} \cdot I\{\text { i years since closure }\}_{c t}+\varepsilon_{c t} \text {. }
$$

Here $\lambda_{c}$ are a set of county fixed effects, $\delta_{t}$ are year fixed effects, and $\varepsilon$ is an error term that allows for arbitrary correlation between observations from the same county. The coefficients of interest, $\beta_{i}$, captures the change in uncompensated care costs in the county for the 4 years before and the 5 years after closure, with the year before the closure serving as the omitted category.

As outcomes, we focus on the number of hospitals in the county, the logarithm of uncompensated care costs for hospitals that do not close, and the logarithm of total uncompensated care costs in the county. Figure 7 presents the estimated change in the number of hospitals after a closure, which is relatively stable in the years prior to the closure and then drops by approximately one in the year following the closure. ${ }^{34}$ Figure 8 suggests that the amount of uncompensated care provided by hospitals that do not close is stable prior to the closure and then increases by approximately 10 percent following the closure. The dashed horizontal line shows that the closing facility accounted for approximately 30 percent of uncompensated care costs in the county prior to it closing. The figure suggests that most of the costs previously born by the closing hospital are not transferred to the remaining hospitals in the county. Therefore, it should not be surprising that in Figure 9 the overall amount of uncompensated care provided by county hospitals falls by 20 percent following the closure. This demonstrates that either the closure of a hospital decreases the amount of uncompensated care consumed by the uninsured, or that uninsured patients travel outside of the original county of treatment to receive these services following a closure.

lar results to our main findings for a sample limited to only markets with a single large closure during the entire sample period.

34 The number of hospitals in the local market does not fall by precisely one, because of entry of new AHA members, mergers of existing hospitals, and other (unobserved) closures. 
In order to distinguish between these two possibilities, we next consider other definitions of the local market. Two traditional market definitions in the literature are the hospital service area (HSA) and the hospital referral region (HRR). These areas provide measures of local health care markets and are defined by the historic utilization care for Medicare patients. HSAs are groups of zip codes in which more Medicare patients receive hospital care in the local hospital than in any single HSA (Wennberg et al., 1996). Therefore, HSAs are a fairly localized hospital market definition. By contrast, HRRs represent a collection of HSAs whose residents were referred for cardiovascular and neurosurgery treatments. This is a far larger market definition. In total, we have 2,886 HSAs and 162 HRRs in our analysis sample.

But these traditional definitions of hospital markets are likely not appropriate in our setting. HSAs likely suffer from the same problem as counties, in that after a facility closes, many uninsured patients leave the HSA to receive medical care. We would then erroneously conclude that a reduction in the total amount of uncompensated care following a hospital closure. On the other hand, HRRs are quite large. Therefore, the closure of a hospital may have little detectable effect on the provision of services in an area that large. In addition, both HSAs and HRRs are based on the flow of Medicare patients. Uninsured patients may seek care based on factors different from Medicare patients. ${ }^{35}$

Therefore, we next consider the spillover of uncompensated care across hospitals located within the same commuting zone. Often used in the local labor markets literature, commuting zones are mutually exclusive collections of counties that have strong commuting ties between each other and weak ties to other areas (Tolbert and Sizer, 1996; Autor and Dorn 2013). These areas have the advantage of being larger than an HSA or county but smaller than an HRR. In addition, given that they are based on daily

\footnotetext{
35 Appendix Figure A7 presents estimates of equation (3) based on HSAs. The estimates for the HSA-based samples largely mirror those from the county-based analysis: a sudden increase in uncompensated care costs for the remaining hospitals, but an overall decrease in the amount of medical care provided without compensation. For the estimates using HRR as the unit of analysis, we are able to clearly identify the closure of a hospital based on the number of hospitals in the area. However, we cannot identify meaningful changes in the uncompensated care costs of remaining hospitals or in the amount of uncompensated care provided in the area. This is likely the result of the size of HRRs. For example, the average hospital closing accounted for only six percent of the uncompensated care costs in the year prior to its closure, making this geographic aggregation underpowered to detect meaningful spillovers.
} 
traffic patterns rather than the medical-care decisions of elderly insured patients, which may better capture the relevant catchment area for uncompensated care.

In our data, we identify 60 commuting zones that had a large closure as their first closure during our sample period. The first of these occurred in 1987 and the last in 1998. The mean hospital closure accounted for approximately 25 percent of the uncompensated care provided in the commuting zone in the year prior to the closure. Figure 10(a) displays the event-study estimates for the log of uncompensated care costs at hospitals in the commuting zone that did not close. These coefficients show little change in uncompensated care costs prior to the closure and then a large and immediate increase that accounts for the vast majority of uncompensated care costs from the closing hospital. Therefore, it should not be surprising that in Figure 10(b), there is at most a slight decline in the overall amount of uncompensated care provided in the commuting zone. None of the event-study coefficients are statistically distinguishable from zero.

There could be a concern that there is something about the act of closing a hospital that causes a general reorganization of the provision of uncompensated care the local market. If this were the case then our spillover estimates could be driven by this unobserved factor. To examine this question, Appendix Figure A8 contains estimates from a sample that contains all closures where the event study coefficient is allowed to vary based on whether there was a large or small closure. The large closure estimates broadly following the pattern in Figure 10(a). However, hospitals that remain open in markets that suffer a small closure see no noticeable change in their uncompensated care costs in the years after the closure. These estimates demonstrate that it is not some other feature associated with markets that suffer closures that are driving our main large closure estimates.

To more carefully estimate the magnitude of these spillovers we next estimated a differences-indifferences specification of equation (4) that replaces the individual post-closure coefficients with a single indicator variable for the 4 years after a closure. Panel A of Table 4 presents estimates of this specification for a dependent variable defined as the log of uncompensated care. Column (1) shows that, following a closure, there is an approximately 17 percent increase in uncompensated care at the remain- 
ing hospitals in a commuting zone following a closure. This accounts for most of the uncompensated care provided by the closing hospital, and as a result the estimate in column (2) shows a statistically insignificant decline in total uncompensated care in the commuting zone of approximately 6 percent. By contrast, a similar model estimated on the county-based sample shows a statistically significant decline in uncompensated care of 25 percent.

\section{B. REVENUE SPILLOVERS FROM HOSPITAL ClOSURES}

In addition to the spillover of uncompensated care, one would also expect a spillover of profits from insured patients. Appendix Figure A9(a) describes the change in revenue for hospitals that remain open in a county after a closure. Following the closure, these hospitals experience an approximately 10 percent increase in revenue. This increase represents only a fraction of the revenue earned by the hospital that closed. This can be seen in Appendix Figure A9(b) which shows a sharp reduction in the consumption of medical services (as measured by revenue) in the county following a closure. This reduction is at least partly the result of insured patients seeking medical care at facilities located outside of their original treatment county.

Guided by our uncompensated care spillover estimates, we next consider revenue spillovers within a commuting zone. The average hospital that closes accounted for 20-30 percent of the revenue in its commuting zone. Figure 11(a) shows a statistically significant increase in revenue for the hospitals in the commuting zone that remained open following a closure. Figure 11(b) suggests that the total revenue for hospitals in the commuting zone decreased following a closure. To examine the magnitude of these changes, Panel B of Table 4 presents difference-in-difference estimates with hospital revenue as the dependent variable. Following a closure, we estimate a 6.4 percent increase in revenue for the remaining hospitals and an overall decline of 10 percent of the revenue in the commuting zone at hospitals.

The revenue estimates suggest that even in commuting zones, hospital closures lead to a reduction in overall care provided by hospitals. This pattern may be driven by insured patients leaving the com- 
muting zone to receive medical care after a closure. We note, however, three facts. First, commuting zones are far larger than counties, suggesting that the average insured patient would have to travel a great distance for care if they left the region. Second, we do not find a statistically significant decrease in a commuting zone's aggregate uncompensated care costs following a closure. Third, many hospitals that close have their facilities converted into outpatient medical facilities. Given these facts, a reduction in the consumption of insured medical services following a closure would be consistent with a model in which the hospital care of insured patients is more discretionary than the hospital care of uninsured patients. This could either be because closing a patients' preferred provider increases the cost of receiving these services and as a result these marginal services are no longer purchased. Or it could be that this care shifts to non-hospital medical settings such as an outpatient facility or a physician's office. By contrast, we see no statistically significant reduction in uncompensated care. While the estimated change in these two outcomes of not statistically distinguishable, the patterns suggest individuals seeking uncompensated care at a hospital are less able to either defer care or switch the type of provider in response to a closure of their preferred facility.

\section{WHICH HOSPITALS SERVE AS INSURERS OF LAST RESORT?}

The totality of our estimates show that hospitals serve as a vital part of the United States social insurance system in providing health care to the uninsured without compensation. A remaining question, however, is whether all hospitals equally bear this burden. In particular, it is unclear whether non-profit hospitals serve a singular role as private social insurers. A unique feature of the American health care sector is the large faction of firms that are structured as non-profit organizations. In our data, 51 percent of all hospitals and 73 percent of private hospitals are non-profits. These organizations are exempt from federal, state, and local taxes. In exchange for this preferential tax treatment, they are expected to provide a community benefit - an important component of which is charity care for the uninsured. 
There exists, however, a divisive debate over whether these organizations actually behave differently from for-profit hospitals.

We examine this question by testing whether non-profit hospitals respond differently to the share uninsured than for-profit hospitals. We begin by estimating our main state-year specification based on the ownership status of the hospital. Given the importance of EMTALA regulations, we would expect that all hospitals, regardless of their ownership structure, should experience an increase in uncompensated care costs resulting from uninsured emergency patients. However, if non-profit hospitals serve a unique role, we would expect them to exhibit a larger increase in uncompensated care costs following changes in the share uninsured.

Table 5 presents the effect of share uninsured on uncompensated care by hospital ownership. Columns (1) through (4) present estimates when the dependent variable is uncompensated care per capita. Panel A presents the estimates for non-profit hospitals and Panel B presents estimates for for-profit hospitals. Accounting for socioeconomic covariates and including region-by-year fixed effects, column (4) suggests that every newly uninsured person in a state is associated with $\$ 624$ in uncompensated care costs for non-profit hospitals. The estimate for for-profit hospitals, however, has the perverse sign and is statistically insignificant at conventional levels. ${ }^{36}$ We can reject the null hypothesis that these two estimates are equal with a $p$-value of $<0.001$.

Estimates for the change in uncompensated care at for-profit hospitals may be imprecise because there are fewer for-profit hospitals, and they tend to be smaller than non-profit hospitals. This smaller size means that even if they change their provision of uncompensated care in response to changes in their local market, this may be hard to detect when measured as state-level uncompensated care per capita. For that reason, columns (5) through (8) present estimates when the dependent variable is uncompensated care costs as a percentage of overall expenditures. For non-profit hospitals, a 10 percentage point change in the share uninsured increases the percentage of overall costs from uncompensated care

\footnotetext{
36 The remaining uncompensated care per capita is provided by government-owned public hospitals.
} 
by 1.8 percentage points. By contrast, we find no statistically significant effect for for-profit hospitals. However, a test of the equality of the coefficients across these hospital types is not statistically significant at conventional levels.

One potential concern with the estimates for non-profit hospitals is that they represent a large and diverse set of hospitals. At the broadest level, these hospitals can be divided into those which are affiliated with a religious organization and those that are unaffiliated with a religious organization. These ownership structures could lead to differences in the intrinsic motivations of the firms. Appendix Table A5 presents estimates of the change in uncompensated care as a percentage of costs for non-profit hospitals based on their religious affiliation. For church-operated hospitals we find that a 10 percentage point increase in the share uninsured results in a 1.7 percentage-point increase in the percentage costs that are uncompensated care. Similarly, we find that other non-profit hospitals experience a 1.4 percentage-point increase in uncompensated care costs as a percentage of costs following a 10 percentage point increase in the share uninsured. These estimates are very close in magnitude and are not statistically distinguishable at conventional levels.

The smaller response among for-profit hospitals does not necessarily mean that these facilities actively simply deny services to uninsured residents seeking care. These facilities may more carefully manage the intensity of services provided to uninsured residents in order to meet certain financial targets. This would allow them to meet the EMTALA requirements of stabilizing emergent patients that present at their facility following a change in the share uninsured without increasing overall costs. In addition, for-profit hospitals may simply locate in different areas or provide a set of services that are less amenable to the provision of uncompensated care. For example, for-profit hospitals may locate in markets in which fewer individuals are on the margin between being insured and uninsured. Changes in the statewide insurance coverage rate may not reflect changes for those markets. In accordance with this view, Norton and Staiger (1994) find that non-profit and for-profit hospitals located in the same area serve a similar number of uninsured patients, but for-profit hospitals choose to locate in areas with fewer uninsured people. 
To explore that possibility, we next examine whether location can explain the difference here between non-profit and for-profit hospitals. Panels C and D of Table 5 present estimates of the same regression solely for hospitals located in HSAs that have both a non-profit and for-profit acute-care hospital with an ED. Given the small size of an HSA, these represent a fairly local market definition. The non-profit hospitals in these HSAs have a fairly similar response as the full non-profit sample. However, the for-profit hospitals in these HSAs have a much smaller response to changes in the share uninsured than the non-profit. The $p$-value on the test of equality of these coefficients is 0.15 . The estimate for these for-profits is also approximately one-fifth the size of the estimate from the full for-profit hospital sample. This provides suggestive evidence that for-profit hospitals with a local non-profit competitor are even less exposed to increased uncompensated care costs resulting from changes in the share uninsured in the state.

These estimates suggest that, at least at the geographic level of the HSA, differential location cannot fully explain the differences in the response of for-profit and non-profit hospitals to changes in the demand for uncompensated care. It should further be noted that even if the remaining differences result from non-profit hospitals choosing to locate or remain in areas within HSAs that result in a greater burden from changes in the share uninsured, this is a difference in firm behavior. ${ }^{37}$

All of these results suggest that non-profit hospitals bear more of the burden from changes in the demand for uncompensated care. We next ask whether the same is true after changes in the supply of uncompensated care. We test whether the closure of a nearby hospital affects non-profit hospitals differently from for-profit hospitals. Columns (3) and (4) of Table 4 present estimates of the change in uncompensated care costs following a closure by ownership of the hospital. Non-profit hospitals ac-

\footnotetext{
${ }^{37}$ To further explore the robustness of these findings, we have also stratified the sample by ownership status in the two case studies. Similar to the state-year results, we find that non-profit hospitals bear the vast majority of the burden of these increased costs in Missouri following disenrollment. By contrast, the estimate for for-profit hospitals has the perverse sign and is statistically insignificant at conventional levels. In Tennessee, the estimates form a similar pattern as the estimates based on both the Missouri disenrollment and the main state-year sample. Non-profit hospitals account for the vast majority of the change in uncompensated care costs per capita following the disenrollment, and the change in uncompensated care costs among for-profit hospitals is positive but statistically insignificant at conventional levels.
} 
count for all of the increase in uncompensated care after the closure of a nearby hospitals. The effect among for-profit hospitals, by contrast, is negative and statistically insignificant. While these estimates are not statistically distinguishable from each other, this is primarily driven by the imprecision of the estimates for for-profit hospitals. Figures $10(\mathrm{c})$ and $10(\mathrm{~d})$ present event-study point estimates for nonprofit and for-profit hospitals respectively. Prior to the closure, the estimates for non-profit hospitals are statistically insignificant and near zero; they then rise in the post-closure years and become statistically significant. We do not see a similar post-closure increase in costs at for-profit hospitals.

Columns (3) and (4) of Panel B in Table 4 present the estimated change in revenue by ownership status. Following a closure, non-profit hospitals see a statistically insignificant increase in revenue of approximately 11 percent. The change in revenue for for-profit hospitals is roughly 5 percent and is also statistically insignificant at conventional levels. This pattern can also be seen in Figures 11(c) and 11(d) which contain event study coefficients for the change in revenue among facilities that did not close for non-profit and for-profit hospitals respectively. The lack of a similarly large revenue increase for for-profit hospitals suggests that some portion of the lack of the increase in uncompensated care may come from the for-profit hospitals serving different local markets from the non-profit hospitals within a commuting zone.

Overall, the results point towards for-profit hospitals being less affected than non-profit hospitals by factors that affect the supply and demand of uncompensated care. While each part of the analysis often lacks statistical power to precisely distinguish the responses of for-profit and non-profit hospitals, the pattern of results consistently suggests that for-profit hospitals are less affected.

\section{Can Hospitals Pass Uncompensated Care Costs onto Privately INSURED PATIENTS?}

As a whole, the results above suggest a non-profit hospital's own costs are a function of the supply and demand for uncompensated care in its local market. A final, remaining question is whether hospitals 
actually bear financial risk from these cost shocks or if they simply pass on these costs by raising the prices that they charge privately insured patients.

Researchers and policymakers have long debated whether hospitals are able to pass on financial shocks to their paying customers. Historically, this question has centered on the degree to which changes in the reimbursement rate for government insurance programs are passed along to the privately insured. For example, the AHA has historically referred to reimbursement cuts as a "hidden tax" on all Americans (Health Insurance Association of America, 1982). Ten years later, a similar argument was made to blunt the complaints of hospitals regarding Medicare reimbursement cuts (ProPAC, 1992). This argument found new life during the debate over the ACA, as proponents of the ACA argued that it would benefit every American by reducing uncompensated care and thus the associated cost shifting (National Federation of Independent Business v. Sebelius).

The attractiveness of cost-shifting arguments to policymakers is obvious. However, there is not strong theoretical or empirical support for this argument. Theoretically, it is unclear how hospitals could raise prices on one group of patients following a lump-sum financial shock from another group. If hospitals were maximizing profits, then prices should have been optimal before the shock. For a price increase to be the optimal response to a financial shock requires two conditions. First, the hospital must possess some degree of pricing power in the private insurance market. Second, the hospital must not have fully exercised this power prior to the shock.

Dranove (1988) provides one such model of non-profit hospital behavior, where hospitals are maximizing both social welfare and profits. Under his model, in prosperous financial times hospitals keep prices low for the sake of social welfare. Following a lump sum financial shock, hospitals raise prices to preserve their profits. ${ }^{38}$ While Dranove (1988) finds evidence of such a phenomena in the 1980s marketplace, an increase in insurer market concentration likely leaves hospitals less able to set prices for privately insured patients (Gowrisankaran and Town, 1997). Accordingly, Dranove, Garthwaite, and

\footnotetext{
38 Other work has found that in a model of capacity constrained physicians, providers can exhibit cost-following where a decrease in Medicare prices results in a decrease in private prices (Clemens and Gottleib, 2014).
} 
Ody (2014) find that only a small subset of hospitals with considerable market power raised prices in response to financial shocks from the 2008 recession. Other hospitals adjust by altering other parts of their community benefit such as decreasing the offering of less profitable services such as trauma centers. The average hospital likely absorbed some or all of the financial shock through lower profit margins.

In an attempt to estimate the financial incidence of increases in uncompensated care costs, we next examine the changes in profits from patient services that come from changes in the local demand uncompensated care. If hospitals can fully recoup the lost funds in the form of higher prices on the privately insured, then their profit margins should be largely unaffected by increases in uncompensated care costs. In order to address this question we require a precise definition of hospitals profits. Given we are interested in the ability of hospitals to pass cost increases onto private patients, we focus our analysis on patient profits. We define patient profits as the direct revenue from treating patients minus the total costs. We focus on the profit margin, profits divided by revenues, as the independent variable. $^{39}$

We begin by returning to equation (1), with this definition of patient margins as the dependent variable. Table 6 presents estimates for different samples of hospitals. Panel A presents the estimates for all hospitals and suggests that a 10 percentage point increase in the share uninsured in a state is associated with a 1.1 percentage-point decline in the patient margin (standard error 0.8 percentage points). Panels $\mathrm{B}$ and $\mathrm{C}$ present the estimates for non-profit and for-profit hospitals respectively. Note that our estimates of increases in uncompensated care costs in Table 5 show that non-profit hospitals bore the majority of these increases. Accordingly, these non-profit hospitals experience a 1.3 percentage point decrease in their patient margin following a 10 percentage point increase in the share uninsured. This estimate is statistically significant; the associated $p$-value is 0.01 . The effect for for-profit hospitals is approximately one-sixth the magnitude of the estimate for non-profit hospitals and is statistically insigni-

\footnotetext{
${ }^{39}$ We rely on profit margins (as opposed to the logarithm of profits, for example) because of the large number of hospitals that have negative patient profits.
} 
ficant. It should be noted, however, that the estimates across ownership type are not statistically distinguishable, primarily because of the imprecision of the for-profit estimates.

These declines in patient margins show that non-profit hospitals are not able to pass all of the uncompensated care costs onto private insurers. We next conduct a back-of-the-envelope calculation to provide some understanding of how much of the cost may have been passed along. Based on our estimates above, in 2011 a 10 percentage point increase in the share uninsured in the United States would increase uncompensated care costs at non-profit hospitals by between $\$ 10.3$ and $\$ 11.5$ billion. ${ }^{40}$ This would decrease patient margins by between 2.0 and 2.2 percentage points. Our estimates suggest that hospitals absorb between 60 and 67 percent of the increased costs in lost profits on patient services. While hospitals are not able fully pass these costs onto the privately insured, this does not mean that they absorbed some of the costs and actually lost profits. It is possible that other revenue sources such as DSH payments or other government transfers could reimburse hospitals for these expenses. If this were the case, then we may see a decline in patient margin even if hospitals could pass this cost on to their privately insured patients. Again, we stress that this behavior should only apply to non-profit hospitals, who may consider the utility of privately insured patients in their objective function. Transfers from government sources should not affect the profit maximizing price for for-profit hospitals or nonprofit hospitals that are choosing to simply maximize profits. Appendix Table A6 contains estimates of the relationship between the share uninsured and both operating margins and total margins. Both of these estimates show a similar decline to the patient profit margin, suggesting incomplete reimbursement for uncompensated care costs and an inability of the hospitals to fully pass on uncompensated care costs onto the privately insured.

In addition, we note that these profit margin estimates provide a useful bounding exercise for concerns about measuring uncompensated care by adjusting hospital charges using a cost-to-charge ratio.

\footnotetext{
40 These costs represent forgone revenues, and therefore we must account for the fact that many of these newly uninsured patients likely came for social insurance programs that pay below the cost of providing care. Therefore, the low end of the range would occur if the change in the uninsured came from Medicaid patients, with an assumption that Medicaid is currently paying hospitals 90 percent of the costs of care (AHA, 2015). The high end of this range assumes that the patients come from payers that are reimbursing the hospital at zero profit level..
} 
These estimates of financial harm do not rely on any charge based measures, and therefore our passthrough estimates could also represent a lower bound of the cost to hospitals in a situation of zero pass-through. Given our main estimates, this would suggest that even if hospitals are unable to actually pass any cost along than each uninsured person would cost approximately $\$ 600$.

\section{CONCLUSION}

American hospitals serve as insurers of last resort, providing an informal form of social insurance that partially fills the holes in the existing social safety net. Hospitals are put in this role by a combination of factors that force hospitals to provide health care regardless of the patient's ability to pay. As a result, when governments do not provide health insurance, hospitals must provide it instead.

Our estimates can inform policymakers about the likely consequences of the ACA. That area is of substantial policy interest due to the recent decision, by some states, not to expand Medicaid. As of May 2015, 21 states have chosen not to implement the ACA's Medicaid expansion, even though the federal government will fund 90 percent of the cost through 2020. As a result, approximately 5.2 million individuals in these non-expanding states will not receive coverage under the ACA (Holahan et. al, 2012). The state portion of the cost of covering these individuals as of 2022 is estimated to be $\$ 6.25$ billion. ${ }^{41}$ Our estimates suggest that the uninsured population will generate approximately $\$ 6.4$ billion in uncompensated care costs that year. That number only includes uncompensated care costs at hospitals, not uncompensated care at other health-care providers. ${ }^{42}$

While hospitals may be able to pass a small portion of these costs onto private insurers, they will be forced to either accept lower profits or adjust to the higher costs in other manners. The Governor of

\footnotetext{
${ }^{41}$ States are responsible for their full portion of the expansion costs after 2022.

42 It is not clear how much uncompensated care physicians provide. Gruber and Rodriguez (2007) study payments made to private physicians' offices and find that uncompensated costs are either negative or very small. Private physicians, according to their results, charge the uninsured patients more for care, on average, than insured patients. It should be noted that, even considering a more standard definition based on adjusted charges, the authors find that physicians provide approximately half the uncompensated care, as a fraction of revenue, than hospitals.
} 
Tennessee, Bill Haslam, alluded to that possibility when he made the following remarks about the potential ACA Medicaid expansion in that state:

We have to remember what the state went through seven years ago when it made the difficult decision to cut a lot of people from the TennCare rolls. We have to be very deliberate about making a decision to add that many and more back to the rolls, but I also understand that the decision isn't just as easy as standing here today and saying, 'We're not going to expand Medicaid.' There are hospitals across this state, many of them in rural communities, that are going to struggle if not close under the health care law without expansion, and that's not something to take lightly (Haslam, 2013).

Similarly, Hsia, Kellerman, and Shen (2011) found that from 1990 to 2009, approximately 30 percent of the nation's EDs closed, primarily due to hospital closures. ED closures were more likely to occur in low-income areas and at hospitals with low profit margins. Our results indicate that an ED attracts a large amount of uncompensated care to a hospital, with sharp increases in uncompensated care when nearby hospitals close. This may explain why areas with low rates of health insurance have seen so many ED closures in recent years.

The manner in which hospitals respond to lower profits from uncompensated care will determine the efficiency of using private firms as unofficial partners in the social insurance system. If policy decisions that leave a large number of individuals uninsured - such as those choosing to not expand Medicaid or leaving undocumented immigrants ineligible for public health insurance coverage - impose costs on state residents beyond those who remain uninsured it may be more costly than simply insuring those individuals in the first place. Future work should investigate the extent to which the combination of factors that make hospitals insurers of last resort also contributes to ongoing challenges in maintaining access to services such as emergency medical treatment in areas with low rates of health insurance. However, we do note that our closure results suggest that even in the advent of a hospital closure, a large majority of individuals seeking uncompensated care appear to have been able to secure those services at another facility in the commuting zone. This is consistent with the recent findings of Joynt et al. (2015) which found no changes in mortality or other adverse outcomes following the closure of a hospital in a patients HSA. Together, these results suggest that even if the ACA were to lead to a series of hospital closures, patients may not be adversely affected to the degree that is commonly assumed. 
Lastly, this paper expands upon research that estimates the benefits of public health insurance programs. This literature has primarily focused on the effect of these programs on access to health care or on the financial well-being and health of the newly insured (Cutler and Gruber, 1996; Gross and Notowidigdo, 2011; Finkelstein et al., 2012;). We broaden this focus to the benefits of public health insurance on the providers themselves. Specifically, we note that health insurance provides financial protection to private firms along with their customers. This financial protection is particularly true for hospitals located in areas with large low-income populations.

We speculate that this financial protection informs the political economy of the Medicaid program. It is often argued that means-tested programs are not politically viable in the United States, that "a program for the poor is a poor program." (McElvaine, 1984). Indeed, traditional cash welfare did not survive the 1990s and the generosity of other safety-net programs, such as food stamps, has recently been pared back (Shear, 2014). But Medicaid has never disappeared from a state and - absent a few isolated disenrollments - the program has only grown in size over time. ${ }^{43}$ Our paper suggests one explanation for this. A unique aspect of Medicaid is that it directly benefits not only the citizens it covers but also the hospitals they visit. Given that hospitals are an important political force at all levels of government, the factors requiring hospitals to provide uncompensated care may thus have unintentionally assured Medicaid's long-term political stability. ${ }^{44}$

\footnotetext{
${ }^{43}$ In 1987 approximately 8 percent of the population (20 million individuals) was covered by Medicaid. By 1997, this increased to roughly 11 percent ( 29 million individuals). By 2012 this had increased to over 16 percent (51 million individuals). In contrast, from 1990-2008 the number of cash-welfare beneficiaries fell from approximately 4 million to 2 million (HHS, 2004).

${ }^{44}$ This can also be seen in the revealed preferences of hospitals in recent years. For example, as part of the state of Tennessee's recent ACA Medicaid expansion, hospitals in that state jointly agreed to finance any expenses above the estimated cost of the program (Goodnough, 2014).
} 


\section{REFERENCES}

American Hospital Association. 2010. "Uncompensated Hospital Care Costs Fact Sheet.”

Anderson, Michael, Carlos Dobkin, and Tal Gross. 2012. "The Effect of Insurance on the Use of Medical Services," American Economic Journal: Economic Policy, 3(4): 1-27.

APS Healthcare. 2006. "The Impact of BadgerCare on Hospital Uncompensated Care in Wisconsin," mimeo for Wisconsin Department of Health and Family Services State Planning Grant.

Autor, David and David Dorn. 2012. "The Growth of Low-Skill Service Jobs and the Polarization of the US Labor Market.” American Economic Review, 103(5): 1553-1597.

Blewett, Lynn, Margaret Brown and Roland Maude-Griffin. 2003. "Hospital Provision of Uncompensated Care and Public Program Enrollment," Medical Care Research and Review, 60(4): 509-527.

Blue Cross Blue Shield of Tennessee. 2005. "Important TennCare Eligibility and Benefit Changes." Jul 1 2005.

Carper, Kelly and Steven Machlin. 2013. "National Health Care Expenses in the U.S. Civilian Noninstitutionalized Population," Agency for Healthcare Research and Quality, Statistical Brief \#396.

Chang, Cyril and Stephanie Steinberg. 2009. “TennCare Timeline: Major Events and Milestones from 1992 to 2009." Methodist LeBonheur Center for Healthcare Economics, the University of Memphis, Nov. 2008. (online) http://healthecon.memphis.edu/

Clemens, Jeffrey and Joshua Gottlieb. 2014. "In the Shadow of a Giant: Medicare's Influence on Private Payment Systems," Working Paper.

Coate, Stephen. 1995. "Altruism, the Samaritan's Dilemma and Government Transfer Policy," American Economic Review, 85(1): 46-57.

Congressional Budget Office. 2013. "Updated Budget Projections: Fiscal Years 2013 to 2023," May 14, 2013. http://www.cbo.gov/publication/44172

Cutler, David and Jon Gruber, 1996. "Does public health insurance crowdout private insurance?" Quarterly Journal of Economics 111, 391-430.

Cunningham, P., and Tu, H. 1997. "A Changing Picture of Uncompensated Care," Health Affairs, 16(4): $167-175$.

Davidoff, Amy, Anthony LoSasso, Gloria Bazzoli, and Stephen Zuckerman. 2000. "The Effect of Changing State Health Policy on Hospital Uncompensated Care.” Inquiry, 37(3): 253-267.

DeLeire, Thomas, Karen Joynt, and Ruth McDonald. 2014. "Impact of Insurance Expansion on Hospital Uncompensated Care Costs in 2014." ASPE Issue Brief available at: http://aspe.hhs.gov/health/reports/2014/UncompensatedCare/ib_UncompensatedCare.pdf

Doyle, Joseph. 2005. "Health insurance, Treatment, and Outcomes: Using Auto Accidents as Health Shocks," Review of Economics and Statistics, 87(2): 256-270. 
Dranove, David. 1988. "Pricing by non-profit institutions: The case of hospital cost-shifting," Journal of Health Economics, 7(1): 47-57.

Dranove, David, Craig Garthwaite and Christopher Ody. 2014. "How Do Hospitals Respond to Negative Financial Shocks? The Impact of the 2008 Stock Market Crash,” NBER Working Papger \#18853.

Duggan, Mark. 2002. "Hospital Market Structure and the Behavior of Not-for-Profit Hospitals." RAND Journal of Economics, 33(3): 433-446.

Finkelstein, Amy, Nathaniel Hendren, and Erzo F. P. Luttmer. 2015. "The Value of Medicaid: Interpreting Results from the Oregon Health Insurance Experiment," Working Paper.

Finkelstein, Amy, Sarah Taubman, Bill Wright, Mira Bernstein, Jonathan Gruber, Joseph P. Newhouse, Heidi Allen, Katherine Baicker, and the Oregon Health Study Group. 2012. "The Oregon Health Insurance Experiment: Evidence from the First Year" Quarterly Journal of Economics, 127(3).

Galewitz, Phil. 2015. “When Hospitals Move, Who Gets Left Behind?” The Atlantic, April 25, 2015.

Gaynor, Martin, Kate Ho, and Robert J. Town. 2014. "The Industrial Organization of Health Care Markets," Journal of Economic Literature, forthcoming.

Goodnough, Abby. 2014. "With Hospitals Under Stress, Tennessee’s Governor Pursues Medicaid Expansion," New York Times, Dec 15, 2014.

Goodnough, Abby and Robert Pear. 2014. "Unable to Meet the Deductible or the Doctor," New York Times, Oct 17, 2014.

Gowrisankaran, Gautam and Robert Town. 1997. "Dynamic Equilibrium in the Hospital Industry," Journal of Economics and Management Strategy, 6: 45-74.

Graves, John. 2012. "Medicaid Expansion Opt-Outs and Uncompensated Care," The New England Journal of Medicine, 367(25): 2365-2367.

Gross, Tal and Matthew J. Notowidigdo. 2011. "Health Insurance and the Consumer Bankruptcy Decision: Evidence from Expansions of Medicaid," Journal of Public Economics, 95(7-8): 767-778.

Gruber, Jonathan and David Rodriguez. 2011. “How much uncompensated care do doctors provide?” Journal of Health Economics, 26:1151-1169.

Hamel, Liz, Mira Norton, Larry Levitt, Gary Claxton, and Mollyann Brodie. 2015. "Survey of Non-Group Health Insurance Enrollees, Wave 2," Kaiser Family Foundation, May 21, 2015, available at: http://kff.org/health-reform/poll-finding/survey-of-non-group-health-insurance-enrollees-wave-2/.

Haslam, Bill. "Why Tennessee is Different," Tennessee State of the State Address, Jan 28. 2013, accessed on August 23, $2014 \quad$ at: $\quad$ http://www.tn.gov/stateofthestate/files/2013/01-2813\%20State $\% 20$ of $\% 20$ the $\% 20$ State $\% 20$ Address $\% 20-020$ FINAL.pdf

Heberlein, Martha, Jocelyn Guyer, and Robin Rudowitz. 2010. "Financing New Medicaid Coverage Under Health Reform: The Role of the Federal Government and States," Kaiser Family Foundation \#8072. 
Herman, Bob. 2014. "12 Statistics on Hospital Profit and Revenue in 2012," Becker Hospital Review, January 21, 2014, accessed online on June 19, 2013 at http://www.beckershospitalreview.com/finance/12-statisticson-hospital-profit-and-revenue-in-2012.html.

Herring, Bradley. 2005. "The Effect of the Availability of Charity Care to the Uninsured on The Demand for Private Health Insurance," Journal of Health Economics, 24(2): 225-252.

Holahan, John, Matthew Buettgens, Caitlin Carroll, Stan Dorn. 2012. "The Cost and Coverage Implications of the ACA Medicaid Expansion: National and State-by-State Analysis", report prepared by The Urban Institute (November 2012). Available at: http:// kff.org/health-reform/report/the-cost-and-coverageimplications-of-the/.

Hsia R. Y. and A. L. Kellerman AL, and Y. Shen. 2011. "Factors Associated with Closures of Emergency Departments in the United States," Journal of the American Medical Association, 305:1978-85.

Joynt, Karen E., Paula Chatterjee, E. John Orav, and Ashish K. Jha. 2015. "Hospital Closures Had No Measurable Impact On Local Hospitalization Rates Or Mortality Rates, 2003-11," Health Affairs, 34(5): 765-772.

Kolstad, Jonathan and Amanda Kowalski. 2012. "The Impact of Health Care Reform on Hospital and Preventive Care: Evidence from Massachusetts," Journal of Public Economics, 96 (11): 909-929

Kopczuk, Wojcieck and Cristian Pop-Eleches. 2007. "Electronic Filing, Tax Preparers, and Participation in the Earned Income Tax Credit," Journal of Public Economics, 91(7-8).

LoSasso, Anthony T. and Bruce Meyer. 2006. "The Health Care Safety Net and Crowd-Out of Private Health Insurance,” NBER Working Paper \#11977.

LoSasso, Anthony T. and Dorian G. Seamster, 2007. "How Federal and State Policies Affected Hospital Uncompensated Care Provision in the 1990s.” Medical Care Research and Review, 64:731-745.

Mann J. M. et al. 1997. “A profile of uncompensated hospital care, 1983-1995,” Health Affairs, 16(4): 223-32.

McElvaine, Robert. 1984. The Great Depression: America 1929-1941. New York: Times Books.

McKinsey and Company. 2003. "Achieving a Critical Mission in Difficult Times - TennCare's Financial Viability,” December 11, 2003.

Miller, Sarah. 2012. "The Effect of Insurance on emergency room Visits: An Analysis of the 2006 Massachusetts Health Reform," Journal of Public Economics, 96(11): 893-908.

Mitchell, Alison. 2013. "Medicaid Disproportionate Share Hospital Payments," Congressional Research Service, R42865.

Morrisey, M. 1994. Cost Shifting in Health Care: Separating Evidence from Rhetoric. AEI Press (Washington, DC).

National Federation of Independent Business v. Sebelius. 2012, 567 U.S. _, Docket No. 11-393.

Norton, Edward C. and Douglas O. Staiger. 1994. "How Hospital Ownership Affects Access to Care for the Uninsured," The RAND Journal of Economics, 25(1): 171-185. 
Pear, Robert. 2015. "New Rules to Limit Tactics on Hospitals' Fee Collections," New York Times, Jan 11, 2015.

Pfunter, Anne, Lauren Wier, Claudia Steiner. 2013. "Costs for Hospital Stays in the United States, 2011." Agency for Healthcare Research and Quality, Statistical Brief \#168.

Rae, Matthew, Nirmita Panchal, and Gary Claxton. 2012. "The Prevalence and Cost of Deductibles in Employer Sponsored Insurance," Kaiser Family Foundation's Health Care Marketplace Project, http://kff.org/health-costs/issue-brief/snapshots-the-prevalence-and-cost-of-deductibles-in-employersponsored-insurance.

Rask, Kevin and Kimberly Rask. 2000. "Public Insurance Substituting for Private Insurance: New Evidence Regarding Public Hospitals, Uncompensated Care Funds, and Medicaid," Journal of Health Economics, 19(1): $1-31$.

Rundall, Thomas, Shoshanna Sofaer, and Wendy Lambert. 1988. "Uncompensated hospital care in California: Private and Public Hospital Responses to Competitive Market Forces," Advances in Health Economics and Health Services Research, 9: 113-33.

Saslow, Eli. 2013. "In Florida, a food-stamp recruiter deals with wrenching choices," The Washington Post, April 23, 2013.

Shear, Michael. 2014. "In Signing Farm Bill, Obama Extols Rural Growth," The New York Times, Feb 7, 2014.

Sloan, Frank A., M. A. Morrisey, and J. Valvona. 1988. "Hospital Care for the 'Self-Pay' Patient," Journal of Health Politics, Policy, and Law, 13: 83-102.

Sloan, Frank A. and Robert A. Vraciu. 1983. "Investor-owned and not-for-profit hospitals: Addressing some issues," Health Affairs 2:25-37.

TennCare Quarterly Report. 2003. Accessed online on March 24, 2013 at: http://www.tn.gov/tenncare/forms/leg0403.pdf.

TennCare Annual Report. 2005. Accessed online on March 24, 2013 at: http://www.tn.gov/tenncare/forms/annual05.pdf.

Timmins, Lori L. 2014. "How do Hospitals Respond to Financial Pain? Evidence from Hospital Markets in Texas,” Working Paper.

Tolbert, Charles M., and Molly Sizer. 1996. "U.S. Commuting Zones and Labor Market Areas: A 1990 Update.” Economic Research Service Staff Paper 9614.

Weisbrod, B. 1988. The Nonprofit Economy (Cambridge, MA: Harvard University Press).

Zuckerman, Stephen, Dawn Miller and Emily Shelton Paper. 2009. "Missouri’s 2005 Medicaid Cuts: How Did They Affect Enrollees and Providers," Health Affairs, 28(2): w335-w345. 
Table 1. The Cross-Sectional Relationship Between

Health Insurance and Uncompensated Care Costs

Dependent Variable: Uncompensated care costs per capita

\begin{tabular}{|c|c|c|c|}
\hline & $(1)$ & $(2)$ & (3) \\
\hline \multirow[t]{2}{*}{ Sample: } & 1990 & 1995 & 2000 \\
\hline & \multicolumn{2}{|c|}{ A. All Hospitals } & \\
\hline \multirow{3}{*}{$\begin{array}{l}\text { Share of population } \\
\text { uninsured }\end{array}$} & 903.30 & 910.44 & 741.59 \\
\hline & $(392.29)$ & $(296.62)$ & $(171.41)$ \\
\hline & {$[0.03]$} & {$[0.00]$} & {$[0.00]$} \\
\hline$R^{2}$ & 0.29 & 0.12 & 0.18 \\
\hline \multirow[t]{2}{*}{$N$} & 51 & 51 & 51 \\
\hline & \multicolumn{2}{|c|}{ B. Hospitals with an ED } & \\
\hline \multirow{3}{*}{$\begin{array}{l}\text { Share of population } \\
\text { uninsured }\end{array}$} & 873.89 & 842.06 & 678.30 \\
\hline & $(369.65)$ & $(287.94)$ & $(172.23)$ \\
\hline & {$[0.02]$} & {$[0.01]$} & {$[0.00]$} \\
\hline $\mathrm{R}^{2}$ & 0.30 & 0.11 & 0.16 \\
\hline \multirow[t]{2}{*}{$N$} & 51 & 51 & 51 \\
\hline & C. $\mathrm{Hc}$ & without a1 & \\
\hline \multirow{3}{*}{$\begin{array}{l}\text { Share of population } \\
\text { uninsured }\end{array}$} & 26.69 & 65.85 & 63.29 \\
\hline & $(27.28)$ & $(23.85)$ & $(38.16)$ \\
\hline & {$[0.33]$} & {$[0.01]$} & {$[0.10]$} \\
\hline$R^{2}$ & 0.04 & 0.17 & 0.10 \\
\hline$N$ & 50 & 50 & 51 \\
\hline
\end{tabular}

Notes: The sample consists of state-year observations based on hospitals in the given sample. Robust standard errors in parentheses; associated $p$-values in brackets. 
Table 2. Effect of Uninsured Population on Uncompensated Care at All Hospitals

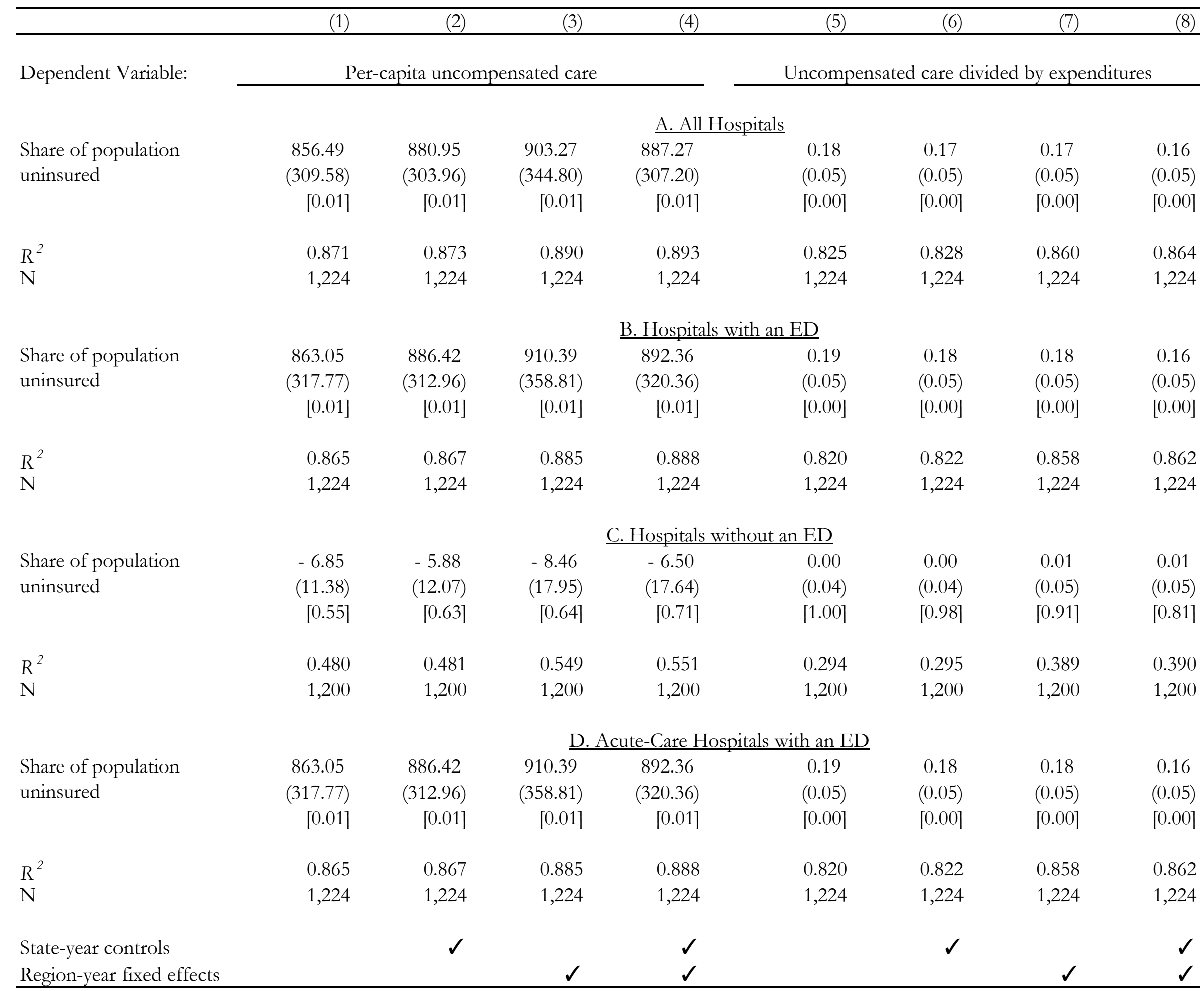

Notes: The sample conists of the dependent variables calculated for each state and year from 1988 through 2011, for the given hospitals. The standard errors in parentheses are robust to auto-corrleation between observations from the same state; associated $p$-values in brackets. Year and state fixed effects not shown. 
Dependent Variable:

Disenrollment and Sample:

Post disenrollment

2004-2005 TennCare disenrollment in

region / 2004 population $\times$ Post 2005

2004-2005 TennCare disenrollment in

region / 2004 population $\times$ Post 2001

Estimated cost per uninsured person

(compare to Table 2, Panel A, Column 4)
Per-capita uncompensated care

Missouri, Tennessee, across state across state

22.804

(5.294)

[0.005]
41.948

(6.829)

[0.000]
Logarithm of uncompensated care

Tennessee, within within across state Tennessee Tennessee
6.713

(2.270)

[0.011]

\section{$\$ 556-\$ 786 \$ 1,048-\$ 1,678$}

Estimates scaled by statewide

disenrollees per capita

0.175

$-1.103$

(4.816)

[0.822]

(compare to Column 3)

$\mathrm{R}^{2}$

0.965

0.935

0.996

0.979

0.965

N

42

102

102

112

Notes: The sample consists of state-by-year total uncompensated care for states in the midwest (Missouri) or south (Tennessee). State and year fixed effects and state-specific linear time trends not shown. The standard errors in parentheses are robust to autocorellation between observations from the same state; associated $p$-values in brackets. We restrict the sample to Midwestern states (for Missouri analysis)) or Southern states (for Tennessee analysis) from 2003 through 2008. 
Table 4. The Effect of a Hospital Closure on Uncompensated Care at Neighboring Hospitals

Dependnent Variable: The logarithm of uncompensated care or patient revenue

(1)

(2)

(3)

(4)

Sample: Remaining Total for Remaining non- Remaining forhospitals commuting zone profit hospitals profit hospitals

Post Closure

0.171

$(0.057)$

[0.003]

A. Uncompensated Care

$(0.057)$
$[0.003]$

$-0.063$

0.190

$-0.028$

(0.055)

(0.086)

(0.250)

[0.249]

[0.028]

[0.912]

$\mathrm{R}^{2}$

0.957

0.957

0.942

0.808

N

13,200

13,200

10,400

4,192

\section{B. Patient Revenue}

Post Closure

0.085

$(0.033)$

$-0.095$

0.108

0.053

[0.010]

(0.030)

(0.074)

[0.002]

[0.143]

[0.746]

$\mathrm{R}^{2}$

0.986

0.986

0.968

0.893

N

13,218

13,218

10,367

4,215

Notes: The sample consists of commuting zones. Commuting zone and year fixed effects not shown. The standard errors in parentheses are robust to autocorellation between observations from the same commuting zone; associated $p$-values in brackets. Patient revenue refers to "net patient revenue," revenue received by the hospital for patient care irrespective of charges. 
Table 5. Effect of Uninsured Population on Uncompensated Care By Hospital Ownership

\begin{tabular}{|c|c|c|c|c|c|c|c|c|}
\hline & $(1)$ & $(2)$ & $(3)$ & $(4)$ & $(5)$ & $(6)$ & $(7)$ & $(8)$ \\
\hline Dependent Variable: & \multicolumn{4}{|c|}{ Per-capita uncompensated care } & \multicolumn{4}{|c|}{ Uncompensated care divided by expenditures } \\
\hline $\begin{array}{l}\text { Share of population } \\
\text { uninsured }\end{array}$ & $\begin{array}{r}543.64 \\
(169.22) \\
{[0.00]}\end{array}$ & $\begin{array}{r}554.76 \\
(153.78) \\
{[0.00]}\end{array}$ & $\begin{array}{r}627.61 \\
(175.63) \\
{[0.00]}\end{array}$ & $\begin{array}{r}\text { A. Non- } \\
624.01 \\
(151.87) \\
{[0.00]}\end{array}$ & $\begin{array}{c}0.21 \\
(0.05) \\
{[0.00]}\end{array}$ & $\begin{array}{c}0.20 \\
(0.05) \\
{[0.00]}\end{array}$ & $\begin{array}{c}0.20 \\
(0.05) \\
{[0.00]}\end{array}$ & $\begin{array}{l}0.18 \\
(0.05) \\
{[0.00]}\end{array}$ \\
\hline $\begin{array}{l}\mathrm{R}^{2} \\
\mathrm{~N}\end{array}$ & $\begin{array}{l}0.868 \\
1,224\end{array}$ & $\begin{array}{l}0.873 \\
1,224\end{array}$ & $\begin{array}{l}0.890 \\
1,224\end{array}$ & $\begin{array}{l}0.891 \\
1,224\end{array}$ & $\begin{array}{l}0.805 \\
1,224\end{array}$ & $\begin{array}{l}0.808 \\
1,224\end{array}$ & $\begin{array}{l}0.842 \\
1,224\end{array}$ & $\begin{array}{l}0.847 \\
1,224\end{array}$ \\
\hline $\begin{array}{l}\text { Share of population } \\
\text { uninsured }\end{array}$ & $\begin{array}{r}-56.48 \\
(72.83) \\
{[0.44]}\end{array}$ & $\begin{array}{r}-56.25 \\
(64.35) \\
{[0.39]}\end{array}$ & $\begin{array}{r}-86.06 \\
(72.17) \\
{[0.24]}\end{array}$ & $\begin{array}{c}\text { B. For-p } \\
-95.50 \\
(64.36) \\
{[0.14]}\end{array}$ & $\begin{array}{c}\text { tals } \\
0.12 \\
(0.04) \\
{[0.00]}\end{array}$ & $\begin{array}{c}0.11 \\
(0.05) \\
{[0.02]}\end{array}$ & $\begin{array}{c}0.11 \\
(0.05) \\
{[0.04]}\end{array}$ & $\begin{array}{c}0.11 \\
(0.06) \\
{[0.07]}\end{array}$ \\
\hline $\begin{array}{l}\mathrm{R}^{2} \\
\mathrm{~N}\end{array}$ & $\begin{array}{l}0.720 \\
1,049\end{array}$ & $\begin{array}{l}0.733 \\
1,049\end{array}$ & $\begin{array}{l}0.822 \\
1,049\end{array}$ & $\begin{array}{l}0.826 \\
1,049\end{array}$ & $\begin{array}{l}0.568 \\
1,049\end{array}$ & $\begin{array}{l}0.573 \\
1,049\end{array}$ & $\begin{array}{l}0.671 \\
1,049\end{array}$ & $\begin{array}{l}0.673 \\
1,049\end{array}$ \\
\hline $\begin{array}{l}p \text {-value from test of } \\
\text { equality with Panel A }\end{array}$ & 0.002 & 0.000 & 0.000 & 0.000 & 0.123 & 0.231 & 0.179 & 0.339 \\
\hline $\begin{array}{l}\text { Share of population } \\
\text { uninsured }\end{array}$ & $\begin{array}{r}317.77 \\
(132.23) \\
{[0.02]}\end{array}$ & $\begin{array}{r}345.14 \\
(118.77) \\
{[0.01]}\end{array}$ & $\begin{array}{c}\text { C. Non-prc } \\
315.12 \\
(123.70) \\
{[0.01]}\end{array}$ & $\begin{array}{r}\text { hospitals y } \\
324.22 \\
(108.84) \\
{[0.00]}\end{array}$ & $\begin{array}{c}y \text { for-pro } \\
0.19 \\
(0.06) \\
{[0.00]}\end{array}$ & $\begin{array}{l}\frac{\text { bital }}{0.17} \\
(0.06) \\
{[0.01]}\end{array}$ & $\begin{array}{c}0.20 \\
(0.07) \\
{[0.01]}\end{array}$ & $\begin{array}{l}0.17 \\
(0.07) \\
{[0.02]}\end{array}$ \\
\hline $\begin{array}{l}R^{2} \\
N\end{array}$ & $\begin{array}{r}0.871 \\
977\end{array}$ & $\begin{array}{r}0.874 \\
977\end{array}$ & $\begin{array}{r}0.895 \\
977\end{array}$ & $\begin{array}{r}0.897 \\
977\end{array}$ & $\begin{array}{r}0.720 \\
977\end{array}$ & $\begin{array}{r}0.723 \\
977\end{array}$ & $\begin{array}{r}0.768 \\
977\end{array}$ & $\begin{array}{r}0.772 \\
977\end{array}$ \\
\hline $\begin{array}{l}p \text {-value from test of } \\
\text { equality with Panel A }\end{array}$ & 0.293 & 0.281 & 0.149 & 0.111 & 0.812 & 0.766 & 0.959 & 0.965 \\
\hline $\begin{array}{l}p \text {-value from test of } \\
\text { equality with Panel B }\end{array}$ & 0.014 & 0.004 & 0.006 & 0.001 & 0.261 & 0.433 & 0.253 & 0.456 \\
\hline $\begin{array}{l}\text { Share of population } \\
\text { uninsured }\end{array}$ & $\begin{array}{r}-81.39 \\
(81.18) \\
{[0.32]}\end{array}$ & $\begin{array}{r}-89.26 \\
(73.73) \\
{[0.23]}\end{array}$ & $\begin{array}{r}\text { D. For-pro } \\
-120.00 \\
(98.12) \\
{[0.23]}\end{array}$ & $\begin{array}{r}\text { ospitals w } \\
-139.65 \\
(85.85) \\
{[0.11]}\end{array}$ & $\begin{array}{c}\text { non-pro } \\
0.05 \\
(0.05) \\
{[0.33]}\end{array}$ & $\begin{array}{c}\text { oital } \\
0.04 \\
(0.05) \\
{[0.47]}\end{array}$ & $\begin{array}{c}0.03 \\
(0.07) \\
{[0.65]}\end{array}$ & $\begin{array}{c}0.02 \\
(0.08) \\
{[0.81]}\end{array}$ \\
\hline $\begin{array}{l}\mathrm{R}^{2} \\
\mathrm{~N}\end{array}$ & $\begin{array}{r}0.590 \\
965\end{array}$ & $\begin{array}{r}0.610 \\
965\end{array}$ & $\begin{array}{r}0.683 \\
965\end{array}$ & $\begin{array}{r}0.698 \\
965\end{array}$ & $\begin{array}{r}0.423 \\
965\end{array}$ & $\begin{array}{r}0.426 \\
965\end{array}$ & $\begin{array}{r}0.555 \\
965\end{array}$ & $\begin{array}{r}0.559 \\
965\end{array}$ \\
\hline $\begin{array}{l}p \text {-value from test of } \\
\text { equality with Panel C }\end{array}$ & 0.011 & 0.002 & 0.007 & 0.001 & 0.062 & 0.105 & 0.098 & 0.150 \\
\hline State-year controls & & $\checkmark$ & & $\checkmark$ & & $\sqrt{ }$ & & $\checkmark$ \\
\hline Region-year fixed effects & & & $\checkmark$ & $\checkmark$ & & & $\checkmark$ & $\checkmark$ \\
\hline
\end{tabular}

Notes: The sample conists of the dependent variables calculated for each state and year from 1988 through 2011, for the given hospitals. The standard errors in parentheses are robust to auto-corrleation between observations from the same state; associated $p$-values in brackets. Year and state fixed effects not shown. We define a non-profit hospital as having a nearby for-profit hospital if at least one for-profit hospital exists in the same HSA. All hospitals in the sample are acute-care hospitals with an emergency room. 
Table 6. Effect of Uninsured Population on Profit Margins

Dependent Variable: Patient-care profit margin

\begin{tabular}{|c|c|c|c|c|}
\hline & $(1)$ & $(2)$ & (3) & $(4)$ \\
\hline \multirow{4}{*}{ Share Uninsured in local } & \multicolumn{3}{|c|}{ A. All hospitals } & \\
\hline & -0.05 & -0.07 & -0.10 & -0.11 \\
\hline & $(0.07)$ & $(0.07)$ & $(0.08)$ & $(0.08)$ \\
\hline & {$[0.46]$} & {$[0.32]$} & {$[0.20]$} & {$[0.16]$} \\
\hline $\mathrm{R}^{2}$ & 0.659 & 0.662 & 0.706 & 0.707 \\
\hline \multirow[t]{2}{*}{$\mathrm{N}$} & 1,224 & 1,224 & 1,224 & 1,224 \\
\hline & \multicolumn{3}{|c|}{ B. Non-profit hospitals } & \\
\hline \multirow{3}{*}{$\begin{array}{l}\text { Share of population } \\
\text { uninsured }\end{array}$} & -0.09 & -0.10 & -0.12 & -0.13 \\
\hline & $(0.05)$ & $(0.05)$ & $(0.05)$ & $(0.05)$ \\
\hline & {$[0.05]$} & {$[0.04]$} & {$[0.01]$} & {$[0.01]$} \\
\hline$R^{2}$ & 0.666 & 0.667 & 0.715 & 0.716 \\
\hline \multirow[t]{2}{*}{$\mathrm{N}$} & 1,224 & 1,224 & 1,224 & 1,224 \\
\hline & \multicolumn{3}{|c|}{$\underline{\text { C. For-profit hospitals }}$} & \\
\hline \multirow{3}{*}{$\begin{array}{l}\text { Share of population } \\
\text { uninsured }\end{array}$} & -0.11 & -0.06 & -0.07 & -0.02 \\
\hline & $(0.17)$ & $(0.17)$ & $(0.18)$ & $(0.19)$ \\
\hline & {$[0.51]$} & {$[0.72]$} & {$[0.72]$} & {$[0.91]$} \\
\hline$R^{2}$ & 0.599 & 0.604 & 0.658 & 0.664 \\
\hline $\mathrm{N}$ & 1,049 & 1,049 & 1,049 & 1,049 \\
\hline \multicolumn{5}{|l|}{$p$-value from test of equality } \\
\hline with Panel B & 0.924 & 0.816 & 0.771 & 0.577 \\
\hline \multicolumn{2}{|l|}{ State-year controls } & $\checkmark$ & & $\sqrt{ }$ \\
\hline \multicolumn{3}{|l|}{ Region-year fixed effects } & $\checkmark$ & $\checkmark$ \\
\hline \multicolumn{5}{|c|}{$\begin{array}{l}\text { Notes: The sample conists of the dependent variables calculated for each state and year from } 1988 \\
\text { through 2011, for the given hospitals. The standard errors in parentheses are robust to auto- } \\
\text { corrleation between observations from the same state; associated } p \text {-values in brackets. Year and } \\
\text { state fixed effects not shown. We define a non-profit hospital as having a nearby for-profit hospital } \\
\text { if at least one for-profit hospital exists in the same HSA. All hospitals in the sample are acute-care } \\
\text { hospitals with an emergency room. }\end{array}$} \\
\hline
\end{tabular}


Figure 1. Share Uninsured and Uncompensated Care Costs

\section{A. 2000 Cross Section}

Uncompensated care per capita

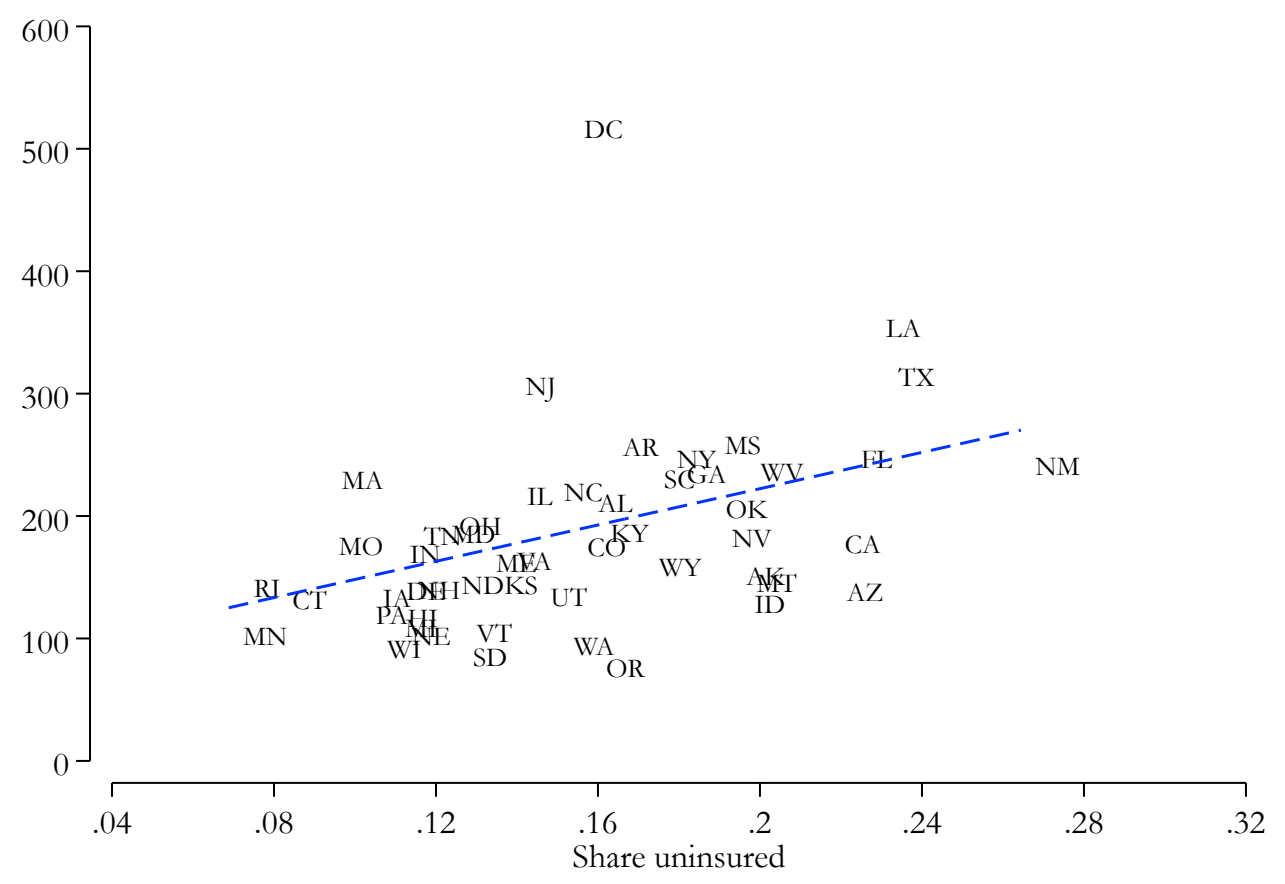

\section{B. 2000-2005 Changes}

Change in uncompensated care per capita

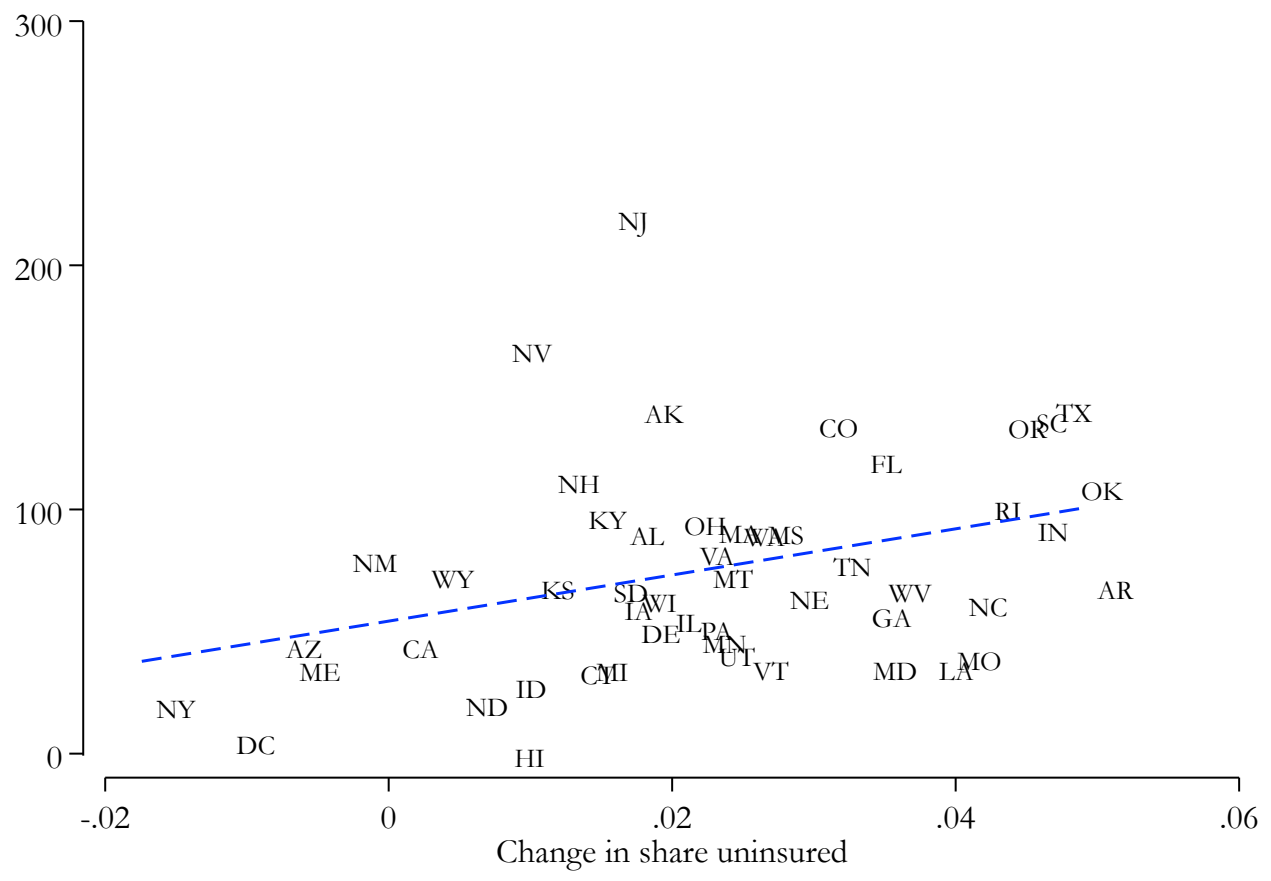


Figure 2. Total Uncompensated Care Costs in Missouri

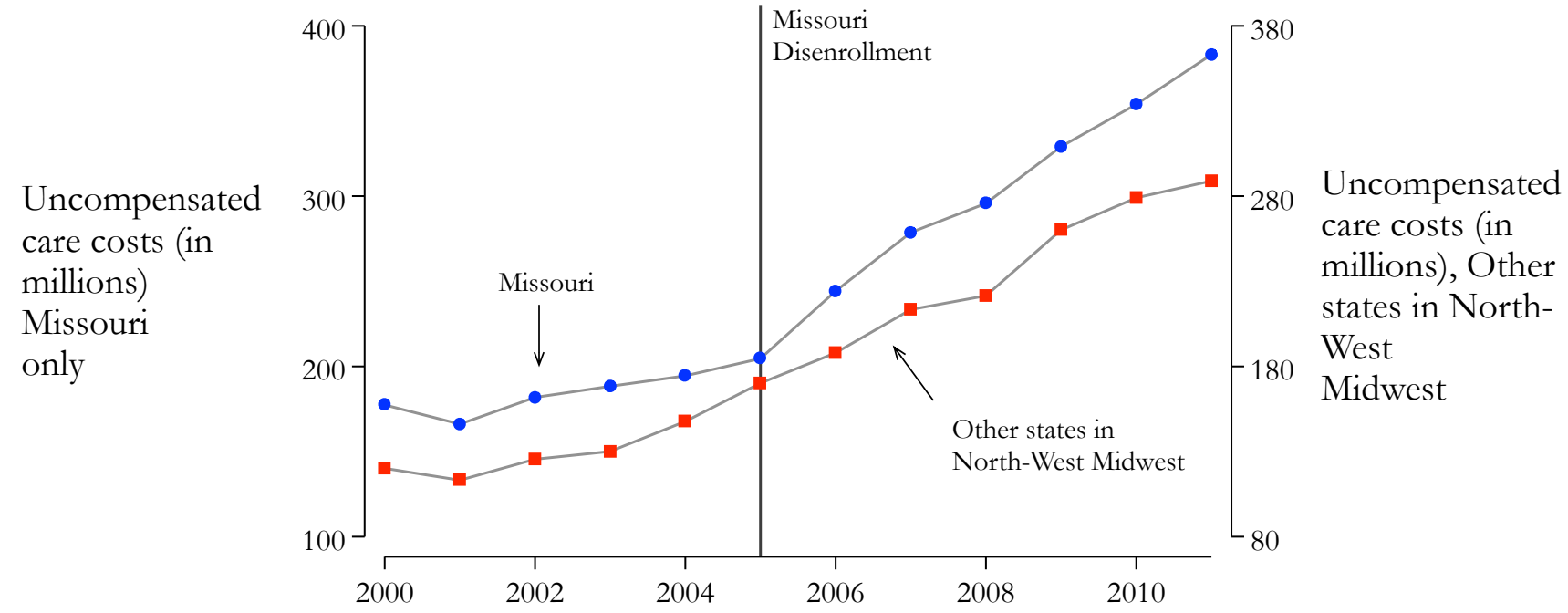

Note: This figure presents total uncompensated care costs in Missouri versus other states in the North-West Midwest, as reported in the AHA survey. See text for details.

Figure 3. Uncompensated Care Costs in Tennessee

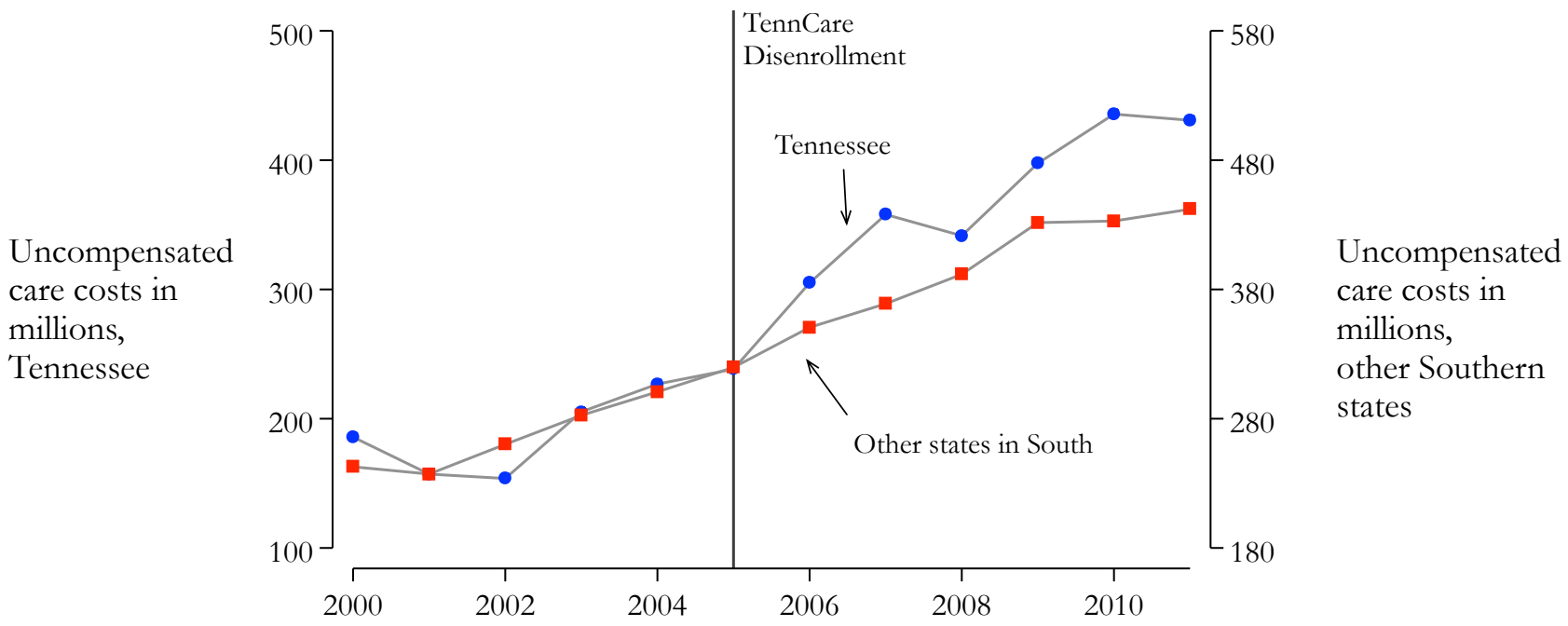

Note: This figure presents total uncompensated care costs in Tennesse versus other Southern states, as reported in the AHA survey. See text for details. 
Figure 4. Changes in Uncompensated Care Costs within Tennessee, Before and After TennCare Disenrollment

Percent change in uncompensated care, 2004 and 2005 to 2006 and 2007

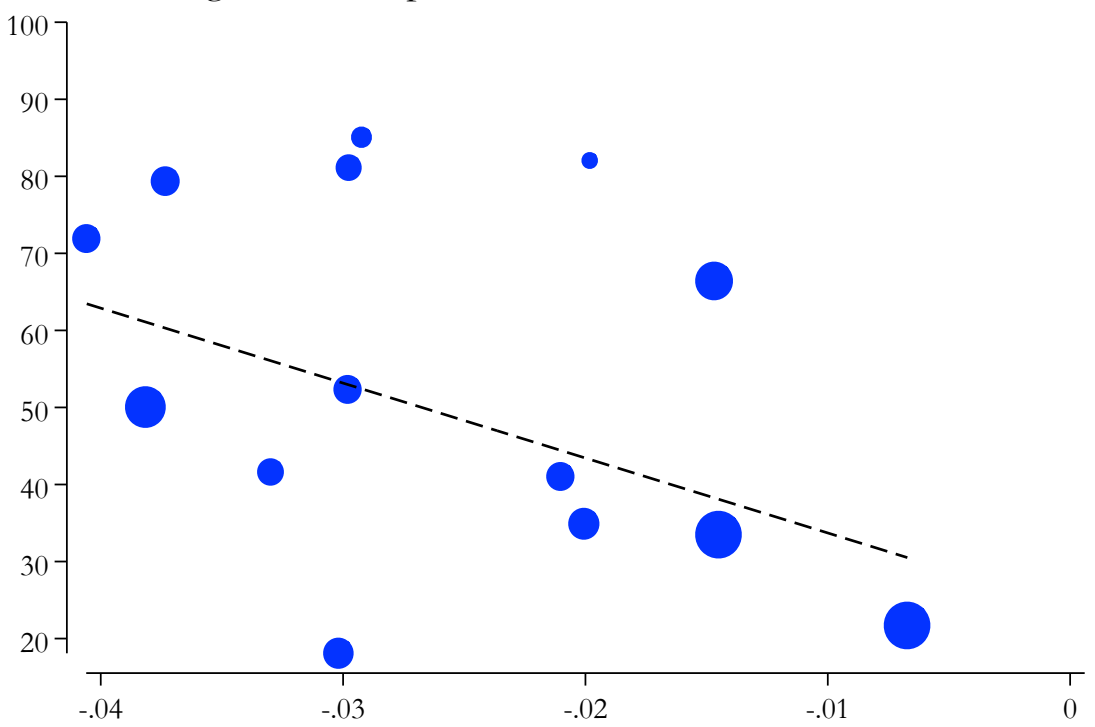

2004-2005 Change in TennCare enrollment divided by 2004 population

Note: This figure presents uncompensated care costs for the 14 health department regions in Tennessee, as recorded in the AHA survey. See text for details.

Figure 5. Changes in Uncompensated Care Costs within Tennessee, Before and After 2002

Percent change in uncompensated care, 2000 and 2001 to 2002 and 2003

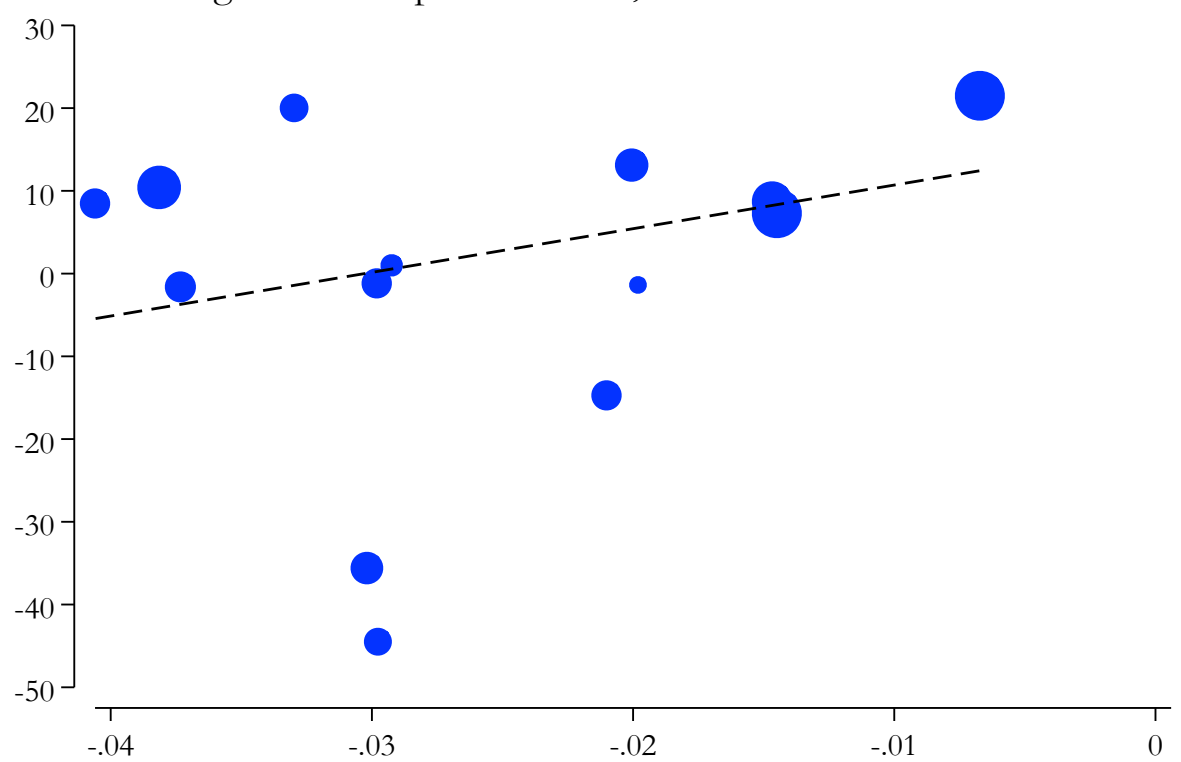

2004-2005 Change in TennCare enrollment divided by 2004 population

Note: This figure presents uncompensated care costs for the 14 health department regions in Tennessee, as recorded in the AHA survey. See text for details. 


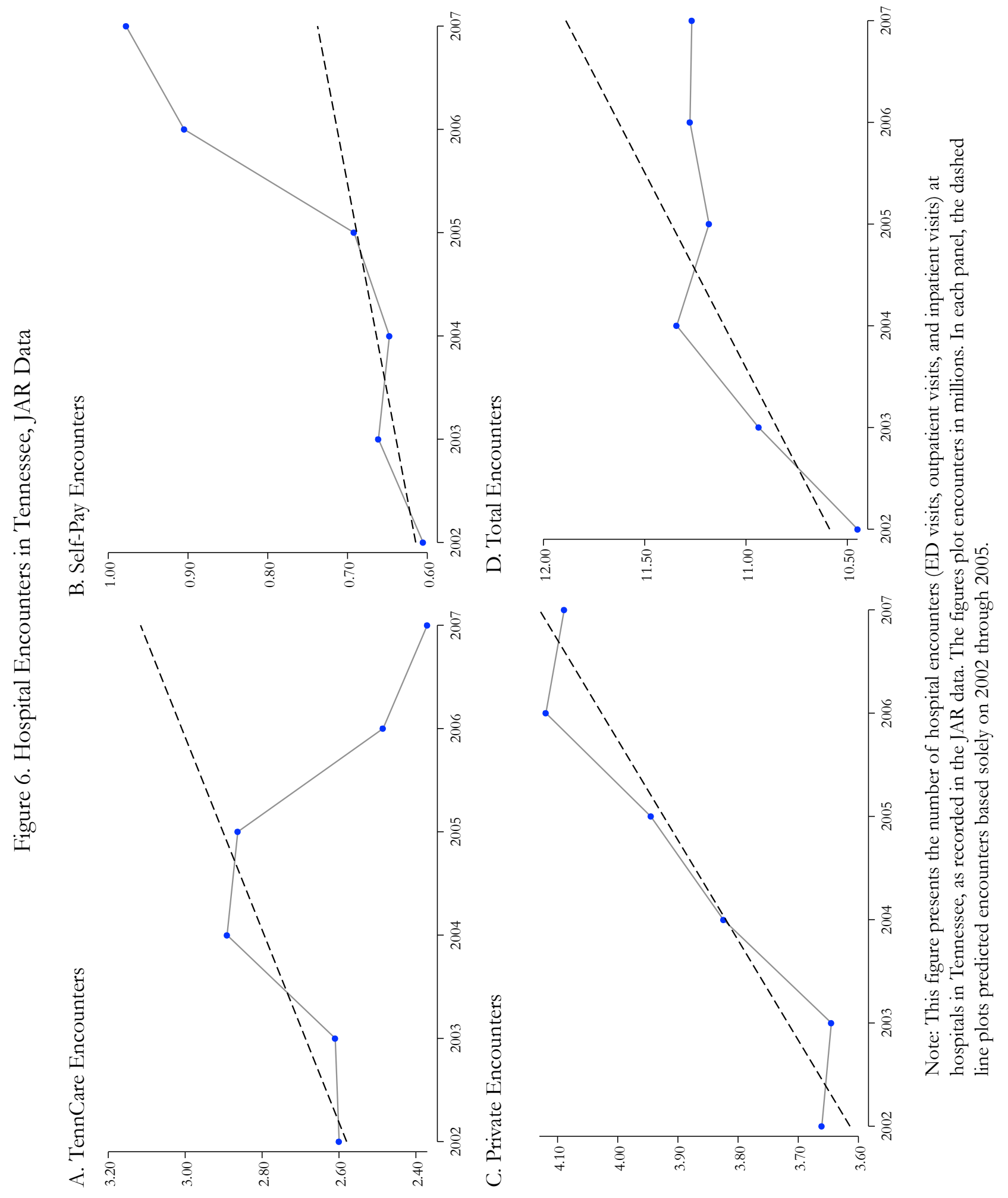


Figure 7. Change in Number of Hospitals in County After a Hospital Closure

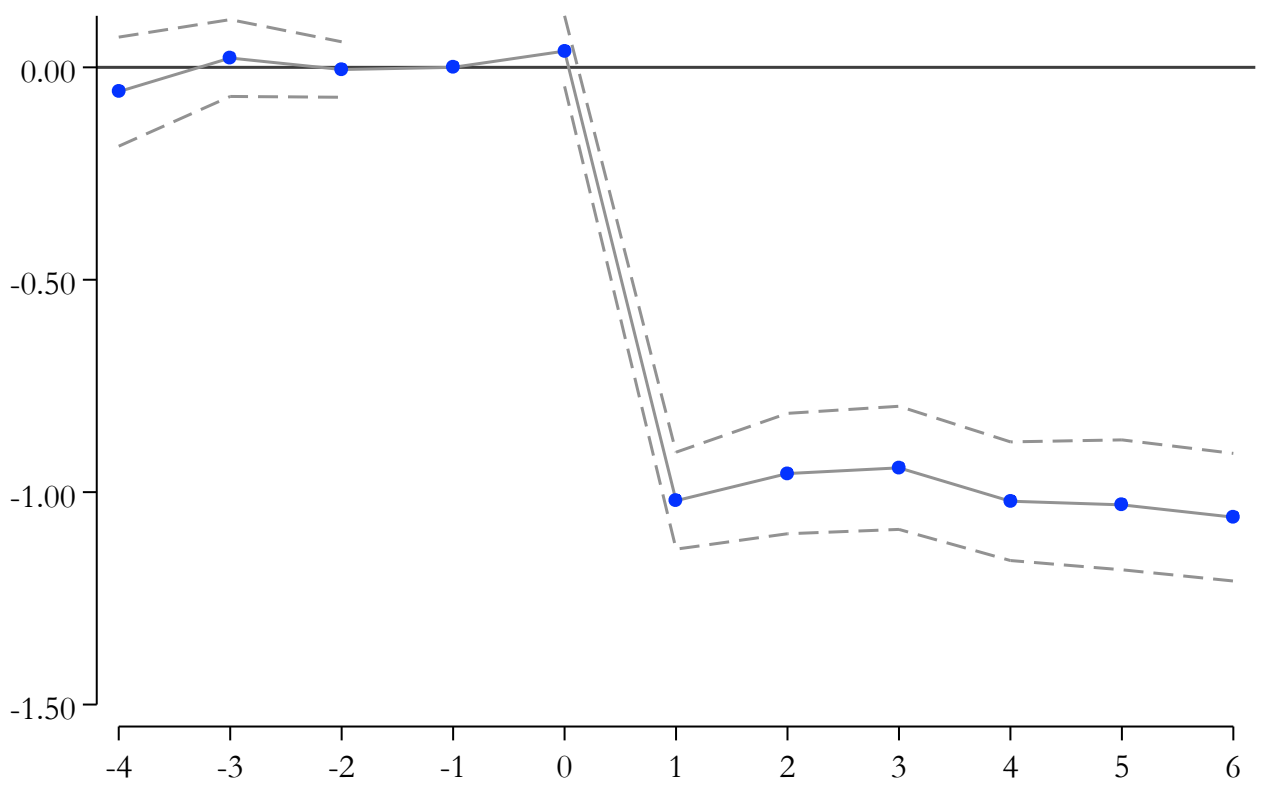

Years since closure

Note: This figure plots point estimates from a regression of number of hospitals in each county on a series of exhaustive indicator variables for the years since the closure of a large hospital. The year before the closure is the omitted category. The data consist of GAO records of hospital closures combined with the AHA survey. See text for details. The dashed lines connect 95-percent confidence intervals. 
Figure 8. Change in Uncompensated Care in County's Remaining Hospitals After a Closure

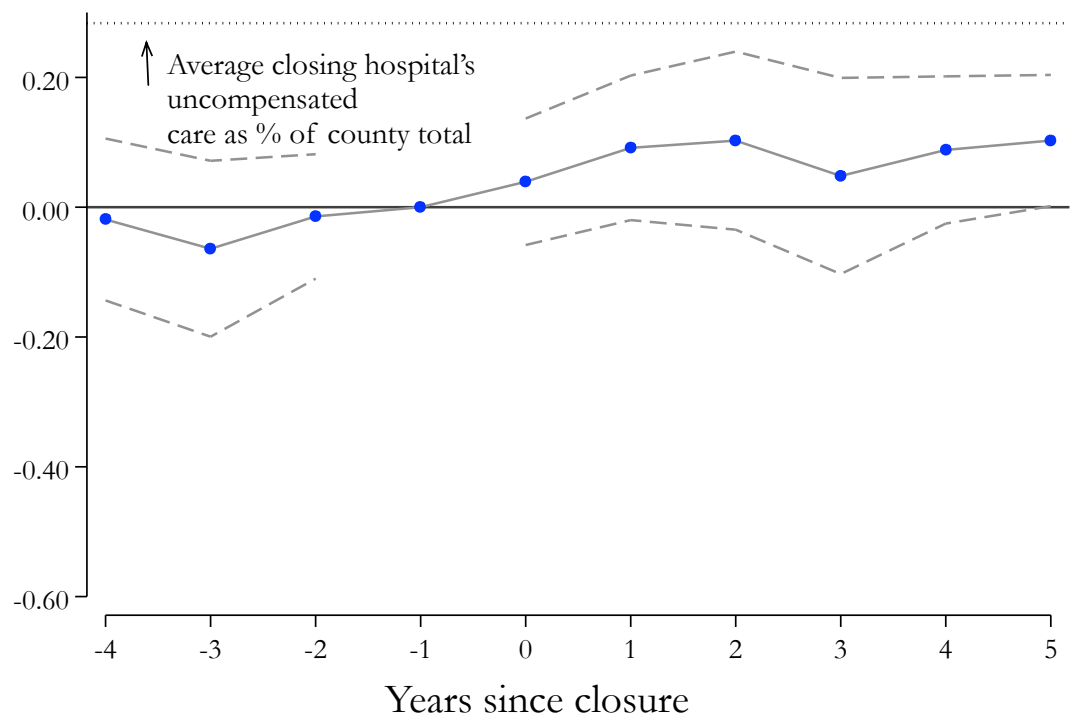

Note: This figure plots point estimates from a regression of total uncompensated care for each county's surviving hospitals on a series of exhaustive indicator variables for the years since the closure of a large hospital. The year before the closure is the omitted category. The data consist of GAO records of hospital closures combined with the AHA survey. See text for details. The dashed lines connect 95-percent confidence intervals.

Figure 9. Change in Total Uncompensated Care in County After a Hospital Closure

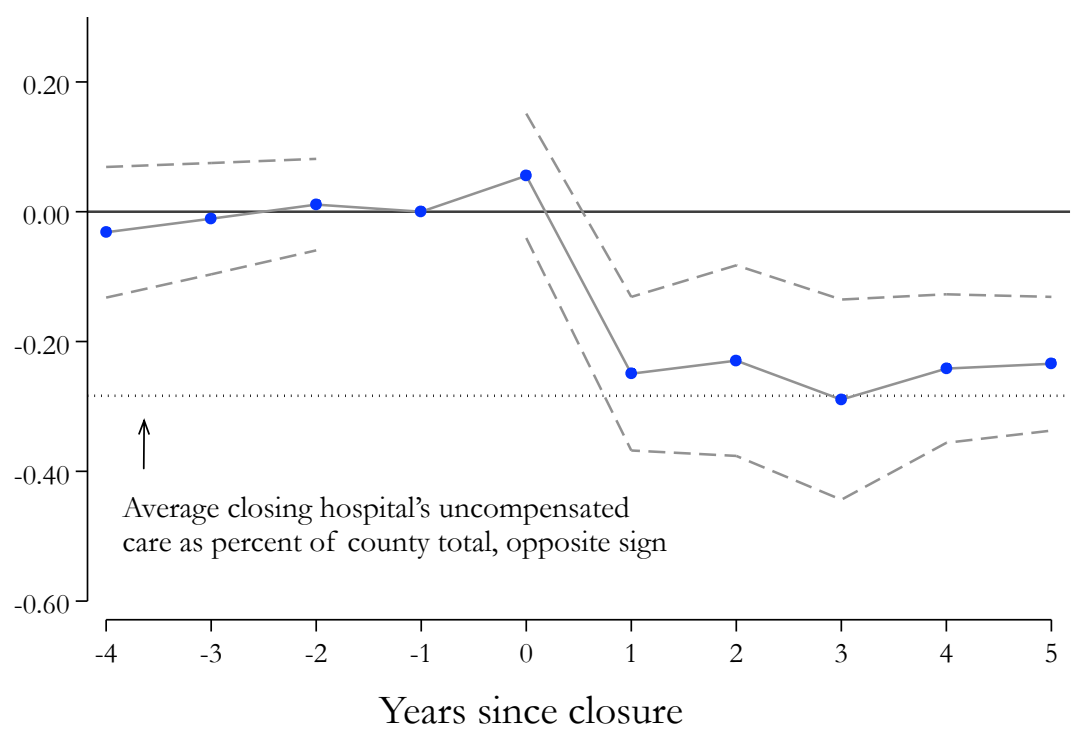

Note: This figure plots point estimates from a regression of total uncompensated care for each county on a series of exhaustive indicator variables for the years since the closure of a large hospital. The year before the closure is the omitted category. The data consist of GAO records of hospital closures combined with the AHA survey. See text for details. The dashed lines connect 95-percent confidence intervals. 


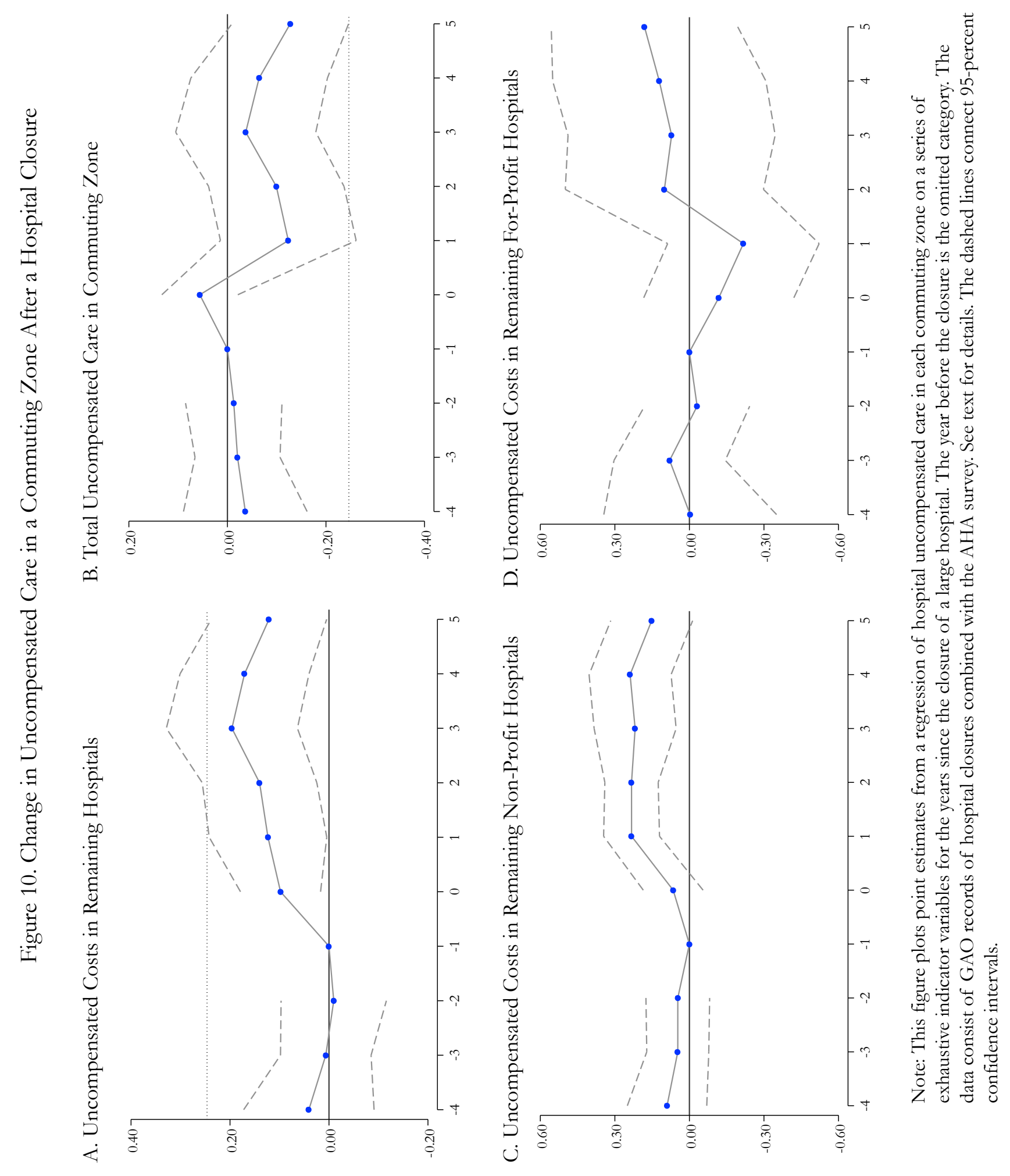




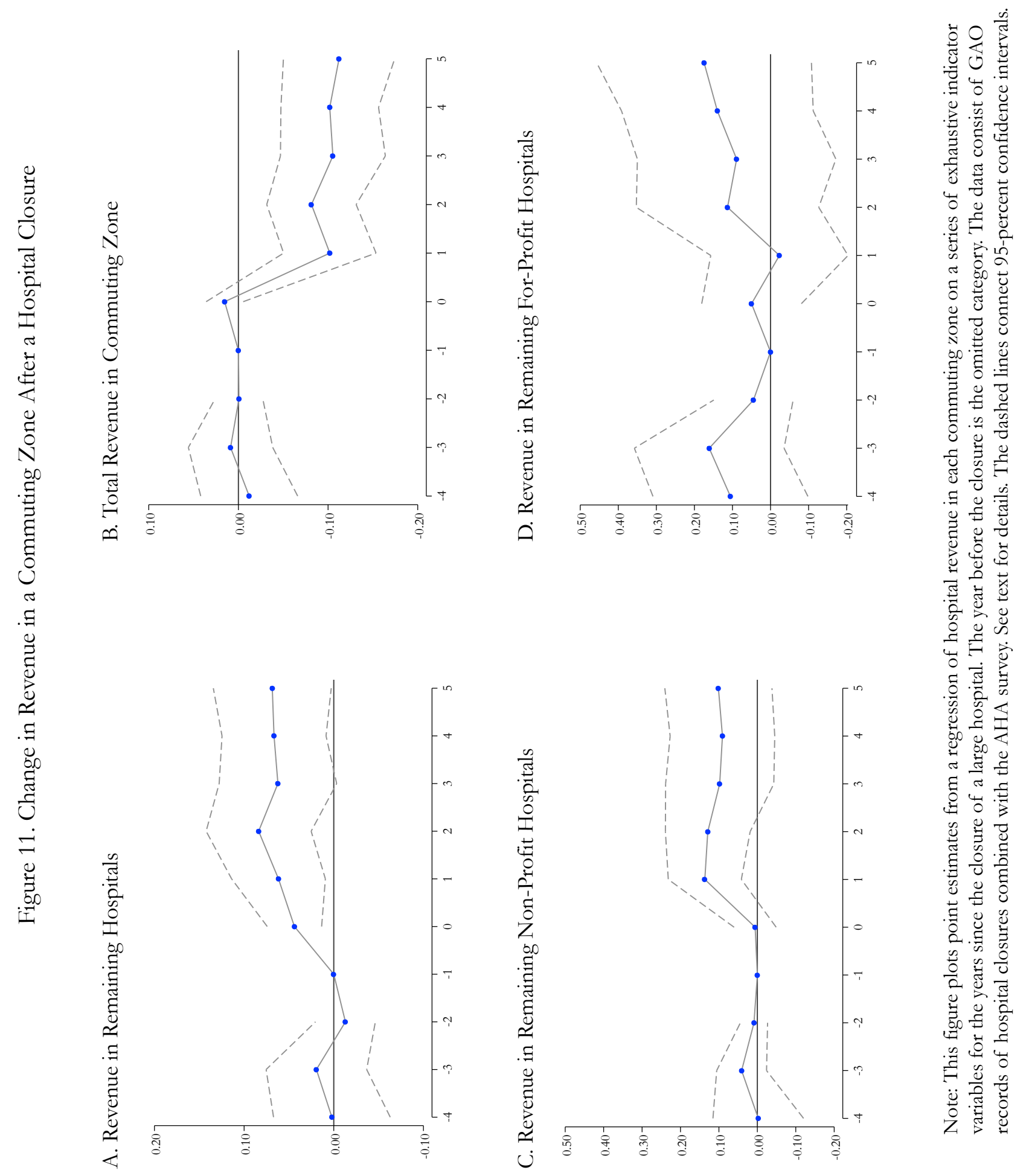


Appendix Table A1. Different Methods of Adjusting Hospital Charges

Dependent Variable: Uncompensated care costs per capita adjusted in the way specified

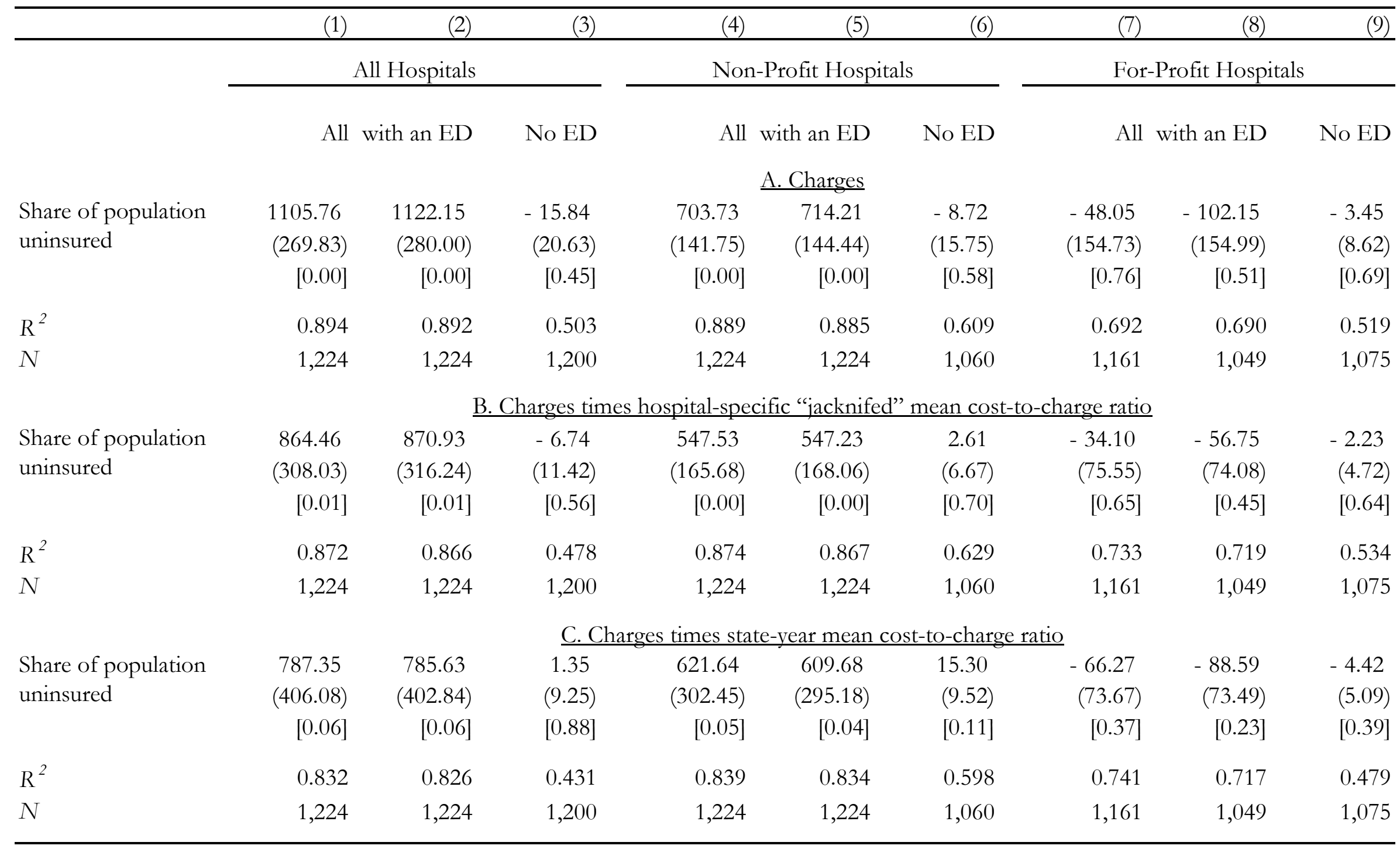

Notes: The standard errors in parentheses are robust to auto-corrleation between observations from the same state; associated $p$-values in brackets. Year and state fixed effects not shown. 
Appendix Table A2. The Effect of The Loss of an ED on Uncompensated Costs

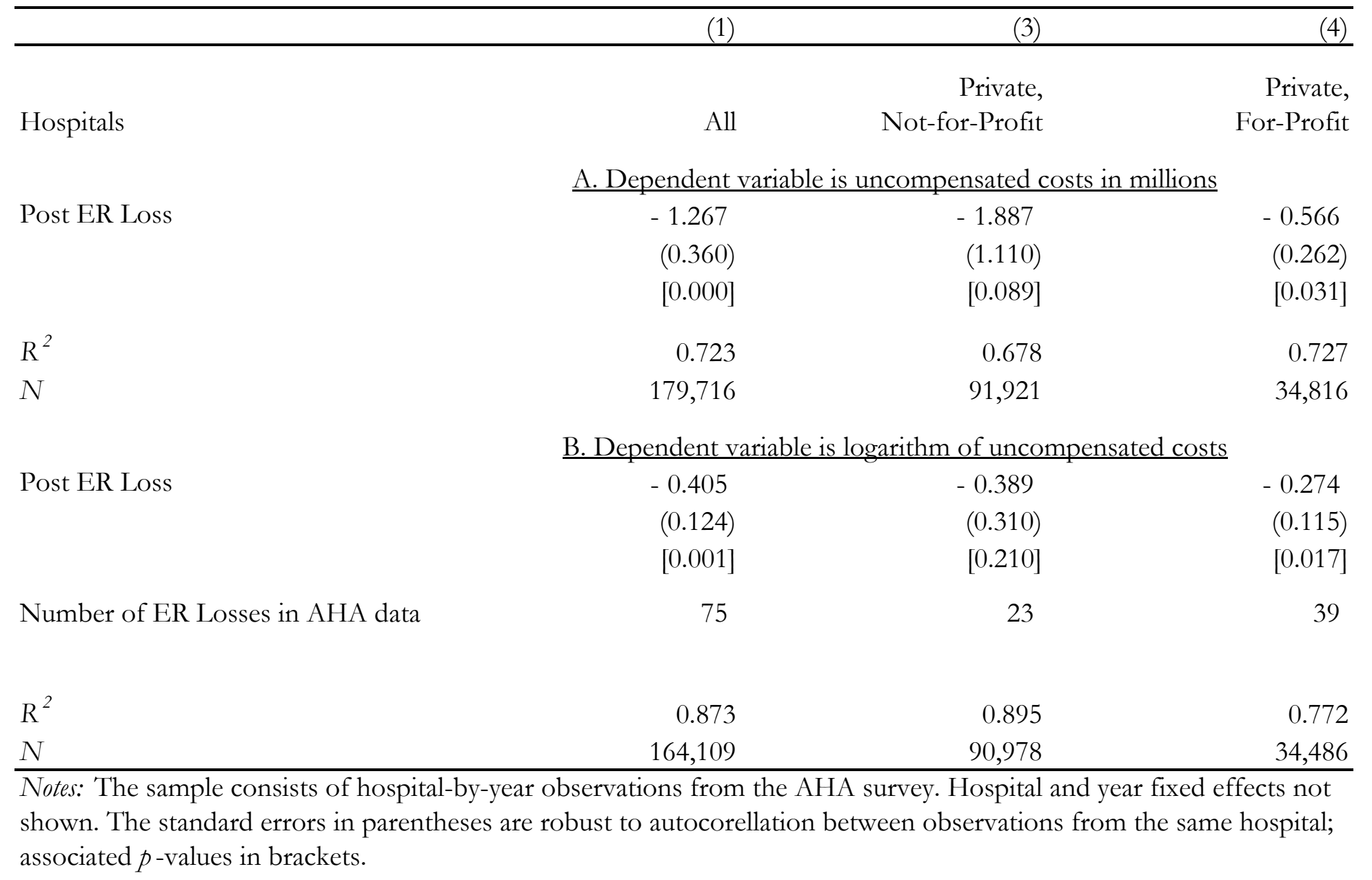


Appendix Table A3. DSH Receipts and Exposure to Uncompensated Care

\begin{tabular}{llllllll}
$(1)$ & $(2)$ & $(3)$ & $(4)$ & $(5)$ & $(6)$ & $(7)$ & $(8)$ \\
\hline
\end{tabular}

Dependent Variable:

Per-capita uncompensated care

Uncompensated care divided by expenditures

\begin{tabular}{|c|c|c|c|c|c|c|c|c|}
\hline \multirow[b]{2}{*}{$\begin{array}{l}\text { Share of population } \\
\text { uninsured }\end{array}$} & \multicolumn{8}{|c|}{ A. Hospital Received No DSH Payments } \\
\hline & $\begin{array}{r}516.17 \\
(208.34) \\
{[0.02]}\end{array}$ & $\begin{array}{r}536.34 \\
(205.54) \\
{[0.01]}\end{array}$ & $\begin{array}{r}451.44 \\
(236.26) \\
{[0.06]}\end{array}$ & $\begin{array}{r}455.18 \\
(217.30) \\
{[0.04]}\end{array}$ & $\begin{array}{c}0.18 \\
(0.04) \\
{[0.00]}\end{array}$ & $\begin{array}{c}0.16 \\
(0.04) \\
{[0.00]}\end{array}$ & $\begin{array}{c}0.15 \\
(0.04) \\
{[0.00]}\end{array}$ & $\begin{array}{c}0.13 \\
(0.04) \\
{[0.00]}\end{array}$ \\
\hline $\begin{array}{l}\mathrm{R}^{2} \\
\mathrm{~N}\end{array}$ & $\begin{array}{l}0.825 \\
1,224\end{array}$ & $\begin{array}{l}0.825 \\
1,224\end{array}$ & $\begin{array}{l}0.853 \\
1,224\end{array}$ & $\begin{array}{l}0.853 \\
1,224\end{array}$ & $\begin{array}{l}0.744 \\
1,224\end{array}$ & $\begin{array}{l}0.750 \\
1,224\end{array}$ & $\begin{array}{l}0.797 \\
1,224\end{array}$ & $\begin{array}{l}0.806 \\
1,224\end{array}$ \\
\hline $\begin{array}{l}\text { Share of population } \\
\text { uninsured }\end{array}$ & $\begin{array}{r}274.26 \\
(172.36) \\
{[0.12]}\end{array}$ & $\begin{array}{r}262.94 \\
(173.04) \\
{[0.14]}\end{array}$ & $\begin{array}{r}\text { B. H } \\
410.53 \\
(180.60) \\
{[0.03]}\end{array}$ & $\begin{array}{r}\text { tal Receiv } \\
377.30 \\
(170.15) \\
{[0.03]}\end{array}$ & $\begin{array}{c}\text { I Paym } \\
0.14 \\
(0.07) \\
{[0.05]}\end{array}$ & $\begin{array}{c}0.12 \\
(0.08) \\
{[0.16]}\end{array}$ & $\begin{array}{c}0.14 \\
(0.07) \\
{[0.05]}\end{array}$ & $\begin{array}{c}0.12 \\
(0.08) \\
{[0.14]}\end{array}$ \\
\hline $\begin{array}{l}\mathrm{R}^{2} \\
\mathrm{~N}\end{array}$ & $\begin{array}{l}0.834 \\
1,128\end{array}$ & $\begin{array}{l}0.836 \\
1,128\end{array}$ & $\begin{array}{l}0.864 \\
1,128\end{array}$ & $\begin{array}{l}0.866 \\
1,128\end{array}$ & $\begin{array}{l}0.808 \\
1,128\end{array}$ & $\begin{array}{l}0.811 \\
1,128\end{array}$ & $\begin{array}{l}0.848 \\
1,128\end{array}$ & $\begin{array}{l}0.851 \\
1,128\end{array}$ \\
\hline
\end{tabular}

Notes: The sample conists of means of the dependent variables by state and year from 1988 through 2011 for the given types of hospitals. The standard errors in parentheses are robust to auto-corrleation between observations from the same state; associated $p$-values in brackets. Year and state fixed effects not shown. All hospitals in the sample are non-profit hospitals with an emergency room. 
Appendix Table A4. The Effect of TennCare Disenrollment on Uncompensated Costs For Different

Types of Within-Tennessee Regions

Dependent Variable: The logarithm of uncompensated costs in each region and year

\begin{tabular}{|c|c|c|c|c|}
\hline & $(1)$ & $(2)$ & (3) & (4) \\
\hline Type of Region & $\begin{array}{r}14 \text { Health Department } \\
\text { Regions }\end{array}$ & $\begin{array}{r}9 \text { Tennessee } \\
\text { Development Districts }\end{array}$ & $\begin{array}{r}8 \text { Hospital Referral } \\
\text { Region }\end{array}$ & $\begin{array}{r}82 \text { Hospital Service } \\
\text { Areas }\end{array}$ \\
\hline $\begin{array}{l}2004-2005 \text { disenrollment in region / } \\
2004 \text { population } \times \text { Post } 2005\end{array}$ & $\begin{array}{r}-7.172 \\
(3.124) \\
{[0.039]}\end{array}$ & $\begin{array}{r}-9.002 \\
(4.201) \\
{[0.065]}\end{array}$ & $\begin{array}{r}-9.350 \\
(6.028) \\
{[0.165]}\end{array}$ & $\begin{array}{r}-4.604 \\
(2.335) \\
{[0.052]}\end{array}$ \\
\hline $\begin{array}{l}\text { Estimates scaled by statewide } \\
\text { de-enrollment per capita (compare } \\
\text { to state-year results) }\end{array}$ & 0.185 & 0.233 & 0.242 & 0.119 \\
\hline$R^{2}$ & 0.971 & 0.975 & 0.983 & 0.986 \\
\hline$N$ & 112 & 72 & 64 & 641 \\
\hline
\end{tabular}

Notes: The sample consists of region-by-year total uncompensated care. The standard errors in paranthesis are robust to autocorellation between observations from the same region; associated $p$-values in brackets. We restrict the sample to 2000 through 2007. The regression presented in column 3 is weighted by each HSA's population, because there exists substantial variation in HSA population. 
Appendix Table A5. Hospital Religious Affiliation and Exposure to Uncompensated Care

\section{(1)}

(2)

(3)

(5)

$(6)$

$(8)$

Dependent Variable: Per-capita uncompensated care

Uncompensated care divided by expenditures

\begin{tabular}{|c|c|c|c|c|c|c|c|c|}
\hline \multirow[b]{2}{*}{$\begin{array}{l}\text { Share of population } \\
\text { uninsured }\end{array}$} & \multicolumn{8}{|c|}{ A. Hospital has no religious affiliation } \\
\hline & $\begin{array}{r}333.73 \\
(106.41) \\
{[0.00]}\end{array}$ & $\begin{array}{r}327.68 \\
(91.97) \\
{[0.00]}\end{array}$ & $\begin{array}{r}434.78 \\
(130.73) \\
{[0.00]}\end{array}$ & $\begin{array}{r}424.16 \\
(114.68) \\
{[0.00]}\end{array}$ & $\begin{array}{c}0.20 \\
(0.05) \\
{[0.00]}\end{array}$ & $\begin{array}{c}0.19 \\
(0.06) \\
{[0.00]}\end{array}$ & $\begin{array}{c}0.20 \\
(0.05) \\
{[0.00]}\end{array}$ & $\begin{array}{c}0.17 \\
(0.05) \\
{[0.00]}\end{array}$ \\
\hline $\begin{array}{l}\mathrm{R}^{2} \\
\mathrm{~N}\end{array}$ & $\begin{array}{l}0.873 \\
1,224\end{array}$ & $\begin{array}{l}0.875 \\
1,224\end{array}$ & $\begin{array}{l}0.899 \\
1,224\end{array}$ & $\begin{array}{l}0.899 \\
1,224\end{array}$ & $\begin{array}{l}0.787 \\
1,224\end{array}$ & $\begin{array}{l}0.790 \\
1,224\end{array}$ & $\begin{array}{l}0.824 \\
1,224\end{array}$ & $\begin{array}{l}0.829 \\
1,224\end{array}$ \\
\hline $\begin{array}{l}\text { Share of population } \\
\text { uninsured }\end{array}$ & $\begin{array}{r}158.80 \\
(50.05) \\
{[0.00]}\end{array}$ & $\begin{array}{r}181.18 \\
(53.32) \\
{[0.00]}\end{array}$ & $\begin{array}{r}152.11 \\
(48.20) \\
{[0.00]}\end{array}$ & $\begin{array}{c}\text { spital has } \\
171.00 \\
(50.10) \\
{[0.00]}\end{array}$ & $\begin{array}{c}\text { ffiliatio } \\
0.16 \\
(0.05) \\
{[0.00]}\end{array}$ & $\begin{array}{c}0.15 \\
(0.04) \\
{[0.00]}\end{array}$ & $\begin{array}{c}0.15 \\
(0.05) \\
{[0.00]}\end{array}$ & $\begin{array}{c}0.14 \\
(0.04) \\
{[0.00]}\end{array}$ \\
\hline $\begin{array}{l}\mathrm{R}^{2} \\
\mathrm{~N}\end{array}$ & $\begin{array}{l}0.739 \\
1,133\end{array}$ & $\begin{array}{l}0.745 \\
1,133\end{array}$ & $\begin{array}{l}0.828 \\
1,133\end{array}$ & $\begin{array}{l}0.833 \\
1,133\end{array}$ & $\begin{array}{l}0.752 \\
1,133\end{array}$ & $\begin{array}{l}0.754 \\
1,133\end{array}$ & $\begin{array}{l}0.804 \\
1,133\end{array}$ & $\begin{array}{l}0.808 \\
1,133\end{array}$ \\
\hline
\end{tabular}

Notes: The sample conists of means of the dependent variables by state and year from 1988 through 2011 for the given types of hospitals. The standard errors in parentheses are robust to auto-corrleation between observations from the same state; associated $p$-values in brackets. Year and state fixed effects not shown. All hospitals in the sample are non-profit hospitals with an emergency room. 
Appendix Table A6. Effect of Uninsured Population on Other Profit Margins Dependent Variable: The given profit margin

\begin{tabular}{|c|c|c|c|c|c|c|c|c|c|c|c|c|}
\hline & $(1)$ & (2) & (3) & (4) & (5) & (6) & $(7)$ & (8) & (9) & $(10)$ & $(11)$ & $(12)$ \\
\hline & \multicolumn{4}{|c|}{ All Hospitals } & \multicolumn{4}{|c|}{ Non-Profit Hospitals } & \multicolumn{4}{|c|}{ For-Profit Hospitals } \\
\hline $\begin{array}{l}\text { Share of population } \\
\text { uninsured }\end{array}$ & $\begin{array}{c}-0.05 \\
(0.03) \\
{[0.16]}\end{array}$ & $\begin{array}{r}-0.04 \\
(0.03) \\
{[0.22]}\end{array}$ & $\begin{array}{r}-0.08 \\
(0.03) \\
{[0.02]}\end{array}$ & $\begin{array}{r}-0.08 \\
(0.03) \\
{[0.02]}\end{array}$ & $\begin{array}{r}-0.08 \\
(0.03) \\
{[0.02]}\end{array}$ & $\begin{array}{r}\text { otal mar } \\
-0.08 \\
(0.03) \\
{[0.03]}\end{array}$ & $\begin{array}{c}-0.11 \\
(0.03) \\
{[0.00]}\end{array}$ & $\begin{array}{c}-0.11 \\
(0.04) \\
{[0.00]}\end{array}$ & $\begin{array}{c}-0.04 \\
(0.16) \\
{[0.82]}\end{array}$ & $\begin{array}{c}0.01 \\
(0.16) \\
{[0.94]}\end{array}$ & $\begin{array}{c}0.01 \\
(0.19) \\
{[0.97]}\end{array}$ & $\begin{array}{c}0.05 \\
(0.18) \\
{[0.80]}\end{array}$ \\
\hline $\begin{array}{l}\mathrm{R}^{2} \\
\mathrm{~N}\end{array}$ & $\begin{array}{l}0.628 \\
1,224\end{array}$ & $\begin{array}{l}0.630 \\
1,224\end{array}$ & $\begin{array}{l}0.685 \\
1,224\end{array}$ & $\begin{array}{l}0.685 \\
1,224\end{array}$ & $\begin{array}{l}0.557 \\
1,224\end{array}$ & $\begin{array}{l}0.557 \\
1,224\end{array}$ & $\begin{array}{l}0.626 \\
1,224\end{array}$ & $\begin{array}{l}0.627 \\
1,224\end{array}$ & $\begin{array}{l}0.600 \\
1,049\end{array}$ & $\begin{array}{l}0.609 \\
1,049\end{array}$ & $\begin{array}{l}0.659 \\
1,049\end{array}$ & $\begin{array}{l}0.668 \\
1,049\end{array}$ \\
\hline $\begin{array}{l}\text { Share of population } \\
\text { uninsured }\end{array}$ & $\begin{array}{r}-0.07 \\
(0.03) \\
{[0.03]}\end{array}$ & $\begin{array}{r}-0.07 \\
(0.03) \\
{[0.04]}\end{array}$ & $\begin{array}{r}-0.09 \\
(0.03) \\
{[0.01]}\end{array}$ & $\begin{array}{r}-0.08 \\
(0.03) \\
{[0.01]}\end{array}$ & $\begin{array}{r}\quad-0.10 \\
(0.03) \\
{[0.00]}\end{array}$ & $\begin{array}{r}\text { rating } \mathrm{m} \\
-0.10 \\
(0.03) \\
{[0.00]}\end{array}$ & $\begin{array}{c}-0.11 \\
(0.03) \\
{[0.00]}\end{array}$ & $\begin{array}{c}-0.11 \\
(0.03) \\
{[0.00]}\end{array}$ & $\begin{array}{r}-0.05 \\
(0.16) \\
{[0.74]}\end{array}$ & $\begin{array}{r}-0.01 \\
(0.16) \\
{[0.97]}\end{array}$ & $\begin{array}{c}-0.01 \\
(0.18) \\
{[0.96]}\end{array}$ & $\begin{array}{c}0.03 \\
(0.18) \\
{[0.87]}\end{array}$ \\
\hline $\begin{array}{l}\mathrm{R}^{2} \\
\mathrm{~N}\end{array}$ & $\begin{array}{l}0.634 \\
1,224\end{array}$ & $\begin{array}{l}0.635 \\
1,224\end{array}$ & $\begin{array}{l}0.684 \\
1,224\end{array}$ & $\begin{array}{l}0.684 \\
1,224\end{array}$ & $\begin{array}{l}0.540 \\
1,224\end{array}$ & $\begin{array}{l}0.540 \\
1,224\end{array}$ & $\begin{array}{l}0.607 \\
1,224\end{array}$ & $\begin{array}{l}0.609 \\
1,224\end{array}$ & $\begin{array}{l}0.606 \\
1,049\end{array}$ & $\begin{array}{l}0.613 \\
1,049\end{array}$ & $\begin{array}{l}0.664 \\
1,049\end{array}$ & $\begin{array}{l}0.672 \\
1,049\end{array}$ \\
\hline $\begin{array}{l}\text { State-year controls } \\
\text { Region-year fixed effects }\end{array}$ & & $\checkmark$ & $\checkmark$ & $\begin{array}{l}\checkmark \\
\checkmark\end{array}$ & & $\checkmark$ & $\checkmark$ & $\begin{array}{l}\checkmark \\
\checkmark\end{array}$ & & $\checkmark$ & $\checkmark$ & $\begin{array}{l}\checkmark \\
\checkmark\end{array}$ \\
\hline
\end{tabular}

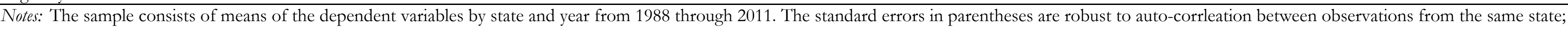
associated $p$-values in brackets. Year and state fixed effects not shown. Only hospitals with an ER are included in the sample for this table. 
Appendix Figure A1. Comparison of JAR and AHA Uncompensated Care Numbers

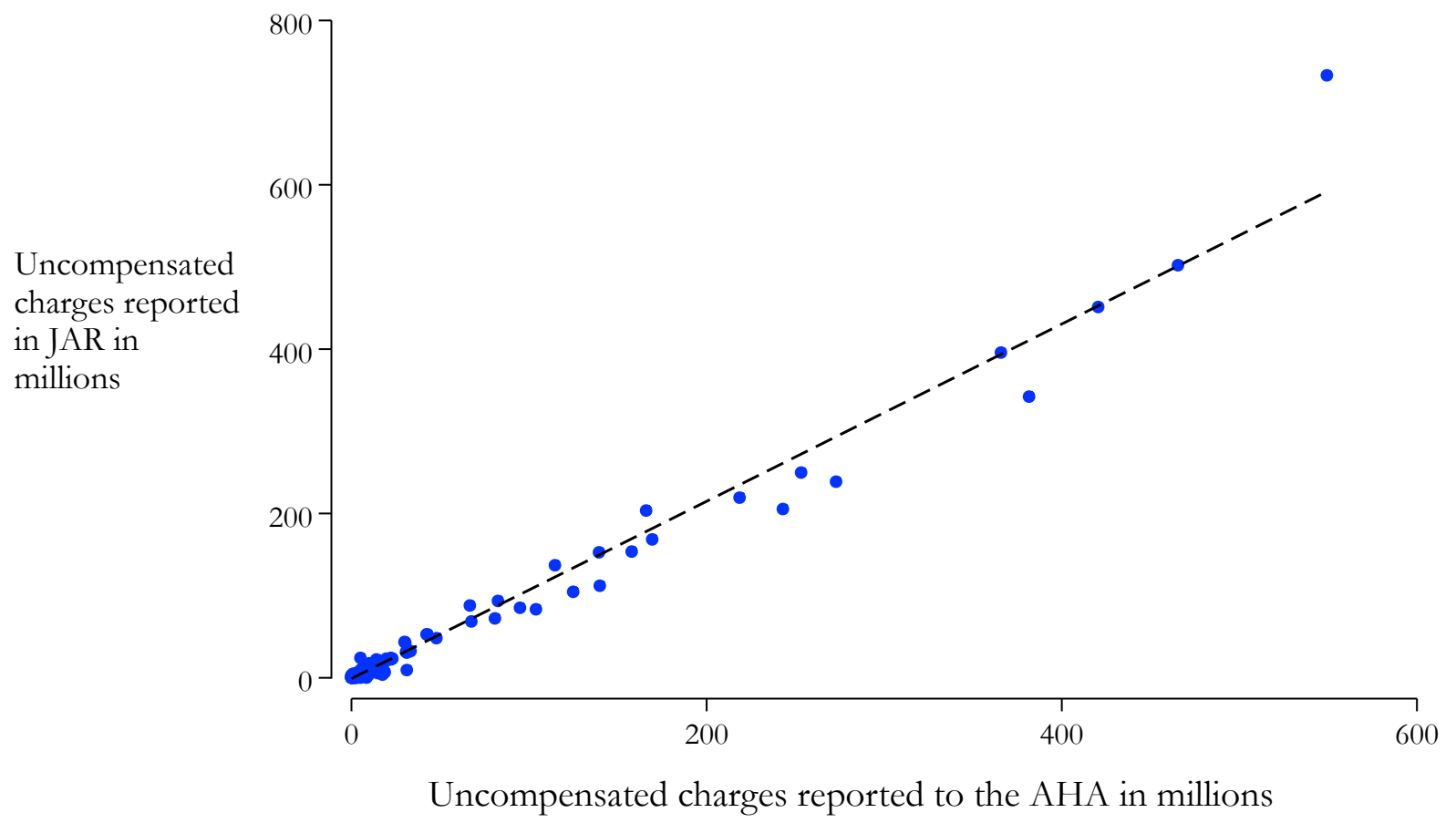

Note: The data for this figure come from both the AHA survey and the JAR data. See text for details. 
Appendix Figure A2. Changes in Uncompensated Care Costs within Tennessee, Before and After TennCare Disenrollment, By Hospital Referral Region

Change

in uncompensated care costs from 2004 and 2005 to 2006 and 2007

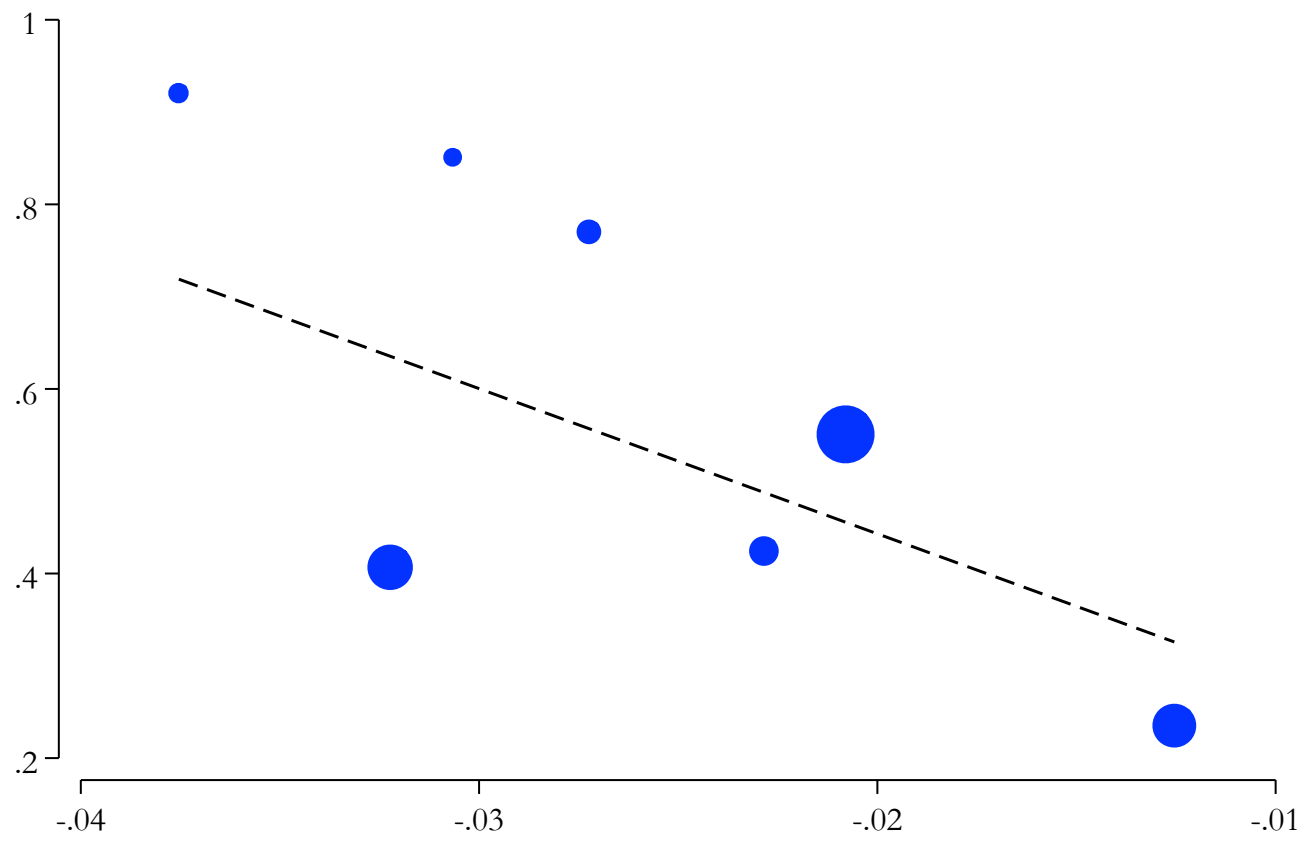

2004-2005 Change in TennCare enrollment divided by 2004 population Note: The scale of each marker indicates the population of each HRR. We drop one HRR from the figure to improve visibility, but it is included in the regression line and in the associated appendix table.

Appendix Figure A3. Changes in Uncompensated Care Costs within Tennessee, Before and After TennCare Disenrollment, By Health Service Area

Change in uncompensated care costs from 2004 and 2005 to 2006 and 2007

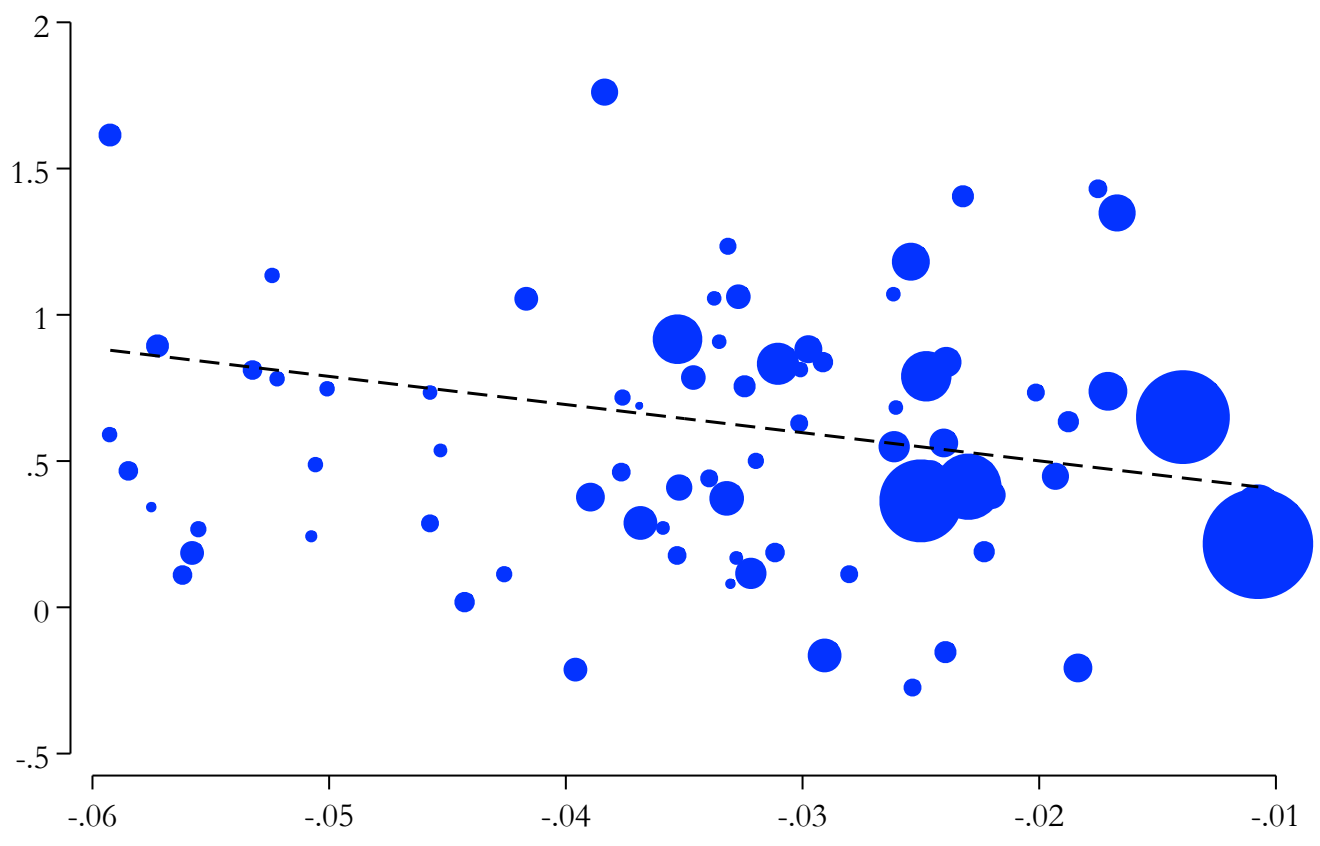

2004-2005 Change in TennCare enrollment divided by 2004 population

Note: The scale of each marker indicates the population of each HSA. We drop three HSAs from the figure to improve visibility, but they are included in the regression line and in the associated appendix table. 
Appendix Figure A4. Changes in Uncompensated Care Costs within Tennessee, Before and After TennCare Disenrollment, By Development District

Change

in uncompensated care costs from 2004 and 2005 to 2006 and 2007

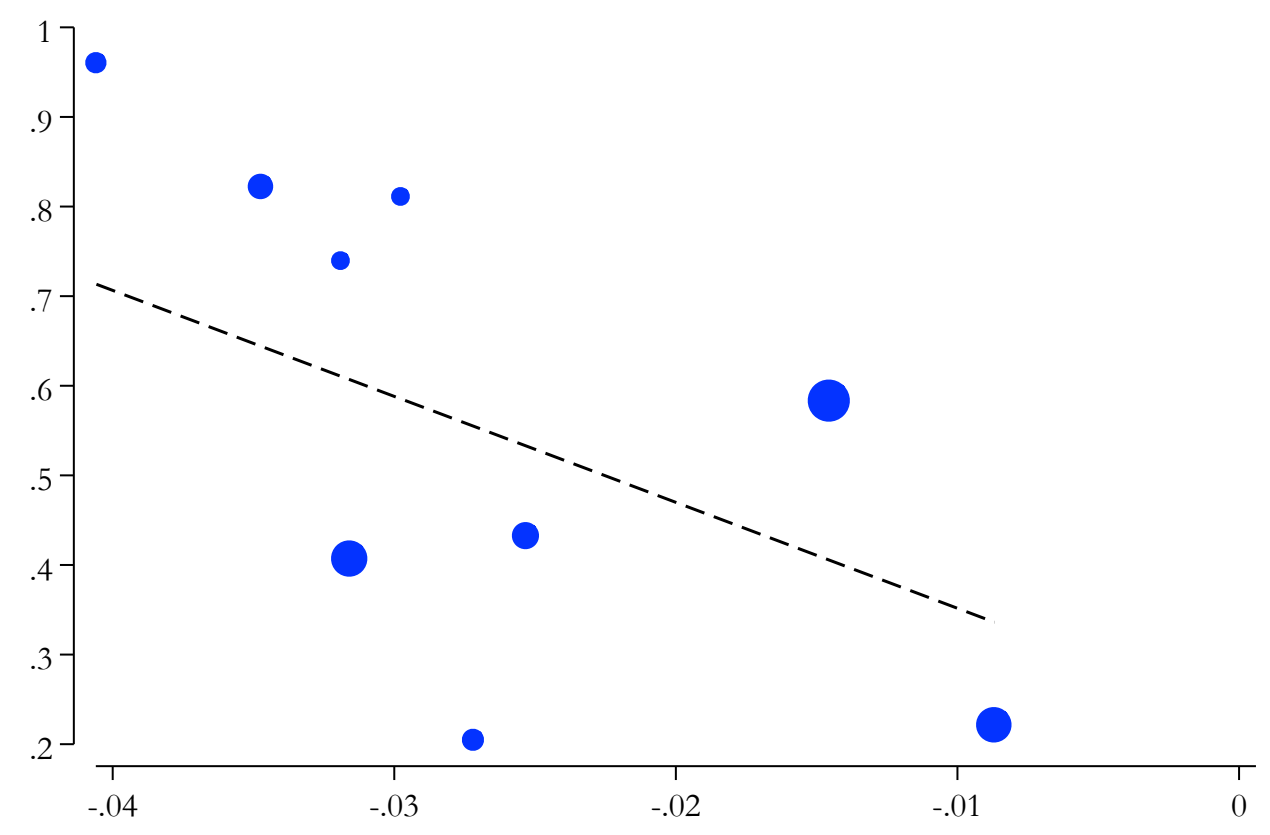

2004-2005 Change in TennCare enrollment divided by 2004 population Note: The scale of each marker indicates the population of each development district. 
Appendix Figure A5. Tennessee Privately Insured Inpatient Visits, JAR Data

Visits

(in millions)

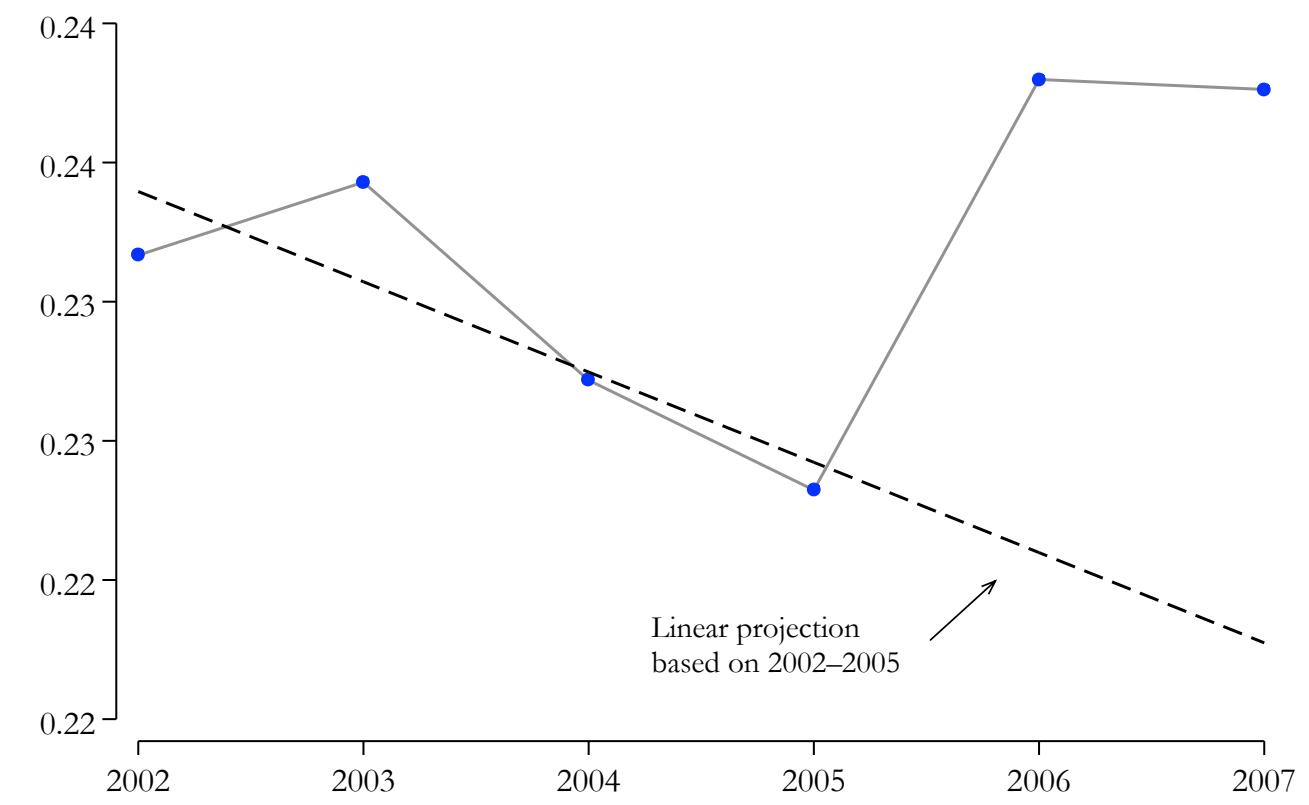

Note: This figure presents the number of privately insured inpatient visits in Tennessee, as recorded in the JAR data. The dashed line plots a linear projection based solely on years 2002 through 2005.

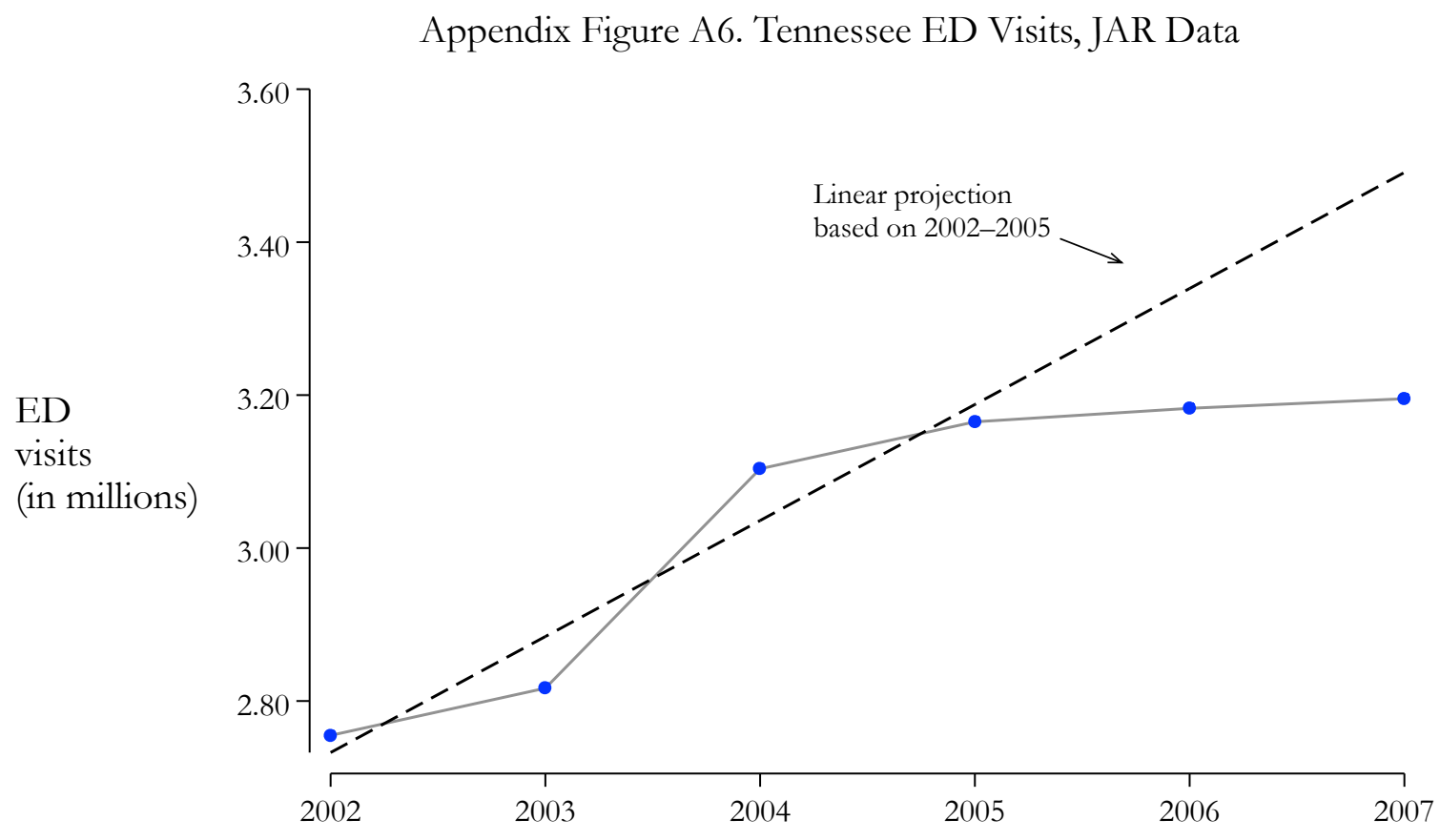

Note: This figure presents the number of ED visits in Tennessee, as recorded in the JAR data. The dashed line plots a linear projection based solely on years 2002 through 2005. 


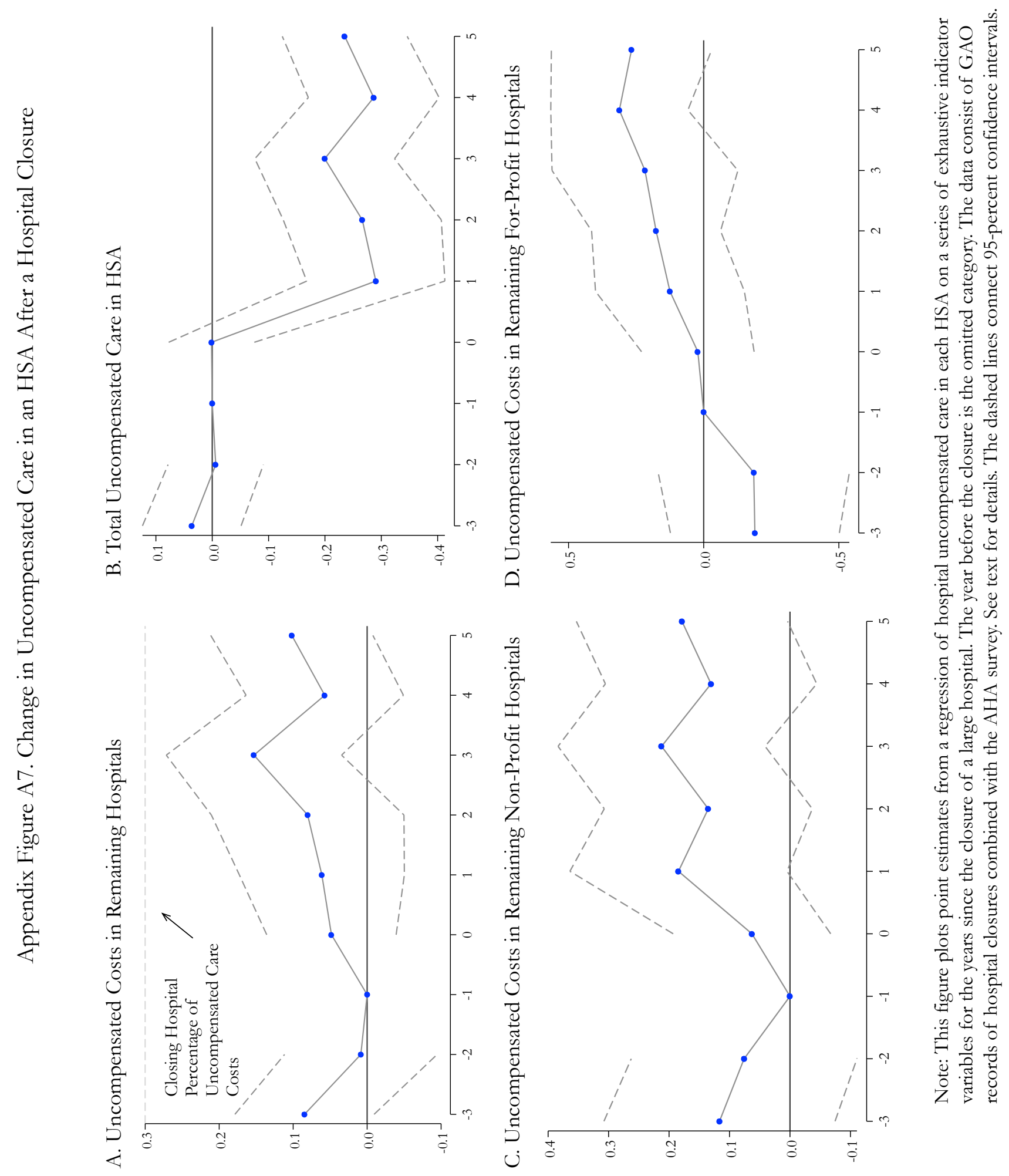




\section{Appendix Figure A8. Effect of Hospital Closures in Commuting Zones}

\section{By Size of Closure}

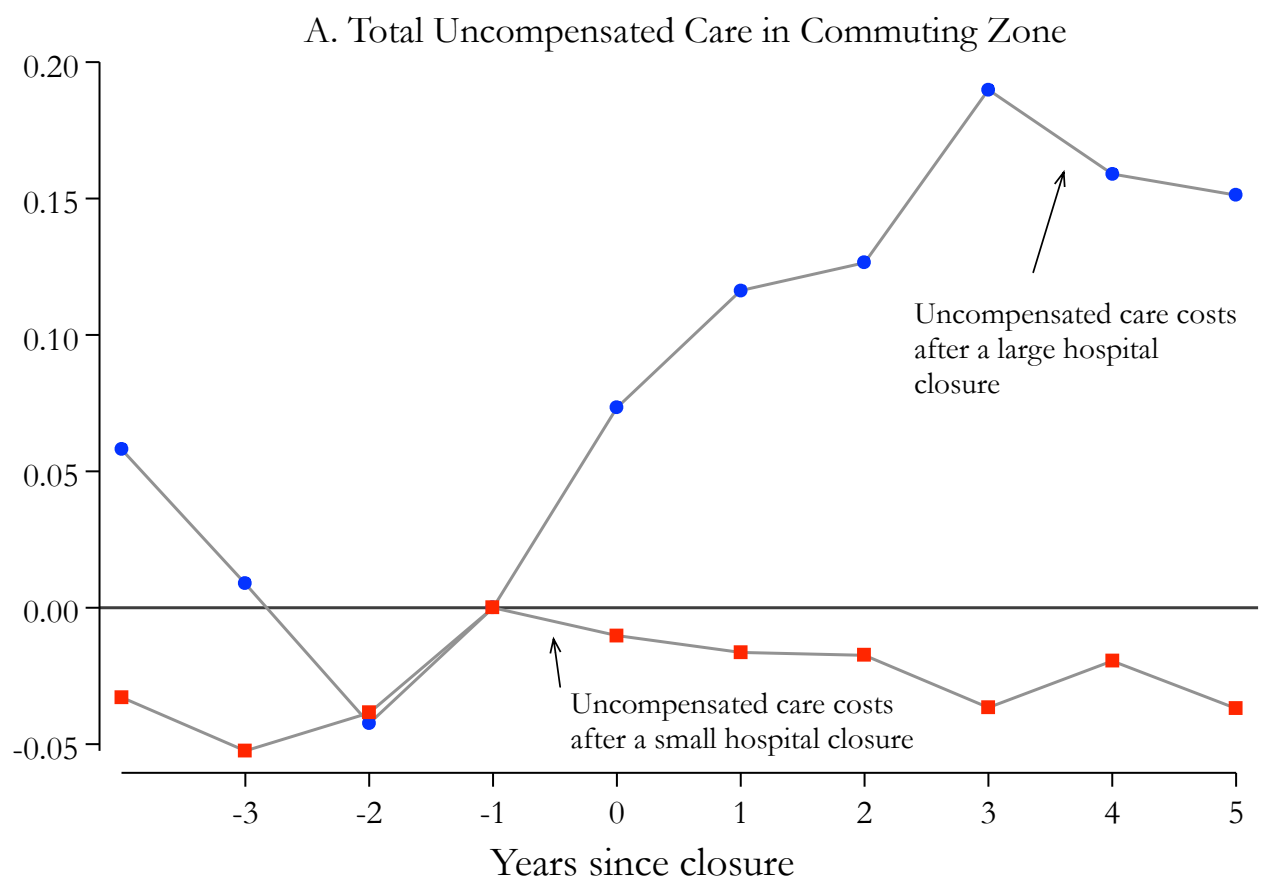

B. Total Revenue in Commuting Zone

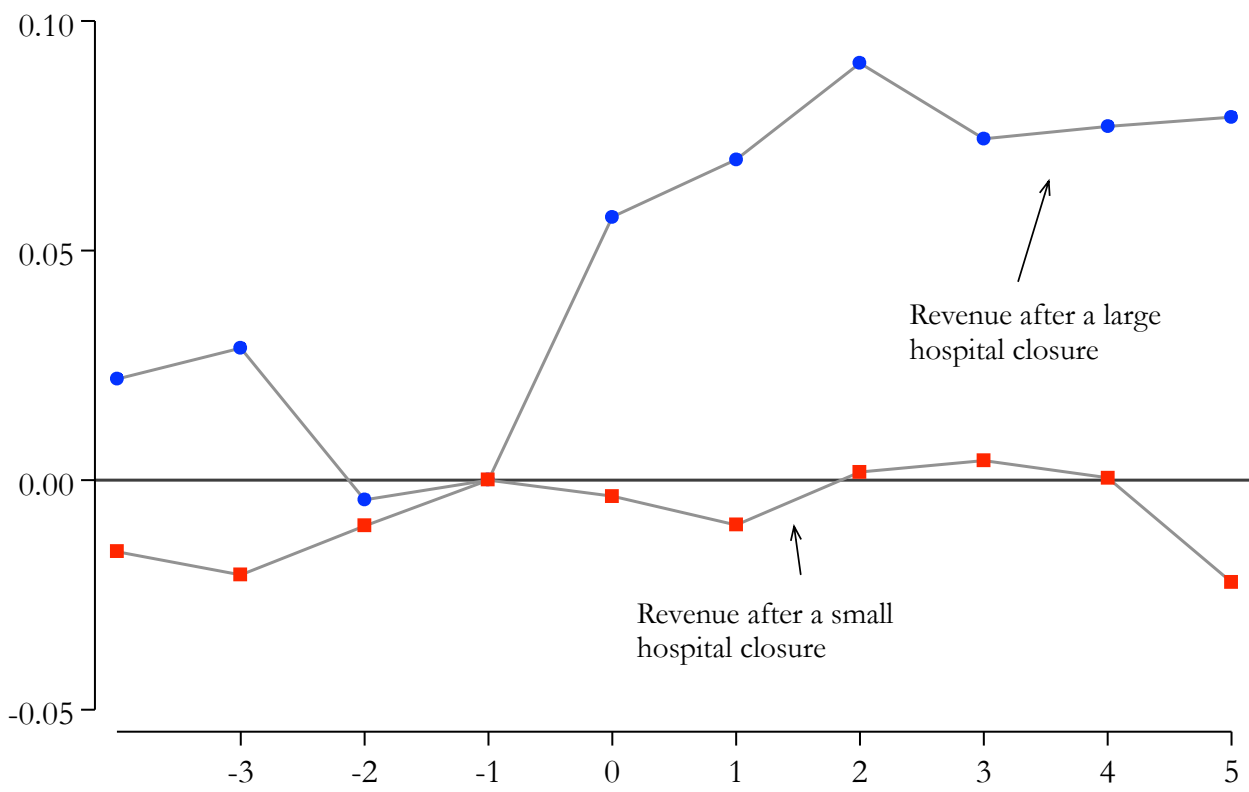

Years since closure

Note: This figure plots point estimates from a regression of uncompensated care costs on a series of exhaustive indicator variables for the years since the closure of a hospital. We categorize hospital closures as large if the hospital provided greater than 7 percent of the region's uncompensated care before closure, given that 7 percent is the median share. The year before the closure is the omitted category. The data consist of GAO records of hospital closures combined with the AHA survey. See text for details. 


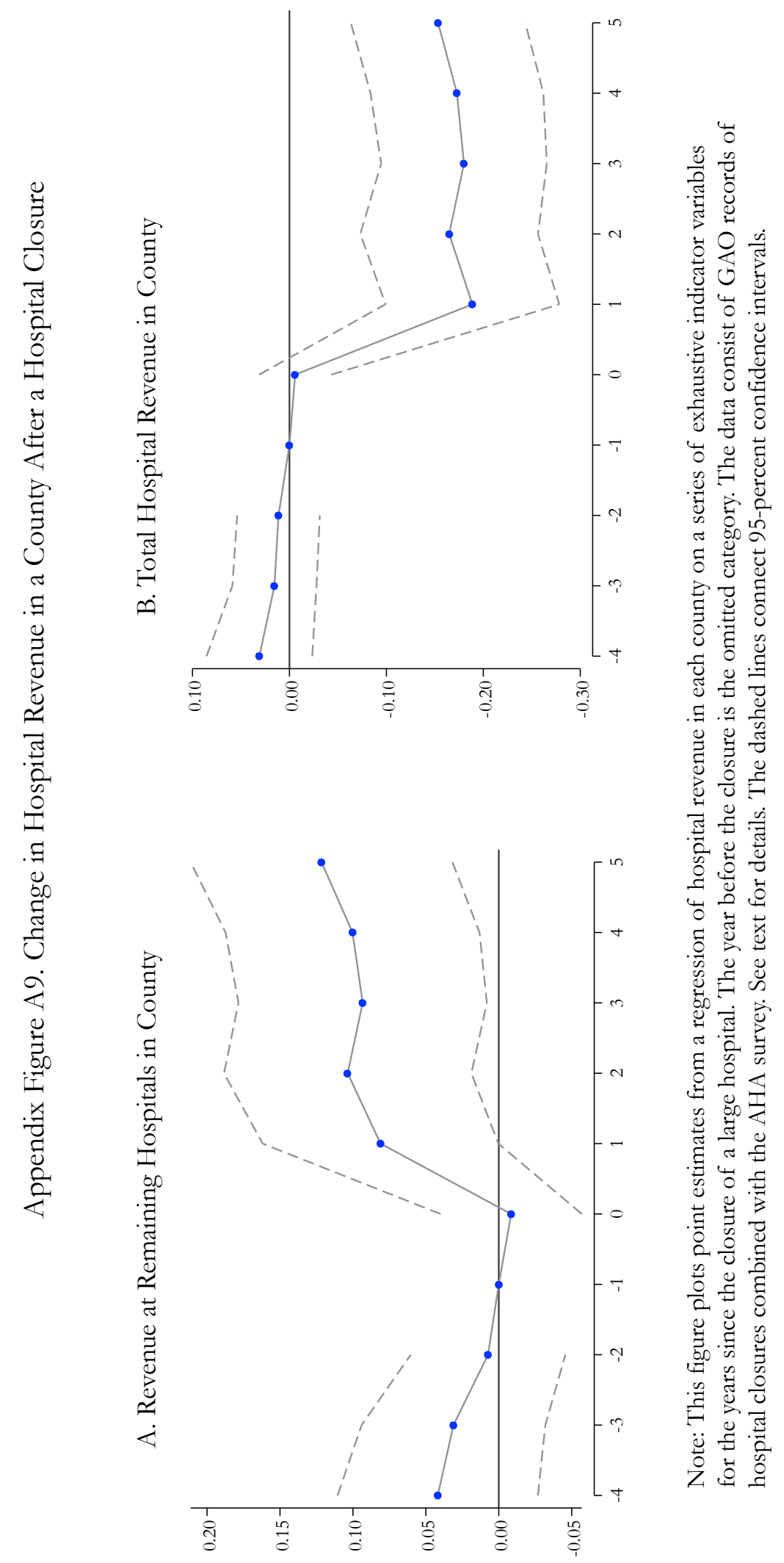


Appendix Figure A10. Changes in TennCare Enrollment by Tennessee Counties

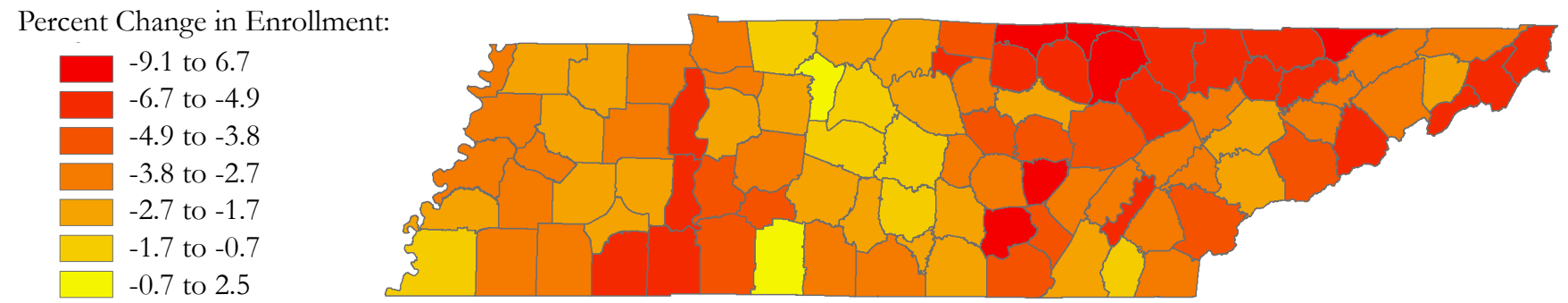

Note: This map indicates changes in Medicaid enrollment for each county in Tennessee as reported in the 2004-2005 and 2005-2006 annual reports for TennCare. 


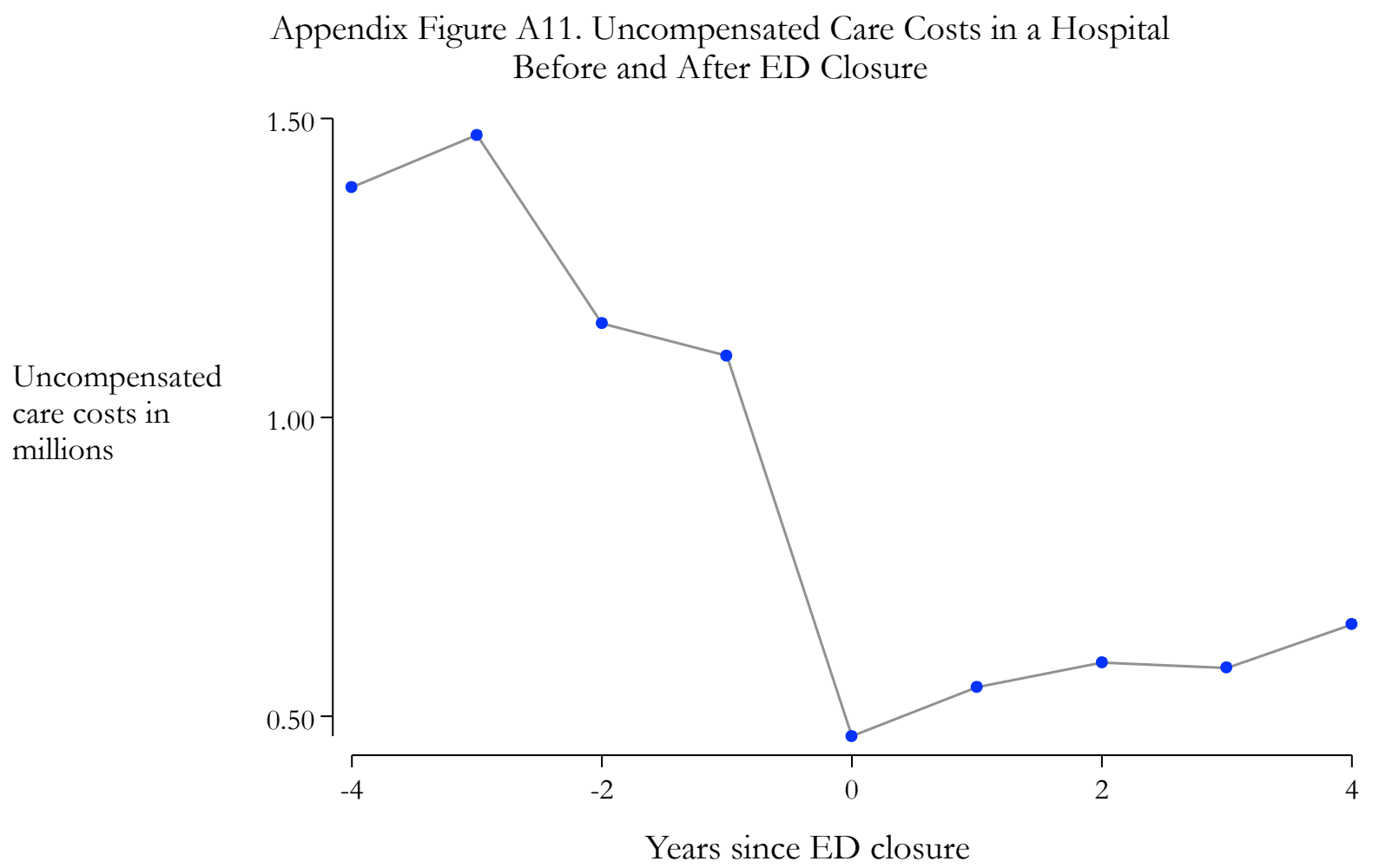

Uncompensated care costs in millions

Note: This figure presents a re-centered time series with average uncompensated care costs in the years before and after a hospital closes its ED. 
Appendix Figure A12. Change in Number of Hospitals in Commuting Zone After a Hospital Closure

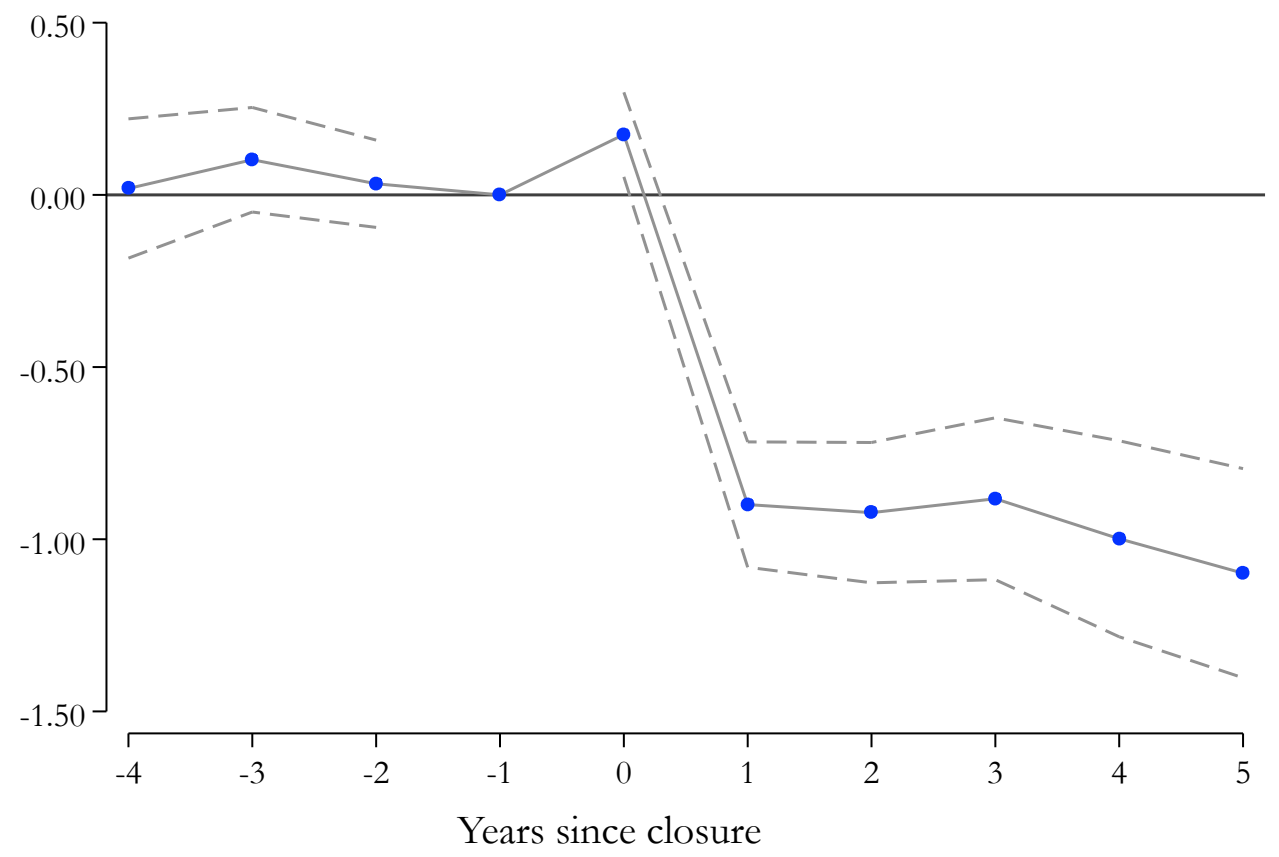

Note: This figure plots point estimates from a regression of number of hospitals in each commuting zone on a series of exhaustive indicator variables for the years since the closure of a large hospital. The year before the closure is the omitted category. The data consist of GAO records of hospital closures combined with the AHA survey. See text for details. The dashed lines connect 95-percent confidence intervals. 